\title{
OECD Survey of Upper Secondary Schools
}

TECHNICAL REPORT
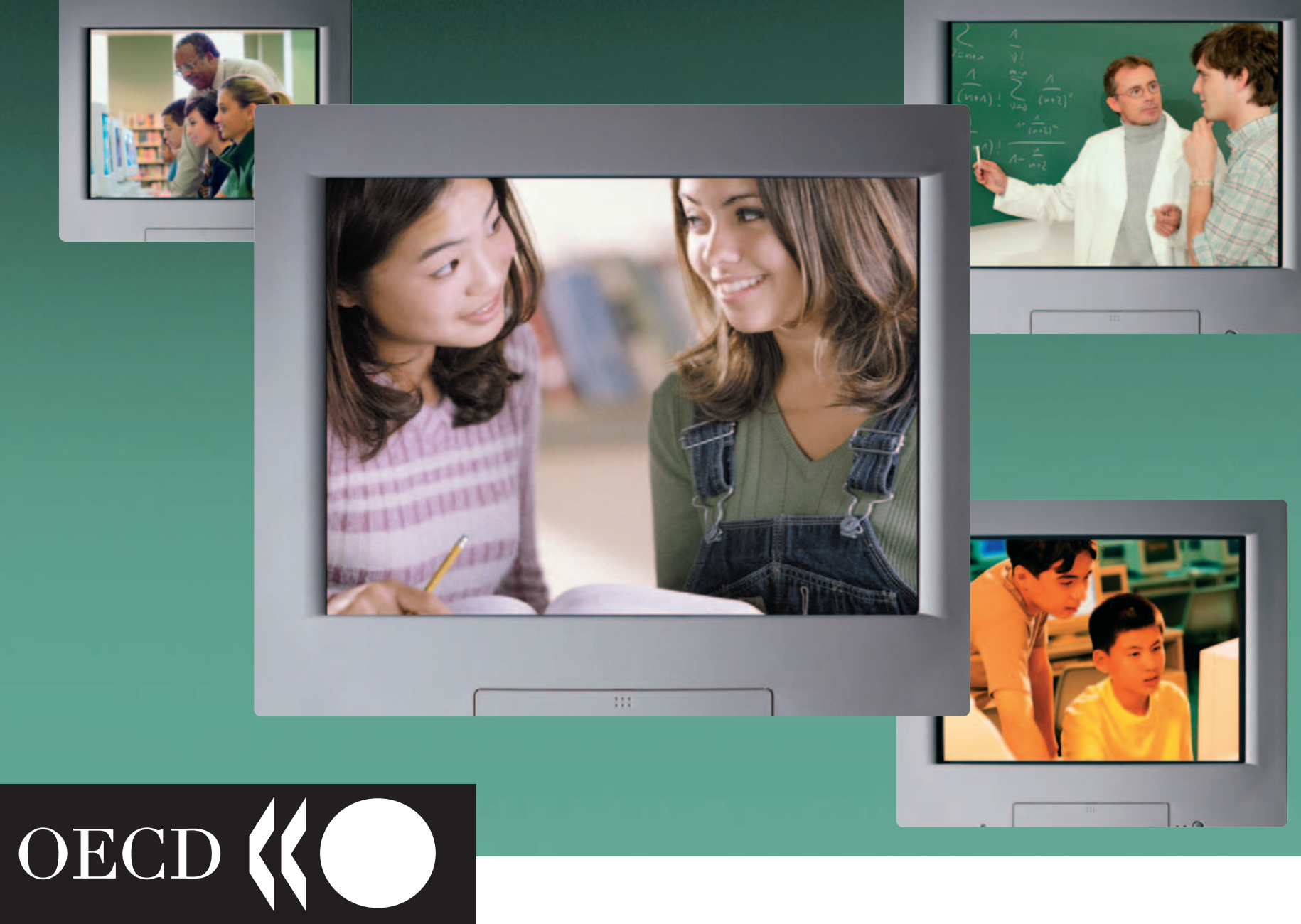
(C) OECD, 2004.

(C) Software: 1987-1996, Acrobat is a trademark of ADOBE.

All rights reserved. OECD grants you the right to use one copy of this Program for your personal use only. Unauthorised reproduction, lending, hiring, transmission or distribution of any data or software is prohibited. You must treat the Program and associated materials and any elements thereof like any other copyrighted material.

All requests should be made to:

Head of Publications Service,

OECD Publications Service,

2, rue André-Pascal,

75775 Paris Cedex 16, France. 


\section{TECHNICAL REPORT}

AN OECD SURVEY OF UPPER SECONDARY SCHOOLS

OECD

ORGANISATION FOR ECONOMIC CO-OPERATION AND DEVELOPMENT 


\section{ORGANISATION FOR ECONOMIC CO-OPERATION AND DEVELOPMENT}

Pursuant to Article 1 of the Convention signed in Paris on 14th December 1960, and which came into force on 30th September 1961, the Organisation for Economic Co-operation and Development (OECD) shall promote policies designed:

- to achieve the highest sustainable economic growth and employment and a rising standard of living in member countries, while maintaining financial stability, and thus to contribute to the development of the world economy;

- to contribute to sound economic expansion in member as well as non-member countries in the process of economic development; and

- to contribute to the expansion of world trade on a multilateral, non-discriminatory basis in accordance with international obligations.

The original member countries of the OECD are Austria, Belgium, Canada, Denmark, France, Germany, Greece, Iceland, Ireland, Italy, Luxembourg, the Netherlands, Norway, Portugal, Spain, Sweden, Switzerland, Turkey, the United Kingdom and the United States. The following countries became members subsequently through accession at the dates indicated hereafter: Japan (28th April 1964), Finland (28th January 1969), Australia (7th June 1971), New Zealand (29th May 1973), Mexico (18th May 1994), the Czech Republic (21st December 1995), Hungary (7th May 1996), Poland (22nd November 1996), Korea (12th December 1996) and the Slovak Republic (14th December 2000). The Commission of the European Communities takes part in the work of the OECD (Article 13 of the OECD Convention).

Permission to reproduce a portion of this work for non-commercial purposes or classroom use should be obtained through the Centre français d'exploitation du droit de copie (CFC), 20, rue des Grands-Augustins, 75006 Paris, France, tel. (33-1) 44074770 , fax (33-1) 463467 19, for every country except the United States. In the United States permission should be obtained through the Copyright Clearance Center, Customer Service, (508)750-8400, 222 Rosewood Drive, Danvers, MA 01923 USA, or CCC Online: www.copyright.com. All other applications for permission to reproduce or translate all or part of this book should be made to OECD Publications, 2, rue André-Pascal, 75775 Paris Cedex 16, France. 


\section{INTRODUCTION}

This technical report is a companion report to the report 'Completing the Foundation for Lifelong Learning - An OECD Survey of Upper Secondary Schools' which presents results from the survey.

This report provides an overview of the main features and technical characteristics of the International Survey of Upper Secondary Schools (ISUSS). The purpose and history of the survey, the design, the sampling and weighting procedures, the description of the questionnaires, the building of an international database including sampling weights and derived variables for analytical purposes are all described in sufficient detail to enable the reader to have a clear understanding of the technical and operational underpinning of the survey.

This technical report is divided into three parts. The first part describes the development of the ISUSS project covering the selection of educational programmes for this survey, the list of participating countries, the design of the survey, the implementation of the ISUSS questionnaire and the operational procedures for sampling and weighting.

The second part describes the data collection process: it covers the methods used by the National Project Managers for data entry, data cleaning and in standardisation of the International ISUSS database.

The third part is related to the description of the organisation and content of the ISUSS International Database which is stored in ACCESS as well as SPSS format.

Electronic files on the OECD website accompany this publication; they are available at the following address: www.oecd.org/edu/isuss. Their purpose is to provide the user with the tools required (both databases and SPSS programmes) to understand the links between the ISUSS questionnaire and the production of Tables and Figures in the ISUSS report 'Completing the Foundation for Lifelong Learning - An OECD Survey of Upper Secondary Schools'. It will also facilitate further analytical and research work on upper secondary education through secondary analyses of the ISUSS data. 


\section{TABLE OF CONTENTS}

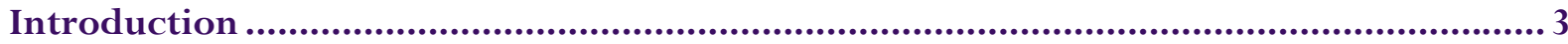

Part I:The International Survey of Upper Secondary Schools .......................................... 7

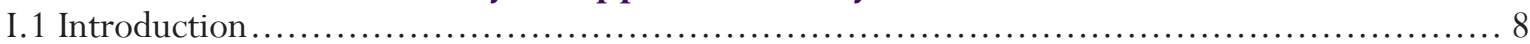

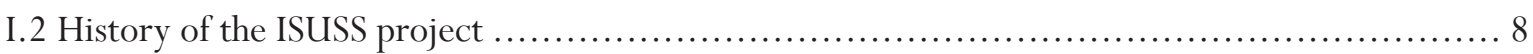

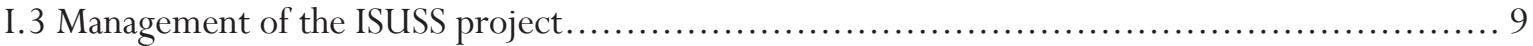

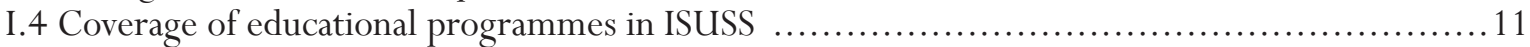

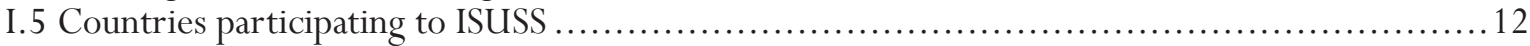

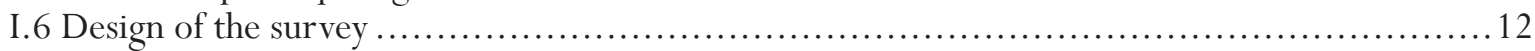

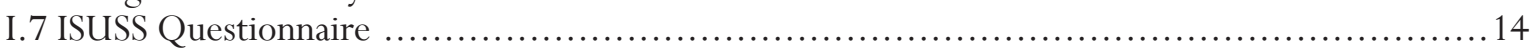

I. 8 Sampling procedures .............................................................. 16

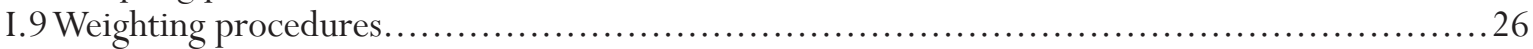

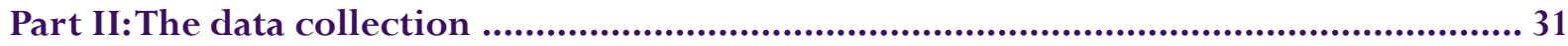

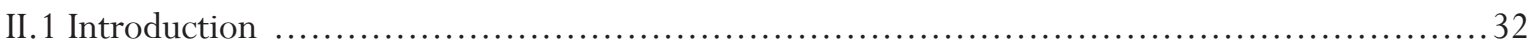

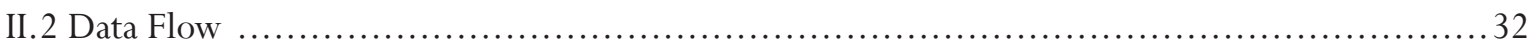

II. 3 Data Entry by the National Project Managers ........................................... 33

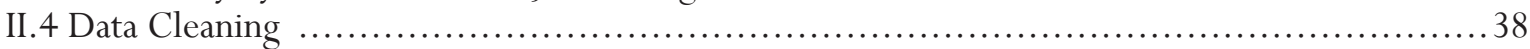

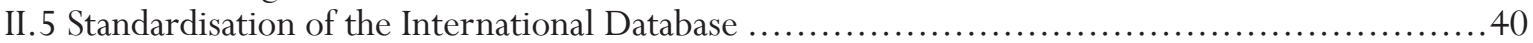

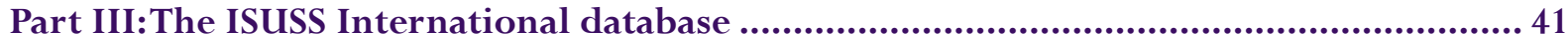

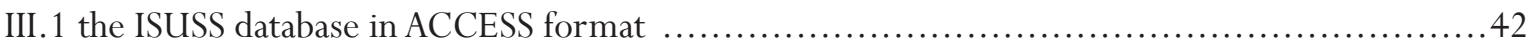

III.2 The ISUSS database in SPSS format ................................................... 44

III. 3 Identification of countries, schools and programmes ................................... 45

III.4 Missing data ................................................................. 46

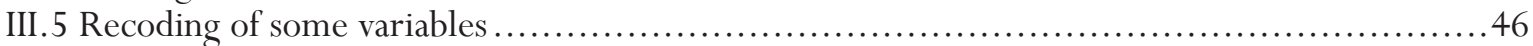

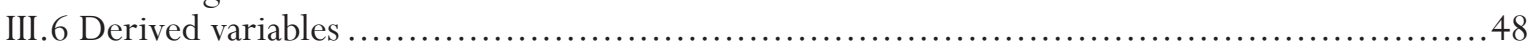

III.7 Development and contents of indices and other derived measures ......................... 48

III. 8 SPSS programmes ............................................................. 52

Annex 1:The 'school and program'questionnaire ................................................ 55

Annex 2: List of Upper Secondary Programmes included in the ISUSS study................. 73

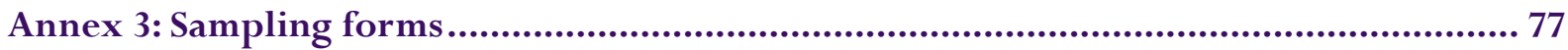

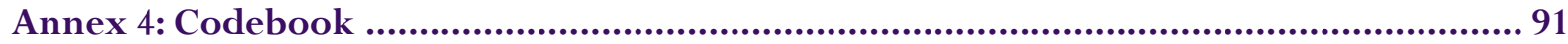

Annex 5: List of Tables published in 'Completing the Foundation for Lifelong Learning - An OECD Survey of Upper Secondary Schools'.......................................................................121

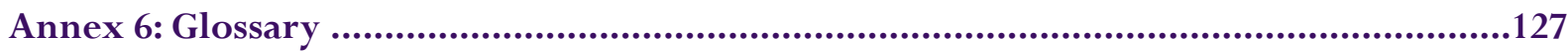


Electronic files available at www.oecd.org/edu/isuss

- International ISUSS database stored in ACCESS format

- International ISUSS database stored in SPSS format

- SPSS programmes for the building/recording of some variables nad for the construction of Tables

- 'National Project Manager's School Sampeling Manual', version 2, USSS Ref. No. 01-02-02, Febuary 15, 2001, American Institute for Research

- 'National Project Manager's Survey Operation Manual', version 2, USSS Ref. No. 01-02-02, Febuary 15, 2001, American Institute for Research 
Part

I

THE INTERNATIONAL SURVEY OF UPPER SECONDARY SCHOOLS 


\section{I.1 Introduction}

Upper secondary education is recognised as a major stage in educational progression across OECD countries. The ISUSS study aimed to provide insights into key aspects of upper secondary education previously not studied by OECD. The main aspects examined were:

- 'Human resources': the composition of school staff, the employment status of teachers, teacher supply and recruitment, the responsibility for recruiting teachers, teacher absenteeism, the demand for teachers in different subject areas and the professional development of teachers (school budget, types and variety of professional development activities).

- 'School and student management': the admission and grouping policies within schools, career guidance activities and the feedback on school functioning.

- 'Availability and use of ICT': the technological conditions, network technologies in schools, their development between 1980 and 2001, teachers and ICT, professional development of teachers related to the use of ICT, integrating ICT into school learning, obstacles to the development of ICT in schools, co-operation for improving ICT in schools.

\section{I.2 History of the ISUSS project}

Countries participating in OECD's Indicators of Education Systems (INES) programmes tried to have a better knowledge of the organisation and management of upper secondary education in their schools. In INES programmes, Network C plays an important role in developing indicators related to the learning environment and organisation of schools. In particular, their activities focus on instructional settings, education service providers and systems. Surveys are an important tool in Network C's mission of focusing policy makers' attention on school and education processes. Responding to the request of the INES Steering Group, Network C began a systematic series of school surveys in 1995 to provide information on institutional processes with the objective of producing indicators on key characteristics of the learning environment and school organisation that contributed to student achievement. The distinctive characteristic of the indicators produced by these surveys was their international comparability.

To further its goal of providing information about educational processes in an international context, Network C extended its surveys to the upper secondary level, an area of international education systems that had not been previously surveyed. The proposal to do an international survey of upper secondary schools was made to the Steering Group of OECD/INES by Network C in 1998. In February 1999, the OECD/INES Steering Group instructed the INES Network C to begin the Survey.

The proposed survey comprised two phases: Phase I consisted of a Classification Study to define the target population for the survey and the design of the survey instrument and Phase II consisted of sampling, implementation and analysis. Based on specifications developed by the Network, the OECD Secretariat launched an international call for tender for Phase I. A contract for this first phase of the survey was awarded in July 1999 to the University of Twente and these activities were completed in February 2000.

Eighteen OECD countries participated in the Classification Study, including: Austria, Belgium (Flemish Community), Denmark, Finland, France, Hungary, Ireland, Italy, Korea, the Netherlands, Mexico, Norway, Portugal, Spain, Sweden, Switzerland, the United Kingdom (England and Scotland) and the 
United States. Each of these tentatively committed to participate in the main ISUSS study. After the completion of Phase I and in agreement with Network C, OECD launched a second call for tender for Phase II, the implementation of the survey. As a result of a competitive offer, the American Institutes for Research (AIR) was contracted in November 2001 to implement the upper secondary school survey using the questionnaire developed in Phase I.

When the contractor withdrew in March 2001, OECD presented Network C with the choice of either stopping work on the survey or continuing without contractor assistance. The Network voted to continue the implementation of the study.

To ensure the independence and technical quality of the work, normally the province of OECD in reviewing contractor plans and deliverables, OECD created a Review and Arbitration Board (RAB) to oversee the work of the international co-ordinator, resolve disputes, and approve technical direction. The $\mathrm{RAB}$ comprised experts in survey design, in international surveys and in the management of complex studies.

\section{I.3 Management of the ISUSS project}

\section{OECD staff and the international co-ordinator}

The International Co-ordinator and key OECD staff were responsible for the direction and co-ordination of the project. Experts at the OECD were assigned to help in managing specific aspects of the design and implementation of the survey at the international level. This included the following:

- Planning, conducting, and co-ordinating all international ISUSS activities, including meetings of the National Project Managers (NPMs), the Review and Arbitration Board (RAB and Network C meetings with respect to ISUSS;

- Continuing to develop and revise the questionnaire, prepare it for review and approval by the RAB and implement further changes as recommended by experts in questionnaire design;

- Implementing sampling procedures for efficiently selecting representative samples of programmes in each country and monitoring sampling operations to ensure that they conformed to OECD policies and standards;

- Developing and documenting operational procedures to ensure efficient collection of all data, including software development in a variety of programmes and programming languages;

- Designing and implementing a quality assurance programme encompassing all aspects of the data collection;

- Supervising the checking and cleaning of the data sets from participating countries and constructing the ISUSS international database; and

- Writing a report based on the first results of the ISUSS and provision of a Technical Report.

\section{Review and arbitration board}

When the OECD assumed control of the ISUSS project after the departure of the contractor, it was necessary to create an independent review and arbitration board to review the work of the international 
co-ordinator, including the tasks of project implementation and technical acceptability. This was an unusual situation, where the OECD would be expected itself to provide this review. A review of operating plans and schedules, as well as quality assurance were of paramount importance and had to be provided in all survey operations. To this end, the Review and Arbitration Board was created, consisting of three outside experts including the chairperson of Network C.

The Review and Arbitration Board was created to:

- Review the project plan and all revisions for the ISUSS study;

- Monitor progress on ISUSS and call attention to technical and implementation feasibility issues that could have implications or present risks for quality and/or feasibility of data collection and indicator development; and

- Arbitrate between the OECD Secretariat and member countries on issues that might arise, particularly with respect to aspects of survey implementation and data quality requirements.

\section{External assistance contracts}

Whereas the OECD team was responsible for implementing the ISUSS study, several important ISUSS functions (including questionnaire development, questionnaire cultural adaptation, sampling design, data entry and processing and creating composite variables) were conducted by centres around the world under the direction of the ISUSS international co-ordinator. In particular, the following centres and individuals have played important roles in ISUSS:

- Network C was responsible for the overall design of the study, approval of the survey instrument and approval of the indicators developed. It also supervised the development of the survey report, advising OECD on its structure and content;

- The University of Twente developed the first draft of the questionnaire and assisted in writing the survey report;

- The American Institutes for Research developed the Sampling Manual and the Survey Operations Manual;

- Aletta Grisay provided invaluable assistance by reviewing the questionnaire and helping to find an alternative to back-translation for the generic version of the ISUSS questionnaire;

- Statistics Canada provided the final refinement of the questionnaire, including a review of format, data entry issues and internal consistency;

- John Coyle of the Educational Research Centre at St Patrick's College in Dublin designed and programmed the ACCESS data entry and cleaning programs in several versions of ACCESS;

- Tamás Káldi and Gábor Lukács of Mentor in Budapest, Hungary designed the table generator programme and provided raw summary reports which were presented at the Network C meeting in Toronto. They have been also used for final checking and cleaning of the data;

- Simon Reusch of UNI-C Denmark designed the final weighting scheme for data analysis and advised on the treatment of missing data in specific cases. He also developed composite indices; 
- The Project Management Team, consisting of the National Project Managers and the Network C delegate of the country were responsible for the implementation of the study in the participating countries including translation and adaptation of the survey instrument, sampling, calculation of weights, data collection and data checking, editing of the national database, checking data summaries and reporting tables for accuracy and consistency. The National Project Managers met twice throughout the survey to plan major activities and to monitor progress.

\section{I.4 Coverage of educational programmes in ISUSS}

ISUSS is designed to gather information at a critical juncture in the education system: the transition between compulsory education and either further education or the world of work. The transition is complex; each country has developed unique institutional structures at the transition point. ISUSS is the first attempt by the OECD to provide internationally comparable survey data for this area of schooling.

The field of upper secondary education is, from a comparative point of view, rather more complex than the primary grades or even than higher education. This complexity is due to various factors. First, the age of transition from lower secondary to upper secondary education varies between countries (from 14 to 16 years of age). Second, the duration of upper secondary programmes varies considerably between and even within countries, with the consequence that the theoretical age of leaving upper secondary education is notably variable, ranging from about 15 years to about 22 years. Third, the structures of upper secondary education differ markedly between countries.

In some countries there is a distinction between institutions providing general upper secondary education and institutions providing vocational education and training, while in other countries such a differentiation in upper secondary institutional settings does not occur. In addition, a distinction can be made between school-based education and training and dual education and training - a distinction which mainly has relevance for vocational education and training. Though several countries have vocational schools alongside a form of dual training (like apprenticeships and the dual systems in Austria and Germany), the relative sizes of age cohorts enrolling in them differs considerably.

The difference between countries is most marked in vocational programmes. Different countries rely on quite different structures to provide vocational instruction: institutions providing theoretical instruction on a part-time basis in a dual system, schools providing part-time vocational programmes, schools providing only non-dual training, vocational programmes that provide short periods of training in enterprises and vocational programmes providing both dual and non-dual training.

In the context of INES, a programme is considered as a set of (related) subjects or modules put together with known combination and sequencing rules, generally lasting for more than one year of study. In the ISUSS study, it refers to the programmes listed at level 3 of the International Standard Classification of Education (ISCED) for a given country. The focus of the ISUSS is on initial education, such as education offered in programmes and/or special institutions that a student might enrol in directly after completing a lower secondary education or by transferring directly from another initial programme at upper secondary education (e.g., the Transition year in Ireland, or the first (general) cycle of vocational school in Hungary). Excluded from consideration in ISUSS are:

- Corporate training/vocational programmes in enterprises which are not under the supervision of a public authority; 
- Programmes that are primarily distance or correspondence education; and

- Special education programmes.

The distinction between initial and continuing (adult) education is not always clearly defined. However, when the distinction can be made, ISUSS is concerned with initial, not continuing education programmes and institutions. Classification studies such as the OECD Classifying educational programmes, Manual for ISCED-97, Implementation in OECD countries (OECD, 1999) and the ISUSS Classification Study have made clearer what age populations are served by the various upper secondary institutions and programmes, so the problem can be partially addressed.

Each country was invited to provide a description of the organisation of mainstream upper secondary education. Annex 2 provides the name of the programme, its destination (A: unlimited access to higher education; B: limited access to education at ISCED 5 level; C: Labour Market); its orientation (G: General; P: Pre-vocational and V: Vocational); the minimum cumulative years of education from entry to primary education (grade) and its entry-requirement (ISCED level).

\section{I.5 Countries participating to ISUSS}

Eighteen countries participated in the first phase of the ISUSS study, which consisted of a classification of programmes, and the development of a questionnaire: Austria, Belgium (Flemish Community), the Czech Republic, Denmark, Finland, France, Hungary, Ireland, Italy, Mexico, Netherlands, Norway, Portugal, Spain, Sweden, Switzerland, the United Kingdom (England and Scotland) and the United States.

Countries participating in the Classification Study provided a description of their upper secondary school programmes and qualification systems. The main focus of inquiry was the qualitative description of various ISCED 3 level programmes and the institutions in which these programmes are offered. In most countries, data on enrolments for different programmes and for different types of providers were available.

Except for Austria, the Czech Republic and the United States, countries participating in the Classification Study committed themselves to implement the survey as well. Korea joined the study in the implementation phase.

During implementation the following countries did not satisfy the guidelines for sample sizes after the sample school replacements: the Netherlands, England and Scotland. Although the Netherlands agreed that their results could be published, they are not included in the international comparisons because of the sampling deficiencies. Data for England and Scotland were withdrawn at the request of the national authorities.

The final international database containing comparable data is therefore composed of the following countries: Belgium (Flemish Community), Denmark, Finland, France, Hungary, Ireland, Italy, Korea, Mexico, Norway, Portugal, Spain, Sweden and Switzerland.

\section{I.6 Design of the survey}

OECD education surveys generally focus on measuring factors related to student achievement and outcomes. ISUSS represents a somewhat different focus, in part because it is the first OECD survey at 
this level of the education system. Accordingly, the factors typically associated with student outcomes are surveyed without a direct measure from students (tests, interviews, or follow-up). In other words, the characteristics of schools that are surveyed in ISUSS are those which are likely to be influential to student outcomes and to be amenable to change through national or local policy initiatives, such as:

- Student recruitment factors;

- Teacher recruitment and professional development;

- Support of transition;

- Co-operation with various stakeholders;

- Resource sources and allocations;

- Availability and use of information and communication technology for both students and teachers; and

- Curriculum contents and duration.

Such school level and classroom features are of course embedded in the political context of the local education structure, which in turn are aspects of each country's education system. However, they represent characteristics that are generally accepted correlates of student outcomes.

The ISUSS study mainly focuses on institutional structures and resources and not on students' outcomes. The respondents to the survey are principals or school heads. Much of the requested data is about programme types, funding, enrolments, personnel (number, managing vacancies and professional development activities), aspects of school functioning, use of information and communication technology, school policies and practices to enhance transition. As the number of years at upper secondary education ranges from two to five years for completion, it is not easy to collect data on students' outcomes; there is no provision for a longitudinal follow-up. Nevertheless, ISUSS provides a first look at disparities in resources for these students; it can also give information on the structure and approach for follow-up surveys.

ISUSS is a descriptive survey of upper secondary school education providers. As such it:

- Examines the school system at the transition point between upper secondary education and postsecondary education or higher education thus enhancing our knowledge of how school systems help students to find suitable options for further studies or work;

- Provides a means for improving the methodology of collecting core data on education providers across countries; and

- Provides information potentially useful to the standardisation of classifications and inquiry methods for international comparisons. 


\section{I.7 ISUSS Questionnaire}

\section{Overview}

The ISUSS study was focussed on schools providing upper secondary (ISCED 3) programmes in the participating countries with the aim of providing school level data for indicators on various aspects of school functioning in upper secondary education. Data on schools were collected through a 'School and Program' Questionnaire asking about school level data and about data from specific upper secondary (ISCED 3) programmes offered at the school site.

The questionnaire was intended to obtain data that could be used to produce indicators of the learning environment and the organisation of schools at the upper secondary level. These indicators were to give an overview of the organisation of upper secondary education in such a way that comparisons could be drawn amongst the participating countries. The questionnaires were completed by the school principals. The expected completion time for the questionnaire was 45 minutes.

The policy questions which ISUSS was aiming to answer were:

- Are the teaching personnel in schools sufficiently qualified? Can teachers keep up with professional development activities? How are teacher vacancies managed?

- How diversified and organised is upper secondary education in different countries? What are admission and grouping policies applied in upper secondary schools? How selective is the initial education system at the upper secondary level?

- How well prepared are schools to use 'new technologies'? How much information and communication technology is used by students and by teachers?

- What per cent of students leave upper secondary education without completing any programme? To what extent does the school help students in their decisions about further studies and/or transition from school to work?

The questionnaire was to address four key issues:

- Human resources: Since all education programmes, vocational and general, depend on teacher qualities, indicators on this issue were sought. Questionnaire data were to be gathered on the ratio of staff to students, stability of staff and turnover, difficulties in hiring teachers in various subject/skill areas methods of covering and responding to teacher vacancies; teacher absenteeism and forms of supporting teacher professional development.

- Aspects of school functioning: A key policy concern is variability in the quality of education provided by upper secondary institutions. The following topics were recommended for inclusion in the survey: equity in admission and grouping policies; selection policies; monitoring of student progress and transparency; school contacts and co-operation in various areas of development.

- Availability and use of information and communication technology (ICT): There was little knowledge about ICT in the upper secondary levels of schooling. Not just the quantitative counts of computer availability, although this was an interesting unknown, but more important was the issue of utilisation of ICT in 
schooling. Were data available to indicate whether new technologies were being used for innovative teaching (e.g., individual instruction, simulations)? Could data be gathered to indicate whether teachers possessed the necessary ICT skills? Not only factual information was desired, but also information about the opinions and perceptions of school directors, especially with regard to obstacles to the realisation of computer-related goals.

- School policies and practices to enhance transition: upper secondary education has a dual role in preparing students for the labour market or for further education. In some cases the link between upper secondary education and labour market or further education may be a direct one. In other cases it may be left to the individual student to decide among future opportunities. The indicators would require data on the amount of time spent by students in practice, human resources available for student counselling and career guidance, school efforts to help students find a job and monitoring of students after they leave school.

\section{Organisation of the Questionnaire}

The 'School and Program' Questionnaire was divided into three parts:

- Part I: Background questions about the school;

- Part II: Questions about Upper Secondary Schools (Human Resources, Aspects of Functioning, Feedback, Stakeholders, Information and Communication Technology); and

- Part III: Questions related to programme (normally, a school which provides more than one programme at the upper secondary level should have completed a separate questionnaire for each available programme but not every country did this. In some cases, countries completed only one or two forms instead of required forms for each programme).

Annex 1 provides the questionnaire with all questions and possible answers.

\section{Translation and cultural adaptation}

The ISUSS questionnaires were prepared originally in English and translated into several languages (with one of the countries collecting data in three languages). These languages were Dutch, Flemish, Finnish, French, German, Hungarian, Irish, Italian, Korean, Norwegian, Portuguese, Spanish and Swedish. In addition, for some countries the international versions needed to be modified for cultural reasons, including in Ireland where the questionnaires were available in English as well as in Irish. For example, the international categories 'ISCED 1', 'ISCED 2' and etc. had to be replaced with the actual national programme names coded as ISCED 1 and ISCED 2 for international comparative statistical purposes. Similarly, 'Grade' appeared to be a term used only in countries with specific types of curriculum control, whereas 'Stage', 'Year' or 'Cycle' seemed more appropriate in other countries. Even the numbering of years is very different across countries depending on institutional structure and programme structure. The generic questionnaire in this case stated the cumulative number of school years targeted in the question, while countries were required to use the local name and number which school principals understand.

Unlike student achievement surveys, where it is essential that testing instruments maintain task equivalence, the ISUSS questionnaire needed to ensure conceptual comparability. From recent international surveys, it was discovered that word-by-word translation of education system terms turned out to present significant 
difficulties even to professional translators. Therefore, ISUSS sought to establish comparable meanings for terms that were commonly used by school administrators, since these were the respondents who would be answering the questions.

To check the appropriateness of translation into national languages, back-translation is commonly used in international surveys. However, this method in itself does not ensure conceptual and linguistic appropriateness of the translation. For this reason, ISUSS relied on the expertise of local school policy personnel to translate the questionnaire. An in-depth discussion on the intention of each question and the desired indicators was organised at one of the National Project Managers' Meetings to raise awareness of the eventual differences in usage of terms across countries. Also, a Translation and Adaptation Guide and a Glossary of Key Terms were developed as an aid to translation and adaptation to national contexts.

This process was a significant administrative change that served to streamline the work of the National Project Managers (NPMs).

Countries translated and adapted the international questionnaire following the guidelines in the Translation and Adaptation Guide. The national translated and adapted version was pre-tested and discussed with a national panel of school administrators (principals and experts) for cultural appropriateness, after which it was submitted for international verification to the OECD Secretariat.

In the international verification procedure countries were requested to submit the translated and adapted national questionnaire version accompanied by a Cultural Adaptation Record (CAR) in which they recorded the translated version, the deviations, and their explanation on why the deviation was necessary. The CAR and the translated version were reviewed and annotated where necessary. The final approval of the national version was the result of clarifications and negotiations between the Secretariat and the NPMs.

\section{I.8 Sampling procedures}

\section{Overview}

Countries carried out all sampling and weighting procedures using NPM staff within the country, following the guidelines in the Sampling Manual and in the Survey Operations Manual developed by the contractor American Institute for Research (AIR) for the purposes of the ISUSS study. These manuals are included in electronic files on website for completeness, though much of the key guidance is reproduced here in the Technical Report. The sampling manual covered procedures for survey sampling, including forms to be completed to ensure compliance with the sampling design as well as to encourage internal checks. The process was described in full, from drawing the sampling frame to final delivery of the completed data sets to OECD.

The sampling procedure was assisted and monitored by the international co-ordinator. Countries documented their sampling procedures by filling in a sequence of sampling forms, which were then submitted for approval to the international co-ordinator.

To be acceptable for ISUSS, national sample designs had to result in probability samples that gave accurately weighted estimates of population parameters and from which estimates of sampling variance could be computed. The ISUSS design was chosen to balance analytical requirements and operational constraints, while keeping it simple enough for all participants to implement. Representative and efficient samples in all countries were crucial to the success of the project. 
Under the organisational structure of ISUSS, much of the operational work and all of the field work for the sampling procedures were to be carried out by the countries' National Project Managers (NPMs). The NPMs were aware that:

- ISUSS was the first OECD international survey of upper secondary schools of this type;

- Preparing efficient sample designs and sampling procedures would be complex; and

- Gathering the required information about the national education systems would place considerable demands on resources and expertise.

At the same time, those directing and coordinating the project realised that the NPMs had only limited numbers of qualified sampling personnel. Keeping the procedures as simple as possible and as similar to the procedures used in other international studies was thus a major consideration.

As well as providing the sampling manual and survey operations manual, AIR provided manuals and expert advice to help NPMs in adapting the ISUSS sample design to their national system and to guide them through the initial phases of sampling. The NPMs' School Sampling Manual (included in the CD-ROM) described how to implement the international sample design and offered advice on planning, working within constraints, establishing appropriate sample selection procedures and fieldwork. The NPMs' Survey Operations Manual (electronic copy available on the website) discussed sample selection field work and data collection procedures as well as administrative operations used to identify and track respondents and non-respondents.

With the change in contracting arrangements in April 2001, NPMs had access to expert support from the international co-ordinator who reviewed and approved later phases of the national sampling plans, sampling data frames, design procedures and sample selection. NPMs were allowed to adapt the basic ISUSS sample design to meet the needs of their particular education systems by using additional sampling information or more sophisticated designs and procedures. These adjustments were subject to review by OECD staff experienced in international survey operations.

\section{Country responsibilities in sampling}

The division of work in ISUSS was typical of OECD international surveys. Each of the participating countries had responsibilities for design and field work which were carried out by the NPMs. The specific tasks required by ISUSS in sampling were:

- Preparation of the sampling framework; based on the instructions provided in the Sampling Manual, each participating country created a sampling frame that reflected the targeted population for the study. The sampling frame included, at minimum, the following information for the first stage of selection:

- The name of each eligible school site;

- The contacting address for each school site;

- If stratification was involved in the sampling, information on stratification variables for each of the school sites (e.g., urban/rural; region of the country; etc.); and

- Enrolment size at each of the school sites for all in-scope programmes (i.e., upper secondary education) and preferably by programme. 
- Implementation of the sampling plan: following the instructions provided in the Sampling Manual, each participating country was to carry out the sampling plan in its own country. Specifically, each NPM was to:

- Prepare an appropriate sampling frame and put it into an electronic data set;

- Stratify the sampling frame and appropriately allocate the sample to various strata;

- Implement the probability sampling within each stratum;

- Calculate the sampling probabilities and sampling weights;

- Check the representativeness of the selected sample and the correctness of the weighting procedure; and

- After the survey administration, calculate the response rates and derive the final sampling weights to take into account non-response.

- Documentation of the sampling process; each NPM was to carefully document every step of the sampling process and produce a final report. The final 'Survey Activities Report' was prepared and is on file at OECD for quality control and data verification. These reports include the following information:

- The sampling frame used in the process and a basic assessment about its appropriateness;

- The stratification involved in the sampling, with explanation;

- Documentation of adherence to the procedures to calculate the sampling probabilities;

- Documentation of adherence to the procedure to calculate the response rates and the final sampling weights; and

- An electronic copy of the selected sample of school sites, including: enrolments, programme type, stratification variables, selection probabilities, and sampling weights.

\section{Sample design}

According to the guidelines set by Network C, a sampling plan was developed which would:

- Allow the production of indicators framed in terms of the percentage of students in schools with certain characteristics; and

- Reflect the major national programme orientation, even though the aim is not to produce estimates at the programme level.

The result was a single-stage sample of school sites drawn with probability proportional to enrolment size that met the general guidelines while, at the same time, greatly simplified the operational aspects of implementing the sample design. The sampling procedures were reduced to mechanical steps, easily followed sequentially, which resulted in a properly defined and drawn sample. The procedures used were in common use and the forms were those used in previous international surveys. There was, therefore, an additional advantage of adopting a system with which there was already some familiarity with the tasks and processes.

The ISUSS sample generally consisted of 400 school sites, selected with probability proportional to the site's enrolment of students at upper secondary education. This number of school sites was selected to meet 
a sampling precision requirement roughly equivalent to that of other established international studies. This sample size was estimated as necessary to ensure that each country would, within 95 per cent probability limits, produce estimates for population values that would be within $+/-0.1$ of the standard deviation.

In some countries, the sample size was large compared to the population size of school sites. In these cases, the sample size requirement was reduced by the 'finite population correction'. Although the precision requirements of the study required an effective sample size of 400 schools, in many countries the actual sample size differed because of the total number of schools in the country. It is well known that for a random sample of size from an infinite population, the variance of the mean is $\sigma^{2} / n$. When the population is finite (i.e., when we know the total number of school sites in the population $=N$ ) the factor $(\mathrm{N}-\mathrm{n}) / \mathrm{N}$ is introduced in computing the variance. This factor is called the finite population correction and its effect is to adjust the variance based on the known population size.

When applied to the determination of sample size for the country samples in ISUSS, the finite population correction reduced the number of sampled units needed to achieve a given precision level. NPMs were given a chart listing the actual number of schools to be sampled in a country given its total number of schools with upper secondary programmes. NPMs could therefore look up the number that corresponded most closely to the number of school sites with upper secondary programmes in their country and find the corresponding number of schools to be drawn in their sample. The resulting number of sample schools was the minimum number of schools a country was expected to sample. Countries could, of course, sample additional units if they wished to increase the precision of their estimates, especially within explicit strata selected for national reporting.

Because previous school surveys indicated that a predictable number of schools would not be able to participate, the ISUSS sampling manuals allowed for 'replacement' schools to be drawn in such a way as to minimise selection bias. As the school sites were drawn into the sample (using the prepared forms), replacement school sites were simultaneously identified according to rules that limited choices and required pre-selection of schools rather than post hoc substitutions. In other words, should school sites be needed to replace non-participating sampled sites, there would be minimum non-response bias because substitute schools had been pre-selected. The required response rate for this study was set at 50 per cent as the initial response rate and 85 per cent after replacement school sites were included.

\section{Target population}

The international desired target population for the ISUSS sample was the set of all school sites containing at least one programme at upper secondary level (as defined by Phase I of the survey). In the vast majority of countries, a school site was equivalent to a school. However, in countries where a school encompassed many educational units, the school site was the physical entity where the upper secondary programme is administered.

The following upper secondary (ISCED 3) programmes were included:

- ISCED 3A general and 3C vocational programmes (unless they were identified as being one of the programmes mentioned below); and

- ISCED 3A pre-vocational or pre-technical programmes through ISCED 3C pre-vocational or pretechnical programmes were included only if they (predominantly) prepare for a higher ISCED level, 
another ISCED 3 programme, or for the labour market, they do not fall outside the typical age range (16-19 year-olds), and they do not fall outside the typical range of cumulative duration (11-13 year-olds).

The following programmes were excluded from the definition of the target population:

- Adult education that is not similar to regular educational programmes. In particular, courses or classes for adults that are primarily for general interest or personal enrichment and/or for leisure or recreation were excluded;

- Labour market training schemes (for employed or unemployed persons) provided outside the formal educational system (e.g., enterprises);

- Special education that deliver programmes adapted to mentally, physically or emotionally disadvantaged students and other groups with special learning needs; and

- Programmes established to function as a safety net catering to early school leavers or youth at risk.

\section{National desired populations}

National Project Managers (NPMs) were strongly encouraged to provide complete coverage when defining their national desired target population. Exclusions were allowed in certain cases where the loss of information would not be a threat to national estimates or international comparisons. ISUSS expected all participating countries to define their national desired population to correspond as closely as possible to the definition of the international desired population. Sometimes, however, NPMs had to make changes. For example, some countries had to restrict geographical coverage by excluding remote regions or atypical segments of their education system. The national sampling forms document any deviations from the international definition of the ISUSS target population. All significant deviations were documented in the required forms (see Annex 3 for Sampling Forms) submitted for approval to the original contractor or, later, to the international co-ordinator.

\section{National defined populations: school exclusions}

Using their national desired population as a general framework, participating countries had to operationally define their population for sampling purposes. This definition, known in OECD terminology as the national defined population, was essentially the sampling frame from which the first stage of sampling took place. The national defined population could be a subset of the national desired population, reduced, for example, by excluding certain schools because their enrolment was radically different from the mainstream education system. All schools that were excluded from the national defined population are referred to as the excluded population.

NPMs were expected to keep the excluded population to no more than 5 per cent of the national desired population. Exclusions could occur at the school level, within schools, or both. Because the national desired population was restricted to schools that contained the targeted programmes, schools not containing these programmes were considered to be outside the scope of the sampling frame and not part of the excluded population. Participants could exclude schools from the sampling frame for the following reasons:

- They were in geographically remote regions;

- They were of extremely small size; 
- They offered a curriculum or a school structure that was different from the mainstream education $\operatorname{system}(\mathrm{s})$.

NPMs were required to define anticipated within-sample exclusions. Because these definitions varied across countries, NPMs were also asked to fully explain any rules and reasons for exclusions. These were noted in the sampling forms and large exclusions were documented in the pertinent forms which were submitted for approval to the original contractor or, later, to the international co-ordinator. In addition, NPMs were asked to estimate the size of such exclusions so that compliance with the 5 per cent rule could be gauged in advance of approvals.

All other sources of exclusions constituted exclusions from the national desired target population. Exclusions therefore described the difference between the national desired and defined target populations.

\section{Units of analysis and sampling units}

The ISUSS analytical focus took into account both the resources available and the educational structures in place. The sample design had to address the measurement of financial and staff resources as well as specific characteristics of the institutions. Because the upper secondary programmes in schools as well as the schools themselves were considered to be potential units of analysis, both were originally considered as sampling units. This led to debate, since several countries did not possess explicit listings of their upper secondary programmes with detailed enumerations of student enrolments. Without this information, it would not be possible to create a sampling frame at the school programme level. Accordingly, the final decision was to use the school site as the sampling unit, with some flexibility for countries where school programs were distributed between multiple, but nearby, school sites.

\section{Sampling precision and sample size}

Sample sizes for ISUSS were specified so as to meet the analytic requirements of the study. Although school sites were the principal units of analysis, the ability to produce reliable estimates for programme characteristics was considered desirable. The ISUSS standard for sampling precision required that all population samples have an effective sample size of at least 400 school sites, which would produce an unpredictable number of programs with either vocational or general characteristics. In other words, the school samples were planned so that data at the school level would have predicable sampling errors, but data at the level of the upper secondary programmes would have predictable sampling errors only when the data was aggregated to the school site.

The general computation that led to the decision to require an effective sample size of 400 school sites was based on calculating the results in the following 95 per cent confidence limits for sample estimates of population means, percentages, and correlation coefficients. An effective sample size of 400 school sites results in the following approximate 95 per cent confidence limits for sample estimates of population means, percentages and correlation coefficients:

- Means: $\mathrm{m}+/-0.1 \mathrm{~s}$ (where ' $\mathrm{m}$ ' is a school mean estimate and 's' is its estimated standard deviation);

- Percentages: $\mathrm{p}+/$ - 5\% (where 'p' is a school-level percentage estimate);

- Correlations: $\mathrm{r}+/$ - 0.1 (where ' $r$ ' is an estimated school correlation). 


\section{Stratification}

Prior to sampling, NPMs could order schools, or stratify them, in the sampling frame of all upper secondary schools in the country. Stratification was recommended when there was some evidence that the school sites within the strata would be less variable than schools in general. Stratification under these conditions would produce low within-stratum variability and would lower the overall sampling error.

There were three conditions cited as good reasons to stratify schools in ISUSS:

- To produce reliable estimates for sub-national domains;

- To improve the sampling efficiency, thereby improving the reliability of national estimates; and

- To ensure that different parts of the population were appropriately represented in the sample.

Examples of commonly used stratification variables that were recommended for consideration included:

- Regions (states, provinces);

- Urbanisation (rural, urban);

- School size (large, small);

- School types (public, private); and

- School programme type (general, vocational).

NPMs were given the option to use a combination of explicit or implicit stratification variables in drawing their school site sample, thus allowing them to increase either precision or representation of specific groups of interest (e.g., private schools). Explicit strata were optional and their use was recommended to provide distinct subsets of the sampling frame that could be of particular policy importance for that country. Implicit strata were part of the overall sampling design, which ordered schools by size and then selected them systematically to ensure proportional allocation across the implicit strata.

\section{Explicit stratification}

For those countries that chose to use explicit stratification, the list of all upper secondary schools was divided into separate lists, or frames, of schools for each stratum, according to the number of variables used to define the strata. For example, if geographic region was used as an explicit stratification variable, then separate school sampling frames were constructed for each geographic region. Although it was possible to then use different sample designs within each stratum, this was not desired or needed in ISUSS. However, for some strata, such as a stratum of large schools, the design was changed from proportional sampling to either sampling with a constant sample size or a census of that stratum.

The example of a stratum of large schools demonstrates the major reason for considering explicit stratification, which was to implement a disproportionate allocation of the school sample to the explicit strata. In the example of a large school stratum, the same number of schools was sampled from the explicit stratum, regardless of their relative sizes. The objective in this situation was to produce predictably reliable estimates for this stratum. 
In theory, a reason for considering explicit stratification in ISUSS was to ensure adequate sample size for a stratum, justifying the disproportionate allocation of the school sample to that stratum. For example, a country might require an equal number of schools from each stratum, regardless of the relative size of each stratum, to ensure comparability for policy reasons. Another reason for defining explicit strata was to deal with specific sample design issues. For example, explicit strata were sometimes required to deal with small schools, as well as with very large schools.

\section{Implicit stratification}

In general, implicit stratification consists of sorting the upper secondary schools in the sampling frame(s) by a set of implicit stratification variables. For ISUSS, this variable was enrolment size or some reasonable measure of enrolment size. This type of stratification is very effective in reducing sampling errors and is a well-regarded design with a long history of use in population sampling. It has the merit of providing a relatively simple way of ensuring a strictly proportional sample allocation of schools across the implicit strata. This ordering produces a simple way of ensuring proportional sample allocation without the complexity of creating additional explicit strata and the extra work of drawing a sample from each stratum.

In addition, implicit stratification typically leads to improved reliability of survey estimates, provided the implicit stratification variables being considered are known to have a significant between-strata variance component. Since school size is almost always a factor in school resources, it appeared a reasonable choice as a variable for implicit stratification.

\section{Replacement schools}

From prior experience in other international surveys, albeit not with upper secondary schools, it was anticipated that a 100 per cent participation rate of schools would not be reached in all countries. To avoid losses in sample size, a mechanism was devised to identify, a priori, two replacement schools for each sampled school. The use of implicit stratification variables and the subsequent ordering of the school sampling frame by a measure of school size led to a method of assigning replacement schools that was deemed likely to produce a low response bias if replacement schools were needed in the final sample.

The method of identifying replacement schools relied on the ordering of the sampling frame by school size as an implicit stratification. For each sampled school site, the next two school sites immediately following it in the sampling frame were designated as replacement school sites. The use of school enrolment size as the implicit stratification variable, and the subsequent ordering of the school site sampling frame by size, ensured that any sampled school site's replacements would be of a comparable size and likely to share other characteristics.

Although each sampled school site in the survey was assigned the next two replacement school sites in the ordered sampling frame, there were constraints. First was the fact that the distribution of schools in a country might mean that adjacent schools were both selected into the original sample. In this case, one school could not serve as replacement for the other. The following rules were devised to be followed by NPMs in assigning replacement schools:

- An already sampled school site could not serve as the replacement for another school site;

- A school site could not serve as replacement for more than one sampled school site; 
- If a sampled school site were the next to last school site listed, then the school sites immediately above and below it could serve as its replacement school sites; and

- If a sampled school site was the last school listed, then the two school sites immediately above it could serve as its replacement school sites.

Several countries used replacement schools to meet the requirements for response rate. Their use and the resulting calculations of response rates were tallied in Form 12 (Annex 3) and approved as appropriate by the international co-ordinator. Figures are shown in Table I.1.

\section{Single-stage sampling}

The sample selection method used in ISUSS made use of a systematic probability proportional to size (PPS) technique. Use of this method required some measure of size (MOS) of the school sites (sampling units). Ideally this was the enrolment in upper secondary programmes in the school. But if this information was unavailable, some other highly correlated measure, such as total school enrolment, was used.

The schools in each explicit stratum were listed in order of the implicit stratification variables, together with the MOS for each school. They were further sorted by MOS within variable. The measures of size were accumulated from school to school, and the running total (the cumulative MOS) was listed next to each school. The cumulative MOS was a measure of the size of the population of sampling elements; dividing it by the number of schools sampled gave the sampling interval.

The first school was sampled by choosing a random number in the range between 1 and the sampling interval. The school whose cumulative MOS contained the random number was the sampled school. By adding the sampling interval to that first random number, a second school was identified. This process of consistently adding the sampling interval to the previous selection number resulted in a PPS sample of the required size.

As each school was selected, the next school in the sampling frame was designated as a replacement school for use should the sampled school not participate in the study, and the next after that as a second replacement for use should neither the sampled school nor its replacement participate.

Two of the many benefits of the PPS sample selection method are that it is mechanically straightforward to implement and that it is relatively easy to verify that it was implemented properly. The latter was critical since one of the criteria of credibility of ISUSS was to be able to verify that a sound sampling methodology had been used.

\section{Small schools}

Small schools tend to be problematic in PPS samples because programmes sampled from these schools get disproportionately large and variable sampling weights. A school was deemed small in ISUSS if the total in-programme enrolment in the school was smaller than the average in-programme school enrolment in the country (defined as ASEC) divided by 4 (defined as ASEC4). Any school where enrolment was less than ASEC4 was considered to be a small school.

Since the weights applied to small schools were numerically large and variable, they introduced a source of error in computing statistical estimates, such as weighted averages. The more small schools there are, the 
greater this problem becomes. Because the population of upper secondary schools was known to include a sizeable proportion of small schools, this problem received special attention in the original sampling design. There were two solutions proposed: to exclude small schools where possible, thereby eliminating the problem; and to separate small schools for separate estimations, thus limiting the error propagation.

NPMs who could demonstrate that enrolments in small schools represented less than 10 per cent of all national enrolments in upper secondary schools were allowed to include small schools in the school sampling frame and let them be subject to normal sampling procedures. The assumption here was that with less than 10 per cent of the enrolments, such schools would not significantly affect the standard errors.

If, however, enrolments in small schools exceeded 10 per cent, NPMs were to define an explicit stratum of small schools. The number of schools to sample from this stratum remained proportional to the stratum size, but all schools had an equal probability of selection. This action ensured greater stability in the resulting sampling weights.

If enrolments in these schools were less than 2 per cent of the eligible population, they could be excluded, provided the overall exclusion rate of school sites in the country did not exceed the 5 per cent limit. In other words, NPMs could choose to exclude small schools (MOS < ASEC4) if the resulting exclusion rate was less than 2 per cent. There was a special form designed to establish this exclusion (Sampling Form 4 in Annex 3). In the original design of this form, there were errors. The form was corrected and used in the few countries where it applied.

\section{Optional preliminary sampling stage}

It was originally planned that some very large countries would chose to introduce a preliminary sampling stage before sampling schools. This would have consisted of a PPS sample of geographic regions. A sample of schools would then be selected from each sampled region. This design was proposed as a cost reduction measure where drawing up a comprehensive list of schools would have been either impossible or prohibitively expensive. Also, this additional sampling stage would reduce the dispersion of the school sample, thereby potentially reducing travel costs. However, computer listings of school sites were evidently easily available in all countries, so this design preparation was not implemented.

\section{School response rates}

Response rates were computed by NPMs in each participating country for the originally selected schools as well as for the final sample that included replacement schools. A form was provided to simplify calculations and to ensure conformity to definitions and operations (Sampling Form 12 in Annex 3). The study response rates were calculated only at the school site level, not for the upper secondary programmes within schools. This was because of the difficulty in enforcing responses to the extensive data requests in Part III of the questionnaire.

Response rates, therefore, apply to both complete and incomplete questionnaire returns. If the respondent did not or was not able to complete the upper secondary programmes' section for all of the school's ISCED 3 programs (there could be up to 10 in some countries) then the questionnaire was accepted with as many of the ISCED 3 program sections as completed. The response rates reported on Form 12 at the end of the data submission deadline are shown in Table I.1. 
Table I. 1

Sampling information

\begin{tabular}{|c|c|c|c|c|c|c|}
\hline & \multicolumn{3}{|c|}{ Initial sample -before school replacement } & \multicolumn{3}{|c|}{ Final sample -after school replacement } \\
\hline & $\begin{array}{c}\text { Number of selected } \\
\text { schools }\end{array}$ & $\begin{array}{c}\text { Number of } \\
\text { participating } \\
\text { schools }\end{array}$ & $\begin{array}{l}\text { Response rate } \\
\text { (per cent) }\end{array}$ & $\begin{array}{c}\text { Number of selected } \\
\text { schools }\end{array}$ & $\begin{array}{c}\text { Number of } \\
\text { participating } \\
\text { schools }\end{array}$ & $\begin{array}{l}\text { Response rate } \\
\text { (per cent) }\end{array}$ \\
\hline Belgium (Fl.) & 256 & 175 & 68 & 256 & 233 & 91 \\
\hline Denmark & 176 & 160 & 91 & 176 & 162 & 92 \\
\hline Finland & 294 & 235 & 80 & 294 & 257 & 87 \\
\hline France $^{2}$ & 401 & 305 & 76 & 401 & 338 & 84 \\
\hline Hungary & 310 & 263 & 85 & 310 & 299 & 96 \\
\hline Ireland & 255 & 198 & 78 & 255 & 231 & 91 \\
\hline Italy & 400 & 247 & 62 & 400 & 358 & 90 \\
\hline Korea & 324 & 323 & 100 & 324 & 323 & 100 \\
\hline Mexico & 400 & 378 & 95 & 400 & 379 & 95 \\
\hline Netherlands ${ }^{1}$ & 275 & 114 & 41 & 315 & 136 & 43 \\
\hline Norway & 212 & 180 & 85 & 212 & 180 & 85 \\
\hline Portugal & 282 & 272 & 96 & 282 & 276 & 98 \\
\hline Spain & 370 & 355 & 96 & 370 & 363 & 98 \\
\hline Sweden ${ }^{2}$ & 235 & 183 & 78 & 235 & 198 & 84 \\
\hline Switzerland & Census & 582 & 100 & Census & 582 & 100 \\
\hline
\end{tabular}

1. Response rate is too low to ensure comparability

2. Although the response rates for France and Sweden were technically below the target of 85 per cent, they were deemed close enough to be acceptable.

\section{I.9 Weighting procedures}

\section{Sample weights}

A sampling weight was assigned to each school; it corresponds to the inverse of the adjusted probability of selection of the schools. Since probability of selection was based on the number of enrolled students in the target population, the smaller a school is, the larger weight it was assigned. For any school listed, the school weight was calculated as:

$W_{i}=\frac{1}{H_{i}}$

where $H i$ is simply the probability of selection adjusted for non-response rate.

Thus, the sum of the school weights multiplied by the measure of size (MOS) for each school in the sample approximates the aggregate measure of size for the upper secondary student population.

\section{Adjusted school weights}

Countries were invited to complete the sampling forms 1 to 13 (Annex 3).

After the ISUSS database had been built, sampling weights were calculated and necessary weight corrections and adjustments were made following similar methods as used in the Programme for International Student Assessment (PISA) database (see the OECD PISA 2000 Technical Report, Chapter 8). 


\section{Trimming of weights}

The original sample weights calculated by the countries were designed to make the PPS-sample represent the true population of schools in each country. Typically a small school would have little probability of being drawn in to the sample, so a small school in the sample typically represents a large number of equally small schools in the population, resulting in a relative large sample weight. In some cases, extreme weights were encountered (e.g., sample weights exceeded the mean sample weight by three to five times). To minimise the bias effect of these in the estimation of variance, it was technically advisable to 'trim' the extreme weights; in other words to set a maximum for acceptable weights. This was done through studying country level distribution of weights and identifying out-liers. Adjustments were necessary in no more than three schools in any country (except for Portugal). The adjusted school weights were used as the school component of the weight formula used in the estimation of frequencies, ratios, and indices.

Table I.2 lists those countries where school weights had to be trimmed and the number of schools in each country that had their weights trimmed.

Table I.2.

Weights of the samples and corrections for adjusted weights

\begin{tabular}{|c|c|c|c|c|}
\hline & Mean weight of the sample & $\begin{array}{l}\text { Weight of the school } \\
\text { greater than }\end{array}$ & $\begin{array}{l}\text { Number of schools } \\
\text { where it occurs }\end{array}$ & $\begin{array}{l}\text { 'Trimmed' weight } \\
\text { for these schools }\end{array}$ \\
\hline Belgium (Fl.) & 2.9938 & 10 & 1 & $3 *$ mean \\
\hline Denmark & 1.9115 & 20 & 1 & $5 *$ mean \\
\hline Finland & 3.8809 & 20 & 2 & $5 *$ mean \\
\hline Hungary & 4.1723 & 50 & 1 & $4 *$ mean \\
\hline Italy & 13.9605 & 100 & 3 & $5 *$ mean \\
\hline Korea & 5.3211 & 20 & 1 & $3 *$ mean \\
\hline Mexico & 21.2115 & 200 & 3 & $5 *$ mean \\
\hline Portugal & 3.5016 & 20 & 11 & $4 *$ mean \\
\hline
\end{tabular}

\section{Sample weights less than one}

In the case of sample weights that were less than 1 (it would mean that the size of the school sample is larger than the sampling interval) the weights have been replaced by 1 (the non-response rates are quite correct; so their weights are not affected); such adjustments were necessary for one school in Finland and Hungary, for four schools in Mexico and for eleven schools in Portugal.

\section{Other adjustments}

France: Post-hoc weighting was necessary because of misunderstandings by completing the sampling forms. Recalculated weights were based on the formula used in the Sampling manual and applied to French data with their approval.

Here, the actual number of upper secondary enrolments in the ISUSS database has been used as 'MOS (measure of size)'. 
Probability of selection of a school ( $\mathrm{i}=$ stratum; $\mathrm{j}=$ school $)$

$\mathrm{P}_{\mathrm{ij}}=\left(\mathrm{N}_{\mathrm{ij}} * \mathrm{n}_{\mathrm{j}}\right) / \mathrm{N}_{\mathrm{i}}$

where:

$\mathrm{N}_{\mathrm{ij}}=$ school MOS (ENR3TOT $=$ sum of SC05Q03 to SC05Q22)

$\mathrm{N}_{\mathrm{i}}=$ stratum size students (Sampling form 8 in Annex 3)

$\mathrm{n}_{\mathrm{j}}=$ number of school in the sample for stratum $\mathrm{j}$

Weight: $\mathrm{W}_{\mathrm{ij}}=1 / \mathrm{P}_{\mathrm{ij}}$.

Ireland: There were two schools which were picked outside of the normal selection process. These were large schools whose size exceeded the sampling interval and they were therefore put in a stratum of their own for 'very large schools'. Strict applications of the sample weight calculation resulted in weights equal to 0.95 and 1.05 but as the two schools were the only schools in the stratum, and thus their probability of selection was equal to one, both school weight values were set to 1 .

The Netherlands: As this country did not meet international sampling requirements, every school weight is equal to 1 . Therefore, results for this country cannot be compared to those for other countries.

\section{Use and calculation of weights in the analysis of results}

Since the weighting model is optimized for assumptions about students rather than about schools, in order to have each case represent the number of students in the sampled schools, sample weights were combined with the number of students enrolled in the schools. The sum of these combined student weights then approximates the total number of upper secondary students in the target population.

Four student weights are used in the analyses:

- To estimate values for school level indicators, the adjusted school weights are used in combination with the upper secondary (ISCED 3) student enrolments in the school. This weight is used in weighted frequencies, ratios, and unstandardised composite indices related to school-level data;

- To estimate values for indicators split by programme type, the adjusted school weights are used in combination with the programme enrolments. This weight is used in programme-level ratios and frequencies;

- To estimate country values on an international standard scale in school-level data, a combination of country weights, schools weights and upper secondary (ISCED 3) enrolment weights is used; and

- To estimate country values on an international scale in programme level data, a combination of country weights, schools weights and programme enrolment weights is used.

Inflating the weight of cases (which is the number of cases observed) leads to underestimation of the standard error of estimation. To avoid this, all four student weights are rescaled to ensure correct standard error estimations. For this reason, the final formulae for the student weights used in calculating results are as follows: 


\section{Weights for estimating national variance and standard error}

\section{Weight for estimating school-level indicators}

Is 3 EnrWt is used to weight the school questionnaire variables. This weight ensures that each item has the relative weight of the total upper secondary (ISCED 3) student enrolment combined with the sample weights. The weights have been scaled to ensure correct standard error estimations.

$$
\text { Is } 3 E n r W t_{i j}=W g h t_{i j} \text { isced } 3 \_t_{i j} \frac{n_{j}}{N_{j}}, \mathrm{j}=1 \text { to } 15
$$

where $\mathrm{Wght}_{\mathrm{ij}}$ is the weight of school $\mathrm{i}$ in country $\mathrm{j}$, isced3_t $\mathrm{t}_{\mathrm{ij}}$ is the number of upper secondary students in school $i$ in country $j$, and $n_{j}$ is the size of she school sample in country $j$, and

$N_{j}=\sum_{i=1}^{n_{j}} W g h t_{i j}$ isced $3 \_t_{i j}$. is the sum of Isced3 enrolment weights in the national sample.

\section{Weight for estimating indicators by programme type}

$\operatorname{PrgEnr} \mathrm{Wt}_{\mathrm{ij}}$ is used to weight the programme questionnaire variables. This weight ensures that each item has the relative weight of the total programme-enrolment combined with the sample weights. The weights have been scaled to ensure correct standard error estimations.

$\operatorname{PrgEnr} W t_{i j}=W g h t_{i j} \operatorname{prg}-t_{i j} \frac{n_{j}}{N_{i}}, \mathrm{j}=1$ to 15

where $\mathrm{Wght}_{\mathrm{ij}}$ is the weight of school $i$ in country $\mathrm{j}$, Prg_t $\mathrm{t}_{\mathrm{ij}}$ is the number of students in programme $\mathrm{i}$ in country $\mathrm{j}$, and $\mathrm{n}_{\mathrm{j}}$ is the size of she school sample in country $\mathrm{j}$, and $N_{j}=\sum_{i=1}^{n_{j}} W g h t_{i j}$ prg_t $t_{i j}$ is the sum of programme enrolment weights in the given programme in the national sample

\section{Weights used for estimating the international mean and standard deviation}

Some of the indices are standardised across countries. For these indices an international mean and standard deviation was calculated. The indices were then transformed into standard scales with the international mean set to zero, and the international standard deviation used as scale unit.

\section{Weights for estimating the international mean and standard deviation based on upper secondary} student enrolment in the school

To obtain the international mean, and standard deviation, the scores of all schools in the international sample were pooled. Countries had different sample sizes, however, which meant that a country with a bigger sampling size would have had a larger weight in shaping the international mean and standard deviation. To avoid this bias, a weighting scheme was used that defines all countries as having equal weight. In addition to the sample weight and the enrolment weight, in the composite weight used for standardisation, a country weight was also included, which equalized the contribution of each country in shaping the OECD international standard. 
Thus, the weight used in standardisation is based on the following formula:

Is $3 T_{o t} W t_{i j}=W_{g h t} t_{i j}$ isced $3 t_{i j} \frac{\bar{n}_{14}}{N_{j}}, \mathrm{j}=1$ to 14 (excluding the Netherlands)

where $\mathrm{Wght}_{\mathrm{ij}}$ is the weight of school $i$ in country $j$, isced3_t $\mathrm{t}_{\mathrm{ij}}$ is the number of upper secondary students in school $\mathrm{i}$ in country $\mathrm{j}, \bar{n}_{14}=\frac{1}{14} \sum_{j=1}^{14} n_{j}$ is the average number of students in the approved countries (excluding The Netherlands), and $N_{j}=\sum_{i=1}^{n_{j}} W g h t_{i j}$ isced $3{ }_{-} t_{i j}$ is the sum of enrolment weights in the total OECD sample.

Weight for estimating international mean and standard deviation based on student enrolment in the programme

Following the same reasoning as in the calculation of standardised school level indicators, a similar weight is used to weight the programme questionnaire variables. This weight ensures that each item has the relative weight of the total programme-enrolment combined with the adjusted school weight. The weights have been rescaled to the sample size to ensure correct standard error estimations. To estimate programme enrolment weight, the following formula was used:

${\operatorname{PrgTot} W t_{i j}}=W_{\text {ght }} \operatorname{prg}_{-} t_{i j} \frac{\bar{n}_{14}}{N_{j}}, \mathrm{j}=1$ to 14 (excluding the Netherlands)

where $\mathrm{Wght}_{\mathrm{ij}}$ is the adjusted school weight of school $i$ in country $j$, Prg_t $\mathrm{t}_{\mathrm{ij}}$ is the number of students in programme $i$ in country $j$, and $n_{j}$ is the size of she school sample in country $j$, and

$N_{j}=\sum_{i=1}^{n_{j}} W g h t_{i j} \operatorname{prg}_{-} t_{i j}$ is the sum of enrolment weights in the total OECD sample. 
Part

II

THE DATA COLLECTION 


\section{I Introduction}

Data collection consists of several general tasks:

- Creating data entry and validation programmes and protocols;

- Formatting countries' data into a consistent format;

- Preparing validity reports and statistical summaries of items to ensure accuracy;

- Data cleaning; and

- Merging countries' data files to create the OECD international database.

Each task was crucial to ensuring the quality and accuracy of the data file for the ISUSS.

This section describes the data entry task undertaken by each National Project Manager (NPM), the data checking and database creation that was implemented by the OECD international co-ordinator, and the steps taken to ensure the quality and accuracy of the international database. It discusses the respective responsibilities for each step in the process of creating the international database; the flow of the data files between those responsible for data processing; the structure of the data files submitted by each country for processing and the resulting files that represent the international database.

Data processing for ISUSS was carried out as a joint activity, with close cooperation between the NPM in each of the participating countries and the OECD international co-ordinator.

The change in schedules for data processing arising from the withdrawal of the original contractor were discussed and agreed at the first meeting of the NPMs in June 2001. There were eventual deviations from the negotiated schedules, but the system allowed all data processing to be done by the international co-ordinator. Moreover, the system proved to have advantages later in the iterative cleaning and editing processes because late data entries and edit changes could be added to the database.

\section{II.2 Data flow}

The data collected in the ISUSS survey were entered into data files using a common international format, as described in the ISUSS Codebook (Annex 4). The data files were then submitted to the OECD international co-ordinator for cleaning and verification. The major responsibilities of the OECD were to check that the data files received matched the international standard and to request modifications as necessary to bring them into compliance. With the exception of one country that lacked this capability and where OECD needed to reformat the data set, all countries carried out the reformatting to codebook standards.

Once the data sets were formatted, OECD then applied standard cleaning rules to the data to verify their consistency and accuracy. A software 'cleaning programme' has been developed to produce a validity report indicating any inconsistencies. The cleaning programme was iterative, so that NPMs could edit and re-run the validation programme to ensure the accuracy and internal consistency of their data.

Finally, when the data appeared to be clean and the validity report indicated no serious inconsistencies or format problems, OECD created statistical summaries for each country using their data. These statistical 
summaries (ranges, means, missing values, etc.) gave a general view of data patterns item by item, which provided yet another view of the data to expose any remaining problems.

Once countries had verified and approved their data and OECD had determined that it was consistent with the international file format, the data were merged into an international database. During the creation of the international database, country codes were added and a final edit check was run for internal consistency. A final summary file of basic item statistics was produced for each country and sent to them for their review. This review, together with data provided by the NPM tracking forms, was used to determine the acceptability of each country's data for the ISUSS international database.

\section{II.3 Data entry by the national project managers}

The diagram shown in Figure II.1 illustrates the various programmes and format conversions which were required from data entry to a final country database file.

\section{Figure 11.1}

Data entry process

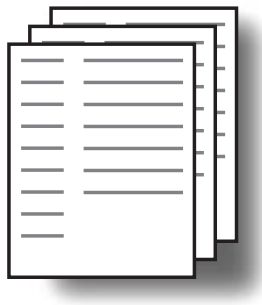

Completed Questionnaires

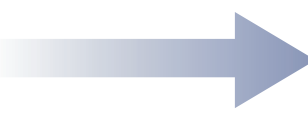

Data entry program (OECD provided:

ACCESS 97

ACCESS 2000

ACCESS XP)
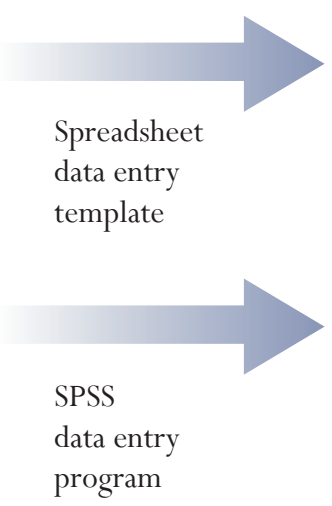

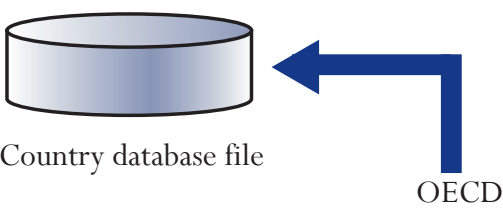

Conversion

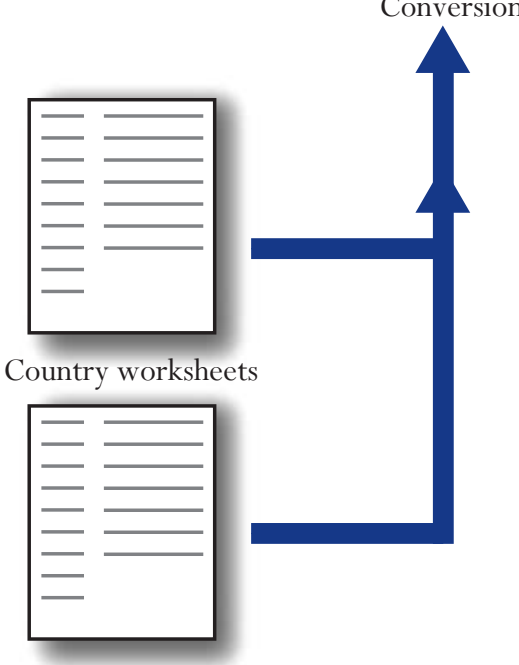

Each country's NPM was responsible for translating and transcribing the information from the national questionnaires into a format based on the generic ISUSS questionnaire and for creating a computer data file. There was some freedom to choose the method of data entry, as long as the format was consistent with the ISUSS codebook. About half of the countries chose to use data-entry software provided by OECD, less than half used SPSS to enter data, many of the remaining countries arranged to use spreadsheets as entry forms, and one country used SAS. 
The Codebook (Annex 4) for the questionnaire was a key for assuring consistent and accurate data for ISUSS. There were two parts to the codebook, the school section which was to be completed for each school, and the programme section(s) to be completed for each upper secondary programme in the school. This structure was inherently hierarchical, with identification numbers to make sure that programmes were linked to the right school. This arrangement meant that there were data files for schools and for programmes within schools, linked as a hierarchy to reflect the arrangement of programmes within schools. The codebook contained the essential information for providing this link.

OECD developed data entry software to facilitate NPMs' work and to ensure compliance with the codebook requirements. There were two alternatives for those countries that had not already decided on a system of data entry: a spreadsheet that incorporated value screens to make data entry consistent with codebook requirements; and a data entry programme based on ACCESS, a database language system. Because countries had different versions of ACCESS, the database system was developed in three versions: ACCESS 97, ACCESS 2000 and ACCESS XP.

Because of the hierarchical nature of ISUSS data, with a variable number of programmes within each school, OECD recommended the use of the ACCESS database system. The alternative spreadsheet data entry system did not automatically ensure a correct link between a school and its programmes, which meant the possibility of error. To facilitate data entry, the ACCESS screens were designed to match the school and programme sections of the questionnaire. Not only did this make data entry easier, but it preserved the link between a school and its programmes.

Opening data entry screen for School Questionnaire Data

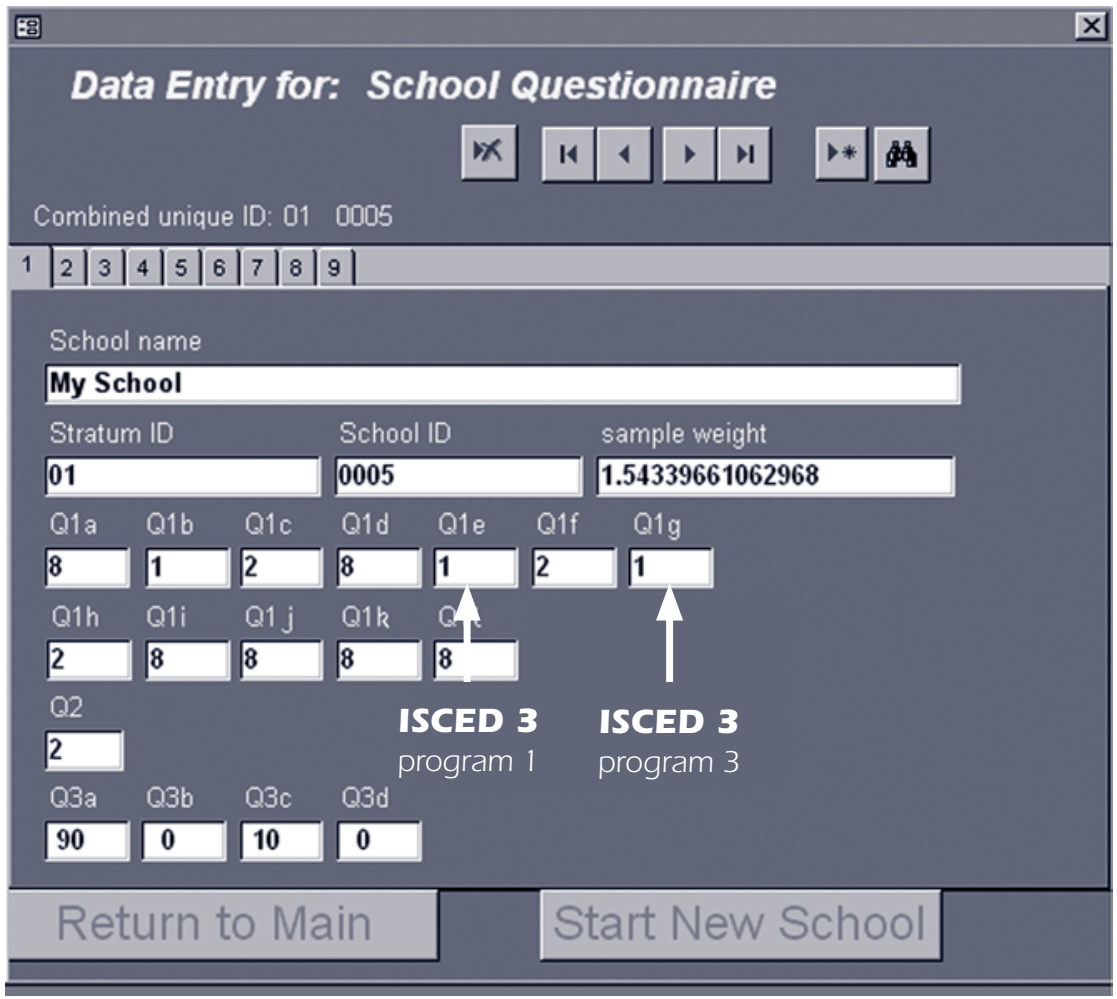


For example, the data entry screen for the first questionnaire item, shown in Figure II.2, illustrates a pattern of educational programmes from primary education through higher education. The responses indicate that the school provides two upper secondary programmes: the first and third in the country's list of programmes (indicated by '1' in Q1e and Q1g). The screen limits the number of data slots available to just those appropriate to this country: two upper secondary programmes.

Figure II. 3 shows the second screen of the school data entry programme. This screen accepts responses to questionnaire item 5 about enrolments in the school for upper secondary programmes. The example shows that the inappropriate data entry boxes for item 5 have been blanked out for this school, leaving only the first and third upper secondary programmes available for data entry. This illustrates one of the advantages of using the OECD supplied software to ensure data accuracy and consistency - data could not be entered in an inappropriate box.

During the course of data entry, there were several changes made to the data entry programmes, in spite of all the pre-planning and pilot testing that had been done. Both the enrolment sizes in some upper secondary programmes and the numbers of computers available to students proved larger than anticipated. The data entry software needed to be modified to hold the larger numbers. It was a simple matter to make changes in the value screens and the codebook, but it turned out to be somewhat more difficult to change the missing values that had already been entered by those countries which had completed some of their data entry.

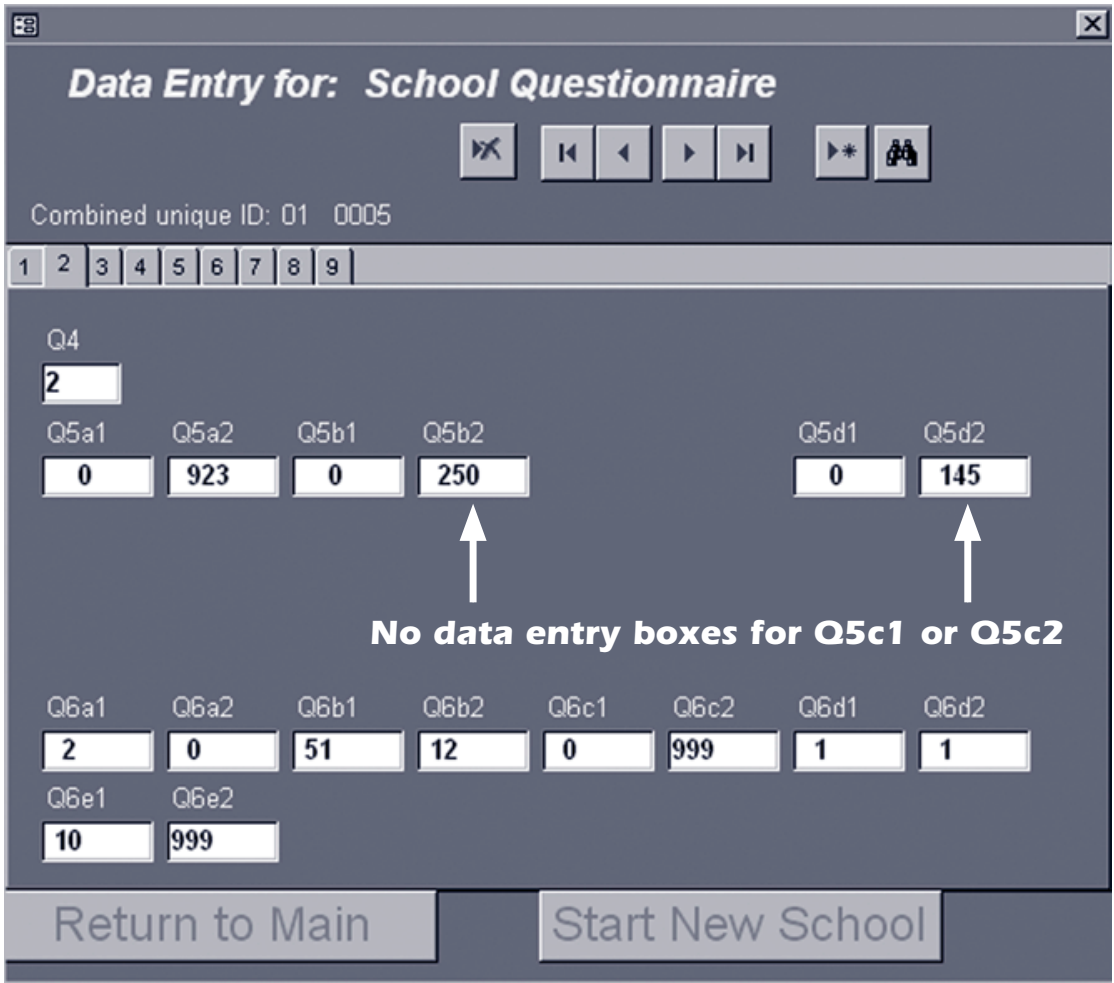


To illustrate this problem, suppose that enrolment data had been entered before the change was made from a 4-digit to a 5-digit field. Before the change in value screens, only 4-digit data could be entered, with the maximum enrolments limited to 5000 and special data codes set to '9997', '9998' and '9999'. After the modification, the maximum enrolments was 15000 with special data codes set to '99997', '99998' and '99999'. Although it was extremely unlikely that one of the 4-digit special data codes would correspond to actual enrolments, this possibility still required checking to avoid converting an actual enrolments figure to a missing value. Figure II. 4 illustrates one attempt to correct for this problem, after confirming with the countries that the conversion would not create inappropriate missing values.

\section{Figure 11.4}

Data cleaning module opening screen

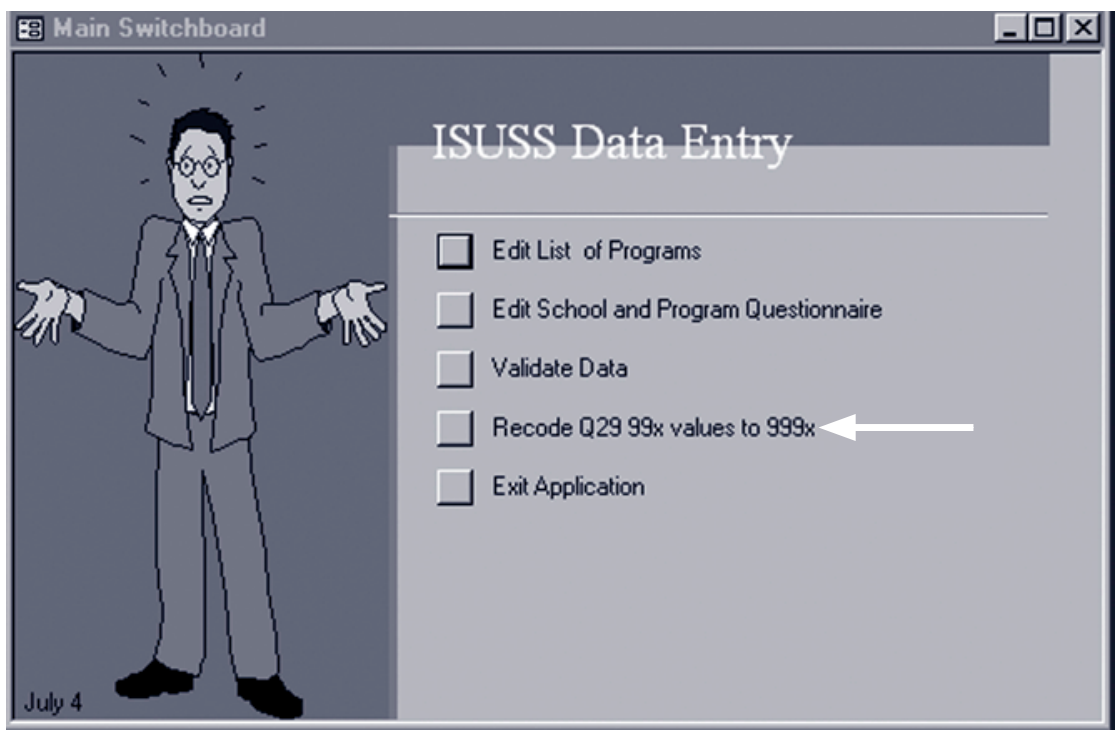

Another change was made to the codebook and data entry programmes during data entry to include information on grade equivalencies for specific upper secondary programmes. It was discovered during routine data checks that several upper secondary programmes were directed to older or younger students, although the ISCED level was the same. To ignore this difference would complicate subsequent analyses of programme data. Therefore, although this information was neither a questionnaire item nor listed in the codebook, a data entry screen was added to the ACCESS programmes to gather additional data on the cumulative years of schooling typical for each year of each programme. Since the data could be accurately completed by the NPM from administrative records, it did not significantly add to the data burden on respondents, so the decision was made to add the information to each country's data file.

For countries not using the ACCESS programme for data entry, the programme by grade screen was included in the data cleaning module so that it could be added when the country made validation edits. The information request is shown in Figure II.5. The example shows a country where two ISCED 3 programmes are available. In each of these, students enter the programme after nine years of schooling in ISCED 1 and ISCED 2 programmes; ISCED 3 programmes are three-year programmes. The examples in the subsequent figures refer to this case. 
Figure 11.5

Additional data entry form on grade level

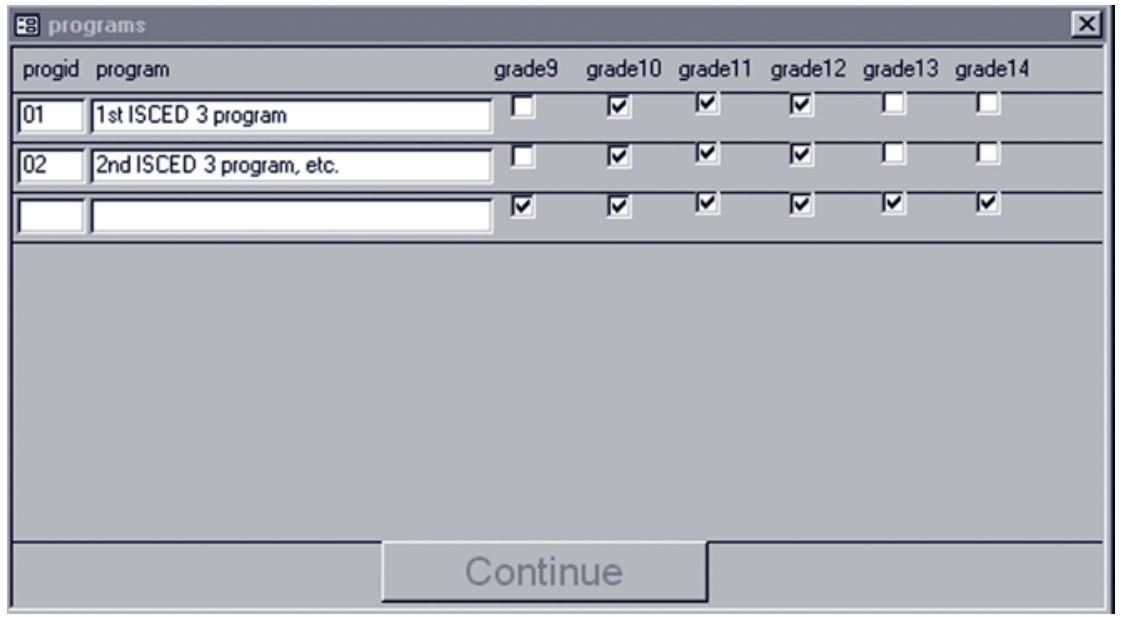

The most difficult part of the questionnaire for respondents and for data entry was Part III, the upper secondary programme data. Figure II. 6 shows the first screen for data entry of Part III of the questionnaire. The screen ensures that the correct upper secondary programme was selected by presenting its name in an un-editable field.

\section{Figure 11.6}

First data entry screen for School Programme Data

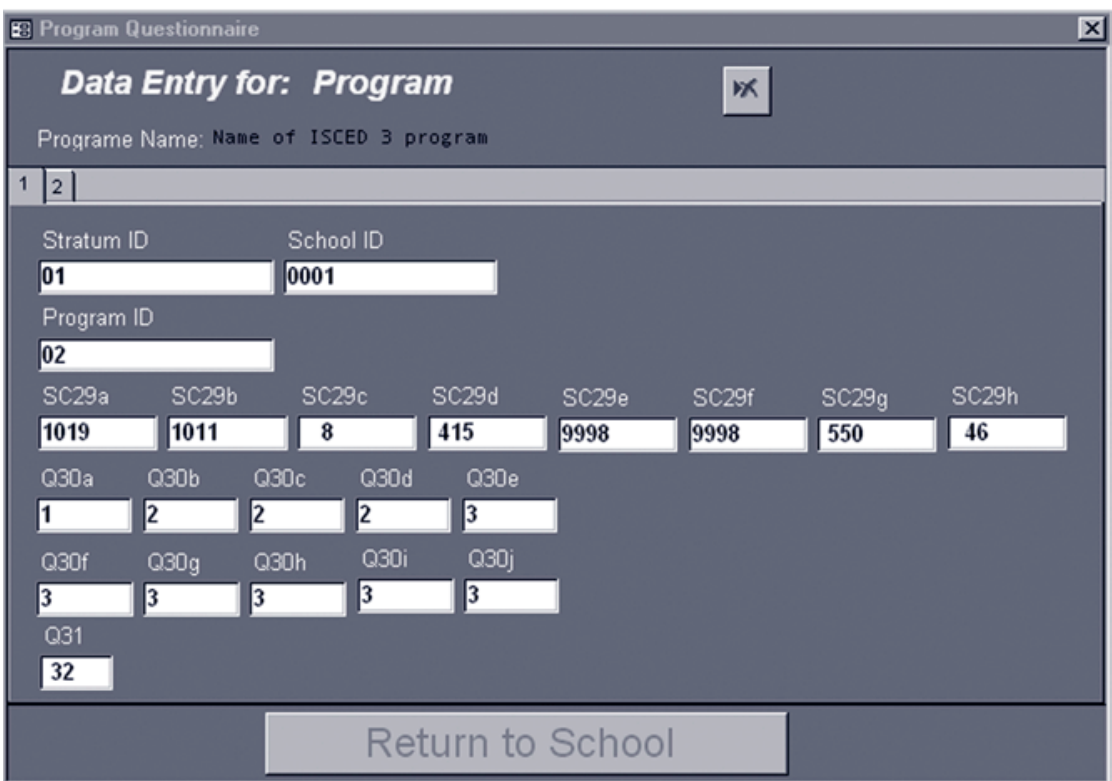


Figure II. 7 shows the second page of the data entry screen for programme information. Here the data cells for grades 9, 13, and 14 are missing, since the programme by grade data as shown in Figure II. 5 indicates that this programme cannot have these grades enrolled. These restrictions on data entry significantly reduced data entry errors.

\section{Figure 11.7}

Second data entry screen for School Programme Data

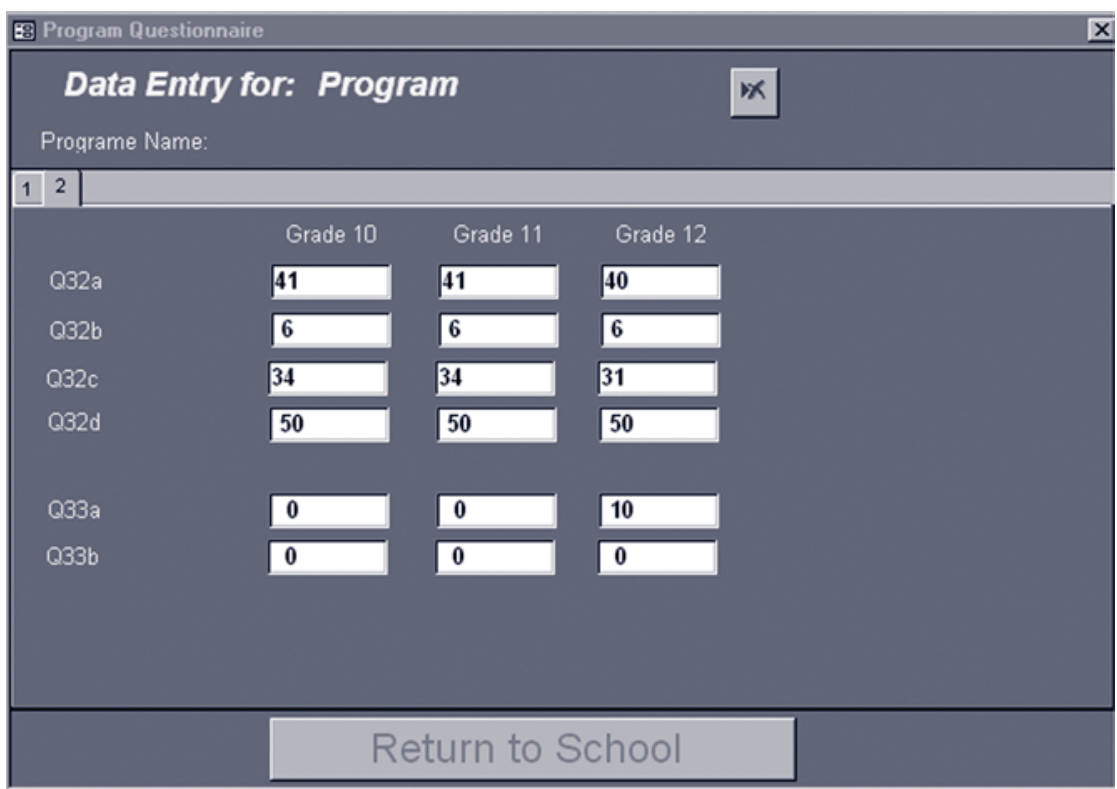

\section{II.4 Data cleaning}

As already noted, not all countries used the data entry programmes provided by OECD. Accordingly, the data entry files submitted by each country differed, depending on the programme used. About half of the countries submitted ACCESS databases, although in three versions. Unfortunately, there was little compatibility between the versions of this programme, so a single version, ACCESS 97, was selected as the ISUSS standard. This provided the needed consistency, although it meant time-consuming data conversions to fit the software requirements of the countries.

For countries using the spreadsheet data entry method, the conversion to an ACCESS 97 file was straightforward. However, some data manipulation was often required because the spreadsheet data entry created two sheets: one for school-level data; and one for upper secondary programme-level data. There was no automatic linkage that ensured an accurate match between the school and its upper secondary programmes, so there was the possibility of error both in data entry and in data conversion. Because of its hierarchical structure, however, the ACCESS database automatically ensured that any anomalies were discovered and could be fixed.

In order to check for the possibility of errors from data entry or from inconsistent responses, the ACCESS data entry programme was enhanced to provide extensive checking of the data. There were consistency and range checks to verify the accuracy and completeness of the data. In addition, the data cleaning 
module included editing capabilities and report generators to produce data validity reports and summary information to be used to pinpoint possible data errors.

The kinds of checks in the data cleaning module were generally of the following sort:

- Codebook format checks: Conformity to coding of variable names and locations;

- Range checks:

- Allowable values for each item with a Yes/No response; and

- Reasonable ranges for each item with numeric data response.

- Consistency checks:

- Numbers of programmes match positive enrolment figures;

- Percentages rounded to 100 per cent; and

- Numbers that are parts of a whole are smaller than the whole.

- Appropriate codes for illegal or missing data.

The ISUSS data cleaning process was designed to identify, document and, where possible, help countries correct deviations from the international file structure of the codebook. This involved developing reports to identify data entry errors and systematic deviations from the international data formats, identifying problems in linking observations across school and programme files, and noting any inconsistencies within and across observations. The objective was to ensure that the ISUSS data adhered to international formats and accurately and consistently reflected the information collected within each country.

Data cleaning involved several steps and was an iterative process, as shown in Figure II.8: some of the steps needed to be repeated until satisfactory results were achieved. During the first step, all incoming data files were checked and reformatted as necessary so that their file structure conformed to the international format in an ACCESS database. As a second step, all problems with identification variables, linkage across school and programme files, codes used for different categories, and missing value categories were detected and reported.

At the last stage of data cleaning, a series of statistical summary reports were generated for each country. The reports contained listings of codes used for each item in both school and programme sections of the questionnaire and pointed to outliers, ranges, missing value patterns and other codes that indicated problematic data (not administered, ambiguous or multiple entry codes). The reports were sent to each participating country using only the data from that country. NPMs were asked to review the data and make changes in the cleaning programme as necessary. In many cases the NPM needed to return to the original questionnaires to resolve questions and update or edit the cleaning file.

In almost all cases, corrections to the data were done by the country using the data cleaning module. In some cases, countries asked for help in making changes to individual school or programme data entries. In all cases where OECD made any change to a country's data, a data validation report was sent to the country along with an updated cleaning programme with the newly edited data. NPMs were asked to verify that the changes had been made in accordance with their instructions. Only in one country was the 


\section{Figure 11.8}

Iterative data cleaning process

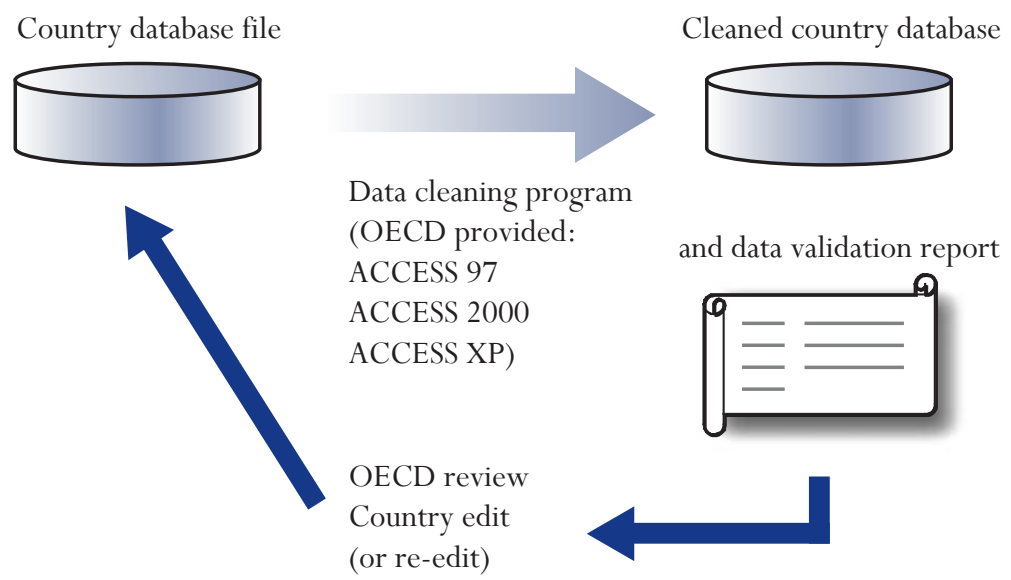

Optional: Spreadsheet conversions for those countries without ACCESS 97, ACCESS 2000

or ACCESS XP. OECD ran data validation and returned the data validation report to countries for edits on the spreadsheet data input form.

NPM not able to make the necessary changes and OECD needed to transform and change data to conform to codebook standards. Even in this case the country reviewed and approved the final iteration of the data validation report.

All changes made to countries' databases were documented. Copies of databases were created that give a chronological file, should there ever be a need to return to an earlier version or discover where an error was made. Thus it is possible to reconstruct each original database received from a country.

\section{II.5 Standardisation of the international database}

The final step in creating the ISUSS international database was to merge all countries' individual data files into a single file. A final validity check was run to ensure that the data were consistent with the required file format and that value ranges were legal and logical. Since the individual country files did not include country names, the merged data also added abbreviated country alphabetic and numeric codes.

It was not clear at the outset whether it would be more useful to have the final format of the ISUSS international data as a database, such as ACCESS, or as a statistical package, such as SPSS. It was therefore decided to produce both formats. However, experience has shown that version control can be a difficult problem in keeping track of final data files. Therefore, the database and statistical formats were created together to prevent different versions in each format.

The ACCESS database was considered the master file and a specific programme was created to make the SPSS conversion from the ACCESS database. During the data cleaning phase, all changes in data were made on the ACCESS database and transferred to the SPSS file by using the conversion programme. All analyses have been done using the SPSS database. 
Part

III

THE ISUSS INTERNATIONAL DATABASE 
The ISUSS database is available in two formats: in ACCESS format and in SPSS format. The original ISUSS international database was created in ACCESS format because of the inherently hierarchical nature of the dataset. To facilitate analysis, the ACCESS database was converted into two SPSS work files: one for analysing school data and one for analysing programme data. The SPSS files were used in the analyses for the initial report. Unlike the ACCESS database they contain the original as well as the derived variables.

\section{1 The ISUSS database in ACCESS format}

The ISUSS database stored in ACCESS format contains all the information gathered during the data collection through the 'School and Program Questionnaire' (Codebook in Annex 4). Data were checked in the course of the year 2002 for accuracy of data entry, fullness and consistency. With the approval of countries, the international database was finalised in May 2003; it contains data for the following countries: Belgium (Flemish Community), Denmark, Finland, France, Hungary, Ireland, Italy, Korea, Mexico, the Netherlands, Norway, Portugal, Spain, Sweden and Switzerland. This is the master file of the ISUSS data. It is stored in the zipped file: ISUSS_ACCESS_DB.zip and is available from the website.

The ACCESS database contains four data tables:

- Table 'ISUSS table of countries': it gives the short names of the originally participating countries (COUNTRY), their ISO3600 three-digit codes (C_CODE), and their weights for estimating international variance and standard error for school-level indicators as well as for indicators by programme type;

- Table 'Programs': it gives the available programme ID-s and names in each country, their destination and orientation and the grade levels (cumulative years of schooling) typically available in the programme;

- Table 'School Questionnaire Data': it contains identification variables and responses from Parts I and II of the ISUSS questionnaire. This table contains 4316 rows corresponding to the 4316 schools participating in the survey across fifteen countries. Each row corresponds to one school with all its school variables (but not the programme variables);

- Table 'Program Questionnaire Data': it contains identification variables and responses from the programme questionnaire (Part III of the ISUSS 'School and Program Questionnaire'). This table contains 6869 rows; each row corresponds to one programme containing identification variables identifying the programme and linking it with the school questionnaire data and responses to Part III of the ISUSS questionnaire. Some schools offer more than one programme and therefore filled in more that one programme questionnaire. This explains why this table contains more rows than the table 'School Questionnaire Data'.

The table 'School Questionnaire Data' contains the following variables:

- Identification variables for the country and the school: C_CODE, COUNTRY, SCHNAME, CODESTR, SCHID.

- The variable SAMPLEWT (weight) which has been revised for some countries and some schools (see Section I.9 on Weighting for more details) and the weights used for estimating school-level indicators, the international mean and standard deviation (Is3EnrWt and Is3TotWt); 
- Responses to the school level questions in the ISUSS Questionnaire (Parts I and II, Questions 1 to 28), i.e., the variables

- SC01Q01 to SC01Q14: programme offer in the school;

- SC02Q01: School governance;

- SC03Q01 to SC03Q04: Funding sources;

- SC04Q01: School location;

- SC05Q01 to SC05Q02: Total number of students in the school by gender;

- SC05Q03 to SC05Q22: Number of students enrolled in upper secondary programmes by programme and gender;

- SC06Q01 to SC06Q10: Number of personnel by category;

- SC07Q01 to SC07Q03: Full-time and part-time temporary teachers, full-time and part-time fully qualified teachers;

- SC08Q01: Teacher hiring responsibility;

- SC09Q01: Teacher vacancies;

- SC10Q01 to SC10Q05: Methods of managing teacher vacancies;

- SC11Q01 to SC11Q11: Covering teacher vacancies by subject of study;

- SC12Q01 to SC12Q05: School support of professional development

- SC13Q01 to SC13Q02: Participation of upper secondary teachers to professional development activities;

- SC14Q01 to SC14Q09: Types of professional development activities for upper secondary teachers;

- SC15Q01 to SC15Q02: Teacher absenteeism;

- SC16Q01 to SC16Q07: Admission policies for upper secondary students;

- SC17Q01 to SC17Q07: Grouping policies for upper secondary students;

- SC18Q01 to SC18Q12: Keeping records on upper secondary students;

- SC19Q01 to SC19Q07: Feedback on school functioning from various stakeholders;

- SC20Q01: Provision of computers/workstations;

- SC21Q01 to SC21Q08: Availability of computers and networks for students and teachers;

- SC22Q01 to SC22Q03:Year of introducing various ICT technologies;

- SC23Q01 to SC23Q03: Percentage of teachers using various ICT technologies

- SC24Q01 to SC24Q08: Computer-related activities in upper secondary schools;

- SC25Q01 to SC25Q06: Use of computers for various educational purposes;

- SC26Q01 to SC26Q25: Co-operation with other organisations in ICT development;

- SC27Q01 to SC27Q22: Obstacles to reaching ICT-related goals; and

- SC28Q01 to SC28Q03:The first, second and third most serious obstacles to reaching ICT-related goals. 
The table 'Program Questionnaire Data' contains the following variables:

- Identification variables for the country, stratum, school and the programme (C_CODE, COUNTRY, CODESTR, SCHID, PROGID, ProgramName);

- Enrolments by gender and total in the programme (PROG_B, PROG_G, PROG_T);

- The weights used for estimating indicators by programme type, the international mean and standard deviation (PRGENRWT and PRGTOTWT). Section I.9 gives more details on weightings;

- The responses to Part III of the ISUSS Questionnaire (Questions on the Programme):

- SC29Q01 to SC29Q08: Completion of programme and transition;

- SC30Q01 to SC30Q10: Methods of career counselling;

- SC31Q01: Percentage of students receiving individual career counselling;

- SC32Q01 to SC32Q24: Instruction time; and

- SC33Q01 to SC33Q12: Time of scheduled work experience.

Annex 4 provides a Codebook with a detailed description of the variables.

\section{III.2 The ISUSS database in SPSS format}

Two SPSS data files have been created from the ACCESS database to facilitate data analysis work for the ISUSS report:

- The 'Schools' file contains all original variables, weight variables and other calculated variables (e.g., ratios, indices, etc.) related to Parts I and II of the ISUSS School and Program Questionnaire. It is stored as 'ISUSS_Schools.sav'. This file contains 4136 records corresponding to the number of schools surveyed;

- The 'Programmes' file contains all original variables from the programme questionnaire, weight variables and other calculated variables related to Part III of the ISUSS School and Program Questionnaire. Additionally, all original school variables of the 'parent' school are included in the programme record as well. This work file is stored as 'ISUSS_Programmes.sav'. The total number of rows is equal to 6869 corresponding to the number of programme questionnaires filled out in the countries.

Both data files are stored in the zipped file ISUSS_SPSSdatafiles.zip which is available from the website.

The 'Schools' file (ISUSS_Schools.sav)

In the SPSS Schools file, each school that participated in the ISUSS project has one record. On the school record, the following information is available:

- Identification variables for the country and the school (same as in the ACCESS database);

- Weight variables (same as in the ACCESS database); 
- Responses on Parts I and II of the 'School and Program Questionnaire' (same as in the ACCESS database); and

- Derived variables developed for the purpose of the analysis. A description of all derived variables is available in part B of Annex 4.

\section{The 'Programmes' file (ISUSS_Programmes.sav)}

In the SPSS Programmes file, each programme for which a programme questionnaire was filled out has a separate record. If a school site offers two upper secondary programmes and that a programme questionnaire for each was filled out, this school site is represented by two records in the SPSS Programmes file. For each type of programme, the following information is available:

- Identification variables for the country, the school and the programme (same as in the ACCESS database);

- Weight variables (same as in the ACCESS database);

- School questionnaire data of the 'parent' school;

- Programme identification and classification variables;

- School, ISCED 3 and programme enrolments total and by gender;

- Responses to Part III questions of the 'School and Program Questionnaire' (same as in the ACCESS database); and

- Derived variables developed for analytic purposes. A description of all derived variables is available in part B of Annex 4.

\section{III.3 Identification of countries, schools and programmes}

Codes for identifying countries, schools and programmes are consistent between ACCESS and SPSS databases.

Each school record has a unique ID number consisting of the Country code (C_CODE), the Stratum code (CODESTR) and the School ID (SCHID). Each programme record has a unique ID number consisting of the Country code (C_CODE), the Stratum code (CODESTR), the School ID (SCHID) and the Programme ID (PROGID).

The country identification variables are labelled C_CODE and COUNTRY. The country codes used in ISUSS are the ISO 3166 country codes.

Although school names are included in the master file, they are removed from the published international database for confidentiality reasons. 


\section{III.4 Missing data}

Three types of missing data are distinguished:

- Item level non-responses (MIS): they are coded 9 for a one-digit variable, 99 for a two-digit variable, 999 for a three-digit variable, etc. in the ACCESS database, while they are coded as '. in the SPSS data files (it is coded SYSMIS in the syntax of SPSS programmes);

- Not administered responses: in some cases, countries decided not to ask a question because it made no sense or did not apply in their situation. To distinguish this kind of missing data (N/ADM) from genuine missing values, the not administered response is coded 8 for a one-digit variable, 98 for a two-digit variable, 998 for a three-digit variable, etc. in both ACCESS and SPSS databases. This option was only used if a question was not asked at the National level or the option does not apply to the school (e.g., a programme is not available); and

- Multiple or ambiguous responses ( $M / R$, Ambiguous): they are coded 7 for a one-digit variable, 97 for a two-digit variable, 997 for a three-digit variable, etc. in both ACCESS and SPSS databases. This option was used if more than one option was selected for the multiple choice type questions. It was also used for illegible, not interpretable responses to numeric type questions and also for responses which were outside the valid range of values for a question.

\section{III.5 Recoding of some variables}

Some variables had to be recoded because the responses were not consistent with responses to other related questions. A typical example is the screening variable Question 20 asking whether the school provides computers (workstations) for teachers and students. All subsequent questions 21 to 28 depend on the response to this question, i.e., a ' $N o$ ' response implies that no meaningful answers can be given to the other questions related to school computers. If such a question was ticked as 'No' but the following questions that are linked to this question were completed while they should have been missing, the corresponding observations were removed from the analysis.

In addition, some variables were recoded in order to change their type for the purposes of calculation used in the ISUSS report (e.g., in calculations of percentages or standardised frequencies). Full details are presented in the syntax files: PG_DerVarSchools.sps and PG_DerVarProg.sps contained in the website. A short description of these programmes follows below.

\section{Variables related to staff}

- When the variables SC06Q03 and SC06Q04 (number of teachers employed full-time and/or part-time) were greater than 0 and the other staff variables (SC06Q01, SC06Q02, SC06Q05 to SC06Q10) were missing, these latter variables were recoded as 0 to allow a calculation of indicators on staff even if some of these other variables are missing;

- When the variables SC06Q03 and SC06Q04 (number of teachers employed full-time and/or part-time) were missing but the other staff variables (SC06Q01, SC06Q02, SC06Q05 to SC06Q10) were not, all staff variables were recoded as missing;

- When all staff variables (SC06Q01 to SC06Q10) were equal to 0 they were recoded as missing as it would otherwise indicate a school without any staff; and 
- In some cases, answers to Question 9 (number of teaching vacancies which had to be filled at the beginning of the school year) and Question 10 (methods used to cover these vacancies) were inconsistent, i.e., the answer to Question 9 was ' 0 ' (there were no vacancies to be filled) but there were 'Yes' responses to Question 10 indicating eventual methods to manage vacancies. In such cases the 'Yes' responses were recoded 'No' to be consistent with Question 9. The same procedure was applied when the answer to Question 9 was missing.

\section{Variables related to ICT}

- Question 20 asked: 'Does your school provide computers for students and/or staff for educational purposes?' If the answer was 'No', the respondent was supposed to skip Questions 21 to 28 and go to Question 29 and the variables related to Questions 21 to 28 were expected to be coded as missing. These variables were recoded as follows: Q21 was recoded as 0, Q22 as missing, Q23 as 0, Q24 as 2, Q25 as 1 and Q26 to Q28 as missing;

- If the answer to Question 20 was missing, variables for questions 21 to 28 were all coded as missing;

- In some schools, the number of computers designated to teachers was extremely large (e.g., more than five computers were reported to be available for each teacher). Such error suspect observations were removed from the analysis (one or two cases); and

- The ratio of computers to all students (or to full-time equivalent teachers) was calculated only when the number of students (or full-time equivalent teachers) was greater than 0 . In the same way, the ratio of computers connected to the Internet (Intranet) was calculated only when the number of computers available at schools was greater than 0 . Otherwise the ratio was missing.

\section{Indices}

Indices (see Section III.7) could only be calculated if none of the component variables were missing. In some cases, the index is the sum of 'Yes' responses to a series of items (see for example the index of variety of professional development activities). Sometimes schools ticked only the boxes corresponding to a 'Yes' answer but left the boxes with a 'No' answer empty. In order to distinguish these from genuine missing values, an intermediate variable was calculated to obtain the number of valid answers within the range of items from which the index is calculated (in SPSS syntax, the NVALID function calculates the number of valid arguments in a given range). If the result was equal to 0 then all values composing the index were missing and consequently the value of the index is missing. If, however, the result of the NVALID question was greater than 0 then at least one of the sub-questions was answered while some of the other variables were left unanswered. Then these other variables were recoded as 'No' and the index was then calculated.

\section{Other variables}

Question 19 asked about the receipt of feedback on the functioning of the school from different groups. The option 'the local school authority or the maintainer of the school' does not apply in France and the option 'external examinations boards (students' results)' does not apply in Sweden. Therefore these options were recoded as 0 to allow a calculation of the index for question 19. 


\section{III.6 Derived variables}

Derived variables developed for the purposes of analysis are included only in the SPSS data files.

In both SPSS data files, there are three types of derived variables:

- Indices developed for the purposes of the analysis. Section III.7 presents the types of indices used in the initial report and explains how these indices were developed;

- Variables used as 'intermediate' variables to build the first type of derived variables (see for example the NVALID variables mentioned in the previous section); and

- Variables created only to change the original data type into another data type for analytic purposes. An example is school size (SCHSIZE), which is a categorical variable derived from SCH_T (total enrolment in the school), which is a numeric variable.

Annex 4 gives a complete list and description of derived variables.

\section{III.7 Development and contents of indices and other derived measures}

\section{What measures are used?}

The following five types of measures are used in the publication Completing the Foundation for Lifelong Learning - An OECD Survey of Upper Secondary Schools: weighted frequencies, ratios, aggregate country scores, standardised frequencies, and standardised indices.

- Weighted frequencies are country mean values aggregated from school level frequencies or reported percentages weighted by student weight. Section I.9 describes the calculation of the upper secondary enrolment weight and the programme enrolment weight used in reporting weighted frequencies;

- Ratios are calculated as weighted country means of school level ratios calculated by dividing two variables;

- Standardised frequencies are weighted frequencies rescaled in such a way that the international mean is set to zero, and the unit of the scale is the international standard deviation. Thus, a country value of +1 means that the country average is higher than the international mean, and its distance from the international mean is the international standard deviation. Alternatively, a country value of -1 means the same distance below the international average. For standardising frequencies, a specific weight was used to calculate the international standard deviation, which is the unit of the international scale. Standardised frequencies are used in reporting feedback from various groups of stakeholders.

- An aggregate country score is reported for the three most serious obstacles to schools' ICT-related goals. This score was obtained by adding up coded school responses to the question about the three most serious obstacles to achieving the school's ICT-related goals. The most serious obstacle was coded 3 a code of 2 was assigned to the second most serious obstacle and a code of 1 to the third most serious obstacle. The scores were weighted by upper secondary enrolments and aggregated on the country level for each of the 22 listed obstacles; and

- Standardised composite indices represent the summary of responses to a series of related questions expressed on an international standard scale. The scale is calibrated in such a way that the international mean is set 
to zero and the international standard deviation is used as scale unit. Section I.9 describes the weights used for estimating the international standard deviation.

\section{How should standardised frequencies and standardised indices be interpreted?}

Standardised frequencies and standardised indices in this study are reported on relative scales depending on the variation across and within countries. The scales measure the distance from the international mean. Negative scale values indicate scores that are lower than the international mean, positive values indicate scores that are higher than the international average. The scale unit is the international standard deviation, which is a measure of variability in the total pool of schools in the participating countries. This means that differences may look bigger than they actually are, if there is generally small variation between schools and countries, and vice versa, differences may seem smaller if there is big variability between schools and countries. The advantage of expressing school's values and country means on an international standard scale is that the same scale can be used for all countries and all schools within countries, showing the relative position of a school or a country in the universe of schools across countries.

\section{Ratios}

Ratios of students to teachers, to professional personnel and to total personnel at school (Tables 3.1a to 3.1d) The ratios of students to teachers, to total professional personnel and to total personnel were calculated as the ratio of the total number of students (headcounts) in the school and the total number of various personnel categories measured as full-time equivalents. Professional personnel includes school management personnel, teachers and professional support personnel. Total personnel includes school management personnel, teachers, teacher aids, professional support personnel and other support personnel. Schools are left out if the ratio of students to teachers (or to professional personnel at school, or to total personnel at school) is equal to or less than 1 or more than 100. Ratios are weighted by the upper secondary student enrolment in the school as described in Section I.9.

\section{Ratio of students to student computers (Table 3.8)}

The ratio of students to computers was calculated as the ratio of the total number of students in the school to the number of computers for students' use in the school. Schools that reported that no computers are provided are included in the calculation. Ratios are weighted by the upper secondary student enrolment in the school as described in Section I.9.

\section{Ratio of teachers to teacher computers (Table 3.8)}

The ratio of teachers to computers was calculated as the ratio of the total number of teachers (full-time equivalents) in the school and the number of computers designated for teachers' use. Schools not providing computers are included in the calculation. Ratios are weighted by upper secondary student enrolment as described in Section I.9.

\section{Ratios of computers connected to the Internet and local area networks (Table 3.9)}

Ratios of computers connected to the Internet and to local area networks were calculated from the total number of computers in the school and the total number of computers connected to the Internet/local area networks. Ratios are weighted by upper secondary student population as described in Section I.9. 


\section{Standardised indices}

All standardised indices were developed by calculating a score from principals' responses to a series of related questions as described below. The scores were transformed to the international scale which was standardised in such a way that the international mean was set to zero and the international standard deviation was used as scale unit. The weight used for calculating the international standard deviation is described in Section I.9. All indices were weighted by a student enrolment weight also described in Section I.9.

\section{Index of admission and placement policies related to students' performance (Table 2.1b)}

The index of performance-related admission policies was calculated by summing the school principal's responses to the question how often they considered the following criteria when admitting or placing students to upper secondary programmes: student's record of academic performance, entrance examination and recommendation of feeder schools. The response alternative always or often was assigned a code of 2, sometimes was assigned a code of 1 , and never was assigned a code of 0 .

\section{Index of selective grouping policies within schools (Table 2.2b)}

The index of selective grouping policies within the school was calculated by summing the school principal's responses to the questions how often upper secondary students were grouped in the school more or less at random, according to similar ability levels, so that classes contain a mixture of ability levels and according to the requests of parents/guardians. In calculating the overall index, the 'integrative' methods (i.e., random grouping and grouping into classes that contain a mixture of ability levels) were considered with a negative sign. The response alternative always or often was assigned a code of 2, sometimes was assigned a code of 1 , and never was assigned a code of 0 . Thus a high score on this index means a strong tendency to stream students by ability or socio-cultural background. A low score means an integrative approach to grouping students.

\section{Indices of variety of career guidance and counselling methods in upper secondary schools (Table 2.5)}

The index of school-related career guidance methods was calculated as a sum of school principals' responses to the question how often they used the following methods: specific classes are set aside in the curriculum, teachers include a module in their teaching, a specific guidance plan is provided, information about possible careers is provided, personal guidance is provided and informal guidance is provided). The index of career counselling methods involving external contacts was calculated as a sum of school principals' responses to the question how often they used the following methods: the school invites employers/practioners to talk to students, the school invites representatives of further educational institutions to talk to students, the school organises visits for students to employment organisations and/or counselling services and the school organises visits to institutions of further education. The response alternative always or often was assigned a code of 2, sometimes was assigned a code of 1 , and never was assigned a code of 0 .

\section{Indices of feedback from various stakeholders (Table 2.8, Table 2.9)}

The index of feedback from various stakeholders was calculated by summing school principals' positive responses to the questions whether the school received information on its functioning from the following stakeholders: regional, national education authorities (i.e., inspectorates), local school authorities, employers, parent groups, teacher groups, student groups and external examination boards (Table 2.9). For each of the listed organisations, standardised frequencies were calculated as well. These are reported in Table 2.8 and Figure 2.11. For Figure 2.11, however, the country mean was set to 3 (instead of 0 ) to avoid negative values. 


\section{Index of difficulty of hiring fully qualified teachers in various study areas (Table 3.6b)}

The index of difficulty to hire fully qualified teachers in various study areas is calculated by summing principals' 'Yes' responses to the questions whether they perceived difficulty in hiring a fully qualified teacher in the following subject areas: mother tongue/language of instruction, mathematics, foreign languages, social studies, sciences, technology, arts, physical education, computer sciences / information technology and business studies.

\section{Index of variety of professional development activities (Table $3.11 \mathrm{~b}$ )}

The index of variety of professional development activities is calculated by summing the school principal's responses to the questions whether any of their teachers participated in the school year 2000/2001 in the following types of professional development activities: observational visits to other schools, regularly scheduled collaboration among teachers on issues of instruction, mentoring and /or peer observation and coaching as part of a formal arrangement that is recognized or supported by the school or educational authorities, collaborative research and/or development on a topic related to education, participation in a professional network of teachers (i.e., one organised by an outside agency or over the Internet); courses or workshops on subject matter, methodology and other education-related topics, conferences where teachers and/or researchers present their methodological and scientific results and discuss educational problems, degree programmes (i.e., qualification programme, master's, Ph.D.), and visits to companies/employers. The index of variety of professional development activities was calculated as the sum of 'yes' answers to the above questions.

\section{Index of variety in educational computer use (Table 3.14b)}

The index of variety in educational computer use was calculated by summing school principals' responses to the questions about how much computers are used in upper secondary programmes for the following educational purposes: to develop skills of independent learning, to provide additional instruction and practicing opportunities for students, to allow students to learn / work at their own pace during lessons, to combine parts of school subjects with one another; to create opportunities for learning by simulation, and to obtain information from the Internet. The response alternative 'a lot' was assigned a code of 2, 'a little' was assigned a code of 1, and 'not at all' was assigned a code of 0 .

\section{Index of variety of computer-related student activities (Table 3.15b)}

The index of variety of computer-related student activities was calculated as a sum of the school principal's 'Yes' responses to the questions about which of the following computer-related activities was a regular part of students' assignments in upper secondary education in their school: operating a computer (saving files, printing, etc.), writing documents with a word processor (typing, editing, layout), making illustrations with graphic programmes, calculating with a spreadsheet programme (sheet creation, use of formulae, organising information), writing programmes, communicating via e-mail with teachers and other students, sending, searching for and using electronic forms of information and using educational software (i.e., taking tests, exercises).

\section{Indices of obstacles to reaching school goals related to development of information and} communication technology (Table 3.16b)

The indices correspond to scores determined by school principals' responses to the following question: do you consider any of the following an obstacle to reaching your school's information technology-related purposes? On the basis of the 22 listed obstacles, five indices were calculated: 
- The index of obstacles related to hardware and infrastructure sums affirmative responses to the following listed obstacles: insufficient number of computers for teachers' use; insufficient number of computers for students' use; outdated (older than 3 years) computers; Internet connection is not available; not enough space to locate computers appropriately; weak infrastructure (telecommunications, electricity);

- The index of obstacles related to availability of software sums affirmative responses to the following listed obstacles: not enough copies of software for instructional purposes; not enough variety of software; poor quality of available software;

- The index of obstacles related to teachers sums affirmative responses to the following listed obstacles: insufficient time for teachers to prepare lessons in which computers are used; difficult to integrate computers into classroom instruction; difficult to use with low achieving students; no time in teachers'schedule to explore opportunities for using the Internet; lack of interest / willingness of teachers to use computers; teachers' lack of knowledge / skills in using computers for instructional purposes; not enough training opportunities for teachers;

- The index of obstacles related to organisation and planning is the sum of affirmative responses to the following listed obstacles: problems in scheduling enough computer time for different classes; no time in the school schedule for using the Internet; insufficient plans and / or resources to prevent theft and vandalism of computers; not enough staff to supervise students using computers; shortage of maintenance and technical support; and

- The index of lack of support is based on the affirmative answer to the following listed obstacle: lack of support from the governing body or community.

'Problem scores' of perceived obstacles to reaching ICT-related goals aggregated on country level (Figure 3.25)

School principals were asked to indicate the three most serious obstacles to reaching the school's ICTrelated goals from a list of 22 obstacles. The rankings were coded 3 if the item was considered to be the most serious obstacle, 2 if it was the second most serious obstacle and 1 if it was considered the third most serious obstacle. School rankings for each of the three obstacles mentioned as one of the three most serious obstacles weighted by upper secondary student enrolment and aggregated on the country level to obtain the three highest ranking obstacles in the country.

\section{III.8 SPSS programmes}

SPSS programmes have been written to calculate the required weights, to recode some variables, to implement the derived variables and finally to build Tables which are presented in the different chapters of the ISUSS report.

The SPSS data files already contain adjusted weights, weights for estimating school-level indicators, indicators by programme type, the international means and standard deviations, derived variables and recoded variables. The SPSS programmes below are included in the files on the website files to document the procedure of building the SPSS database for the purposes of the ISUSS report. 


\section{The programmes were run in the following order:}

- PG1_Wght.sps: Implementation of weight adjustments (from the variable SAMPLEWT originally provided by countries) for some schools in some countries. Weight adjustment procedures are described in Section I.9 (Weighting procedures);

-PG2_SE_Wght_ISC3.sps: Implementation of weights for estimating school-level indicators in the 'Schools' data file. For the calculation of weights by ISCED 3 enrolments see Section I.9 (Weighting procedures);

- PG2_SE_Wght_Prog.sps: Implementation of weights for estimation of indicators by programme type in the 'Programmes' data file. The calculation of weights used in programme level indicators is described in Section I.9 (Weighting procedures);

- PG3_Recoding.sps: All details are provided in section III.5 (Recoding of some variables);

- PG4_DerVar_PROVPG.sps: Implementation of the derived variable PROVPG. This variable depends on countries because of their number of programmes and their types;

-PG5_DerVar_Schools.sps: Implementation of derived variables for the 'Schools' data file. Details of calculation for all variables are provided in Annex 4 (Codebook, Part B: List of Derived Variables);

- PG5_DerVar_Prog.sps: Implementation of derived variables for the 'Programmes' data file. All Details of calculation for all derived variables are provided in Annex 4 (Codebook, Part B: List of Derived Variables);

- PG_Chapter2.sps: Building tables in Chapter 2 of the first ISUSS report 'Completing the Foundation for Lifelong Learning - An OECD Survey of Upper Secondary Schools';

- PG_Chapter3.sps: Building tables in Chapter 3 of the first ISUSS report 'Completing the Foundation for Lifelong Learning - An OECD Survey of Upper Secondary Schools'; and

- $\boldsymbol{P G}$ _ Annex2.sps: Building tables in Annex 2 in the first ISUSS report 'Completing the Foundation for Lifelong Learning - An OECD Survey of Upper Secondary Schools';

These SPSS programmes are included in the files on the website for users who wish to reproduce tables from the SPSS database. All these SPSS programmes are stored in the zipped 'ISUSS_SPSSprogrammes.zip'.

Since the weights used are different for each 'block of tables' since there are sometimes filters used (for example, Tables 3.1 and 3.8) it is preferable to run the programmes within programme files separately by 'block of tables'.

\section{AN IMPORTANT NOTE FOR USERS OFTHE SPSS PROGRAMMES}

After running any of the programmes provided on the website, NEVER SAVE the original SPSS data files because some raw (or derived) variables may be modified by the programme for the needs of tables. Moreover, since weights are taken into account and applied they should not be saved in the original SPSS data files. 
Annex

1

\section{THE 'SCHOOL AND PROGRAM' QUESTIONNAIRE}

The 'School and Program' Questionnaire was divided into three parts:

- Part I: Background questions about the school

- Part II: Questions about Upper Secondary Schools (Human Resources, Aspects of Functioning, Feedback, Stakeholders, Information and Communication Technology)

- Part III: Program questionnaire (Questions related to programmes) 
OECD International Survey of Schools at the Upper Secondary Level

$<$ Country name $>$

School ID:

\section{SCHOOL AND PROGRAM QUESTIONNAIRE}

\section{International Generic Version}

School Name

Site Adress

City/town/village

Region/state/province

Zip code:

Respondent:

Phone: 


\section{'SCHOOL AND PROGRAM' OUESTIONNAIRE}

\section{PREFACE}

What is this survey about?

This survey is being administered in 18 OECD countries to compare how upper secondary education is provided. The questionnaire asks for information about:

- The educational programs offered in your school site;

- The school's resources;

- Teachers;

- The use of information technology and the obstacles in this area;

- The contacts of the school with higher education and the world of work;

- Some pedagogical and administrative practices.

How will the information be used?

Your information will help reveal disparities of resource distribution - particularly for new technologies - both within and between countries. You will receive a summary of the information collected in your country so that you may compare your own situation to other schools in the country where upper secondary education is provided.

By filling out this questionnaire you also contribute to Education at a Glance, one of the leading educational publications of the Organisation of Economic Co-operation and Development. Using comparative statistics, OECD in co-operation with the Member countries identifies and develops indicators and international benchmarks in key issues in education to help policy makers who seek to improve their countries' education systems.

For further information on OECD's activities and publications related to education you may want to consult www.oecd.org and www.pisa.oecd.org.

How should you respond to this questionnaire?

The questionnaire should be completed by the < principal $>_{\text {or }}$ designate. Some of the questions ask information about which you may want to consult staff members in your school. Once you have this information, the questionnaire should take about 45 minutes to complete.

If you do not know an answer precisely, your best estimation will be adequate for the purposes of this survey.

Your answers will be kept confidential. Thank you. 
We ask about this school site

Part I of this questionnaire (Questions 1 - 6) refers to the school site.

If your school has other school sites as well, please exclude these from your answers. In this questionnaire school always refers to the school site sampled for this survey.

We ask about <upper secondary education>

Part II of this questionnaire (Questions 7 to 28) refers to the whole of the <ISCED 3 programs $>$ in your school.

If some of the programs - or parts of the programs - offered at your school fall outside the <ISCED definition of upper secondary education>, exclude this from your answers as far as possible (e.g., by estimating or pro-rating for the relevant student population).

\section{We ask about <programs>}

Part III of this questionnaire (Questions 29 to 33) refers to the <upper secondary> programs listed in Question 1. These questions should be answered separately for each <ISCED $3>$ program offered at your school site. If you have more than one $<$ ISCED $3>$ program in your school, fill in Part III of the questionnaire separately for each program you offer at your school site.

\section{How should you mark your answer?}

There are three types of answers in this questionnaire:

- In some questions (Q2 and Q4) the response alternatives are printed in separate rows and you must

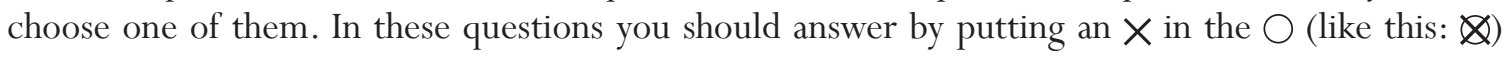
You will be reminded by the instruction: 'Mark only one of the circles.')

- In many questions you should answer by ticking $(\checkmark)$ the box $(\square)$ of the best answer in each row. You will be reminded of this by the instruction 'Tick one box in each row.'

- Some questions require you to write in text, numbers or percentages. For these questions you should write your answer on the line provided ( expected to estimate a percentage as your answer ). You will be reminded in the cell, if you are $r($ $\%$ ). 
1. What levels of education are offered at your school site?

Tick one box in each row.
a. <Country name for primary education (ISCED Level 1)>
$\square_{1}$ Yes
$\square_{2}$ No
b. <Country name for lower sec. education (ISCED Level 2) $>$
$\square_{1}$ Yes
$\square_{2}$ No
c. <Country name for ISCED Level 4>
$\square_{1}$ Yes
$\square 2 \mathrm{No}$
d. < Country name for ISCED Level $5>$
$\square_{1}$ Yes
$\square_{2}$ No
e. <Country name for ISCED 3 Program 1>
$\square_{1}$ Yes $\quad \square_{2}$ No
f. <Country name for ISCED 3 Program 2>
$\square$ Yes
$\square$ No
g. <Country name for ISCED 3 Program 3>
$\square$ Yes
$\square_{2}$ No
h. < Country name for ISCED 3 Program 4>
$\square_{1}$ Yes
$\square_{2}$ No
i. < Country name for ISCED 3 Program 5>, etc.
$\square_{1}$ Yes
$\square_{2}$ No

2. Is your school a <public $>$ or a <private> school?

Mark only one.

A $<$ public $>$ school

$<$ This is a school managed directly or indirectly by a public education authority, government agency, or governing board appointed by government or elected by public franchise.>

A $<$ private school $>$

$<$ This is a school managed directly or indirectly by a non-government organisation; e.g.,

a church, trade union, businesses, other private institutions. $>$

3. About what percentage of your total funding for a typical school year comes from the following sources?

a. Government (includes departments, local, regional, state and national)

$\%$

b. Student fees or school charges paid by parents

$\%$

c. Benefactors, donations, bequests, sponsorships, parent fund raising

$\%$

d. Other

$\%$

Total

$100 \%$ 
4. Which of the following best describes the area in which your school is located?

Mark only one.

$<A$ metropolitan area is a large city with the surrounding settlements well integrated in the urban public transportation system $>$

A $<$ village, hamlet or rural area $>$ (fewer than 3000 people)

A $<$ small town $>$ (3 000 to about 15000 people)

A $<$ town $>(15000$ to about 100000 people $)$

A $<$ city $>$ (100 000 to about 1000000 people)

Close to the cultural/business/shopping center of a $<$ city $>$ with over 1000000 people

Elsewhere in the $<$ metropolitan area $>$ of a city with over 1000000 people

5. How many students were enrolled in your school as of <the end of the first month of this school year>?

a. Total enrolment in the school

b. Enrolment in <Country name for ISCED 3 Program 1>

c. Enrolment in <Country name for ISCED 3 Program 2>

d. Enrolment in <Country name for ISCED 3 Program3>

e. Enrolment in <Country name for ISCED 3 Program 4>

f. Enrolment in <Country name for ISCED 3 Program 5>, etc.

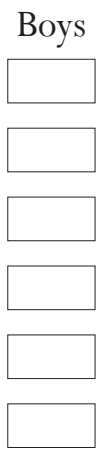

Girls

6. For each type of position listed, provide the number of staff (full-time and part-time) currently working in your school.

A full-time person is one who is employed for more than 90 per cent of the statutory working time. A part-time employee is one employed for less than 90 per cent of the statutory working time

Fill in the number of full-time and part-time persons for each category.

If a full-time person is working in more than one position (e.g. a librarian, or deputy principal with teaching duties), include that person in the category where he/she spends the larger part of the statutory working time.

INCLUDE TEMPORARY PERSONNEL AS WELL!

In the whole school

a. School management personnel (principal, deputy principals)

b. Classroom teachers (directly involved in instructional practice)

c. Teacher aides (non-professional personnel who provide instruction or support teachers in providing instruction)

d. Professional support personnel (e.g., guidance counselors, librarians, psychologists, nurses, social workers, speech therapists)

e. Other support personnel (e.g., secretaries, bookkeepers, caretakers, cleaners, gardeners, etc.)

Full-time

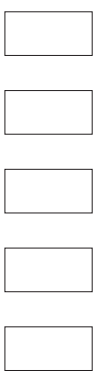

Part-time

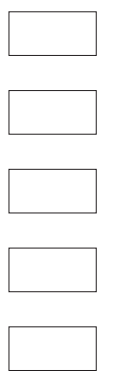


7. What percentage of the teachers currently teaching at the <upper secondary level> ...

a. are temporaries?

$<$ a person employed for a fixed term not longer than one school year $>$

b. are fully qualified?

$<$ Full qualification means that a teacher has fulfilled all the training requirements for teaching a certain subject at the upper secondary level and meets all other administrative requirements (e.g., probation period). $>$

\begin{tabular}{|c|c|}
\hline$\%$ & $\%$ \\
\hline$\%$ & \\
\hline
\end{tabular}

8. Is the hiring of new teachers <at the upper secondary level> the responsibility of the school (e.g., <the principal's or the department head's>?

If teachers are assigned to your school by an external agency, e.g., a government agency or school district, the answer to this question should be 'No'.

$\square_{1}$ Yes $\quad \square_{2}$ No

9. How many teaching vacancies <at the upper secondary level> needed to be filled for this school year?

Please answer this and the following question even if hiring teachers is the responsibility of another organisation (like the local or regional school authority).

If none, write ' 0 '.

posts

10. Which of the following methods were used to cover these vacancies?

Tick one box in each row.

a. A fully qualified teacher was hired on a permanent or temporary basis

$\square_{1}$ Yes

$\square_{2}$ No

b. A person with less than full qualification was hired

$\square_{1}$ Yes

$\square 2 \mathrm{No}$

c. A planned course offer was cancelled

$\square_{1}$ Yes

$\square 2 \mathrm{No}$

d. The sizes of some of the classes were expanded

$\square_{1}$ Yes

$\square$ No

e. Sections (courses) were added to other teachers' normal teaching hours

$\square_{1}$ Yes

$\square_{2}$ No 
11. In which study areas is it difficult to hire a fully qualified teacher <at the upper secondary level> in your experience?

Tick one box in each row.

a. Mother tongue

$\square_{1}$ Yes

$\square_{2} \mathrm{No}$

b. Mathematics

$\square_{1}$ Yes

$\square$ No

c. Foreign languages

Yes

$\square_{2} \mathrm{No}$

d. Social studies

Yes

$\mathrm{No}$

e. Sciences

$\square_{1}$ Yes

$\square_{2} \mathrm{No}$

f. Technology

$\square_{1}$ Yes

$\square_{2} \mathrm{No}$

g. Arts

Yes

$\square_{2} \mathrm{No}$

h. Physical education

Yes

$\square_{2}$ No

i. Computer science/informatics/information technology

Yes

$\square_{2} \mathrm{No}$

j. Business studies

Yes

$\square_{2}$ No

\section{k. Other}

12. Which ways does your school support or encourage the <professional development> of <upper secondary teachers $>$ ?

$<$ By professional development we mean any activity that develops an individual's skills, knowledge, expertise and other characteristics as a teacher. These include personal study and reflection, collaborative development of new approaches, as well as formal courses $>$.

Tick one box in each row.

a. The school has a separate budget for the professional development of teachers

b. The school provides time for teachers for professional development (e.g., by building in professional days within the regular school year, by organising rotated schedules for PD and organising replacement for teachers attending courses).

c. The school organises staff development activities (e.g., peer observation of classes, mentoring of young teachers, staff conferences on particular educational subjects, participation in developmental work, action research)

d. The school collects and circulates information on professional development courses in the school district

$\square_{1}$ Yes

$\square_{2} \mathrm{No}$

e. Other 
13. Consider the past school year. What percentage of <upper secondary teachers> participated in professional development activities?

Write a percentage or tick the box in each row. If 'none', write $0 \%$.

a. $<$ ICT $>$ related professionaI develoment activities

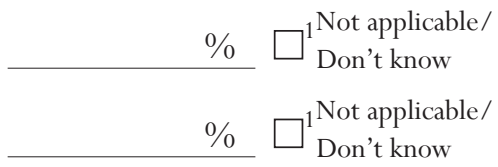

b. Other professional development activities

Not

14. Consider the past school year. Did any of the <upper secondary teachers> participate in the following kinds of <professional development activities $>$ (including $<\mathrm{ICT}>$ training)?

Tick one box in each row. applicable/

a. Courses or workshops on subject matter, methodology and other education related topics

b. Conferences where teachers and/or researchers present their methodological and scientific results and discuss educational problems

c. Degree program (e.g., qualification program, master's, Ph.D.)

d. Observational visits to other schools

e. Regularly-scheduled collaboration among teachers on issues of instruction (do not include administrative meetings)

f. Mentoring and/or peer observation and coaching as part of a formal arrangement that is recognized or supported by the school or educational authorities

g. Collaborative research and/or development on a topic related to education (e.g., new methods of teaching, curriculum development, integration of computer use in the curriculum)

h. Participation in a network of teachers (e.g., one organized by an outside agency or over the Internet)

i. Visits to companies/employers

15. Consider the <second month of this school year>. Please estimate the percentage of the class periods that had to be cancelled or covered by somebody else <at the upper secondary level> because of the absence of the assigned teacher?

Write a percentage or tick the box in each row. If 'none', write $0 \%$.

a. cancelled (not held)

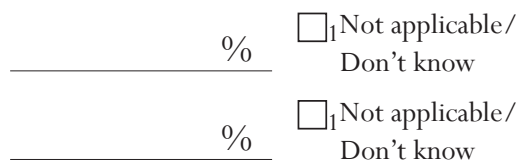

b. covered by another teacher

Don't know 


\section{How often are the following factors considered when students are admitted to <upper secondary programs $>$ in your school?}

Tick one box in each row.

a. Residence in a particular area

b. Student's record of academic performance (including placement tests)

c. Entrance examination

d. Recommendation of feeder schools

e. Parents' endorsement of the instructional or religious philosophy of the school

Never or Some- Often or rarely times Always

$\begin{array}{lll}\square_{1} & \square_{2} & \square_{3} \\ \square_{1} & \square_{2} & \square_{3} \\ \square_{1} & \square_{2} & \square_{3} \\ \square_{1} & \square_{2} & \square_{3} \\ \square_{1} & \square_{2} & \square 3\end{array}$

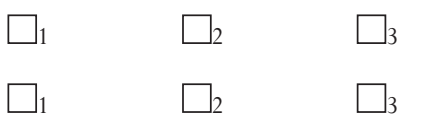

17. In general, how often does your school group <upper secondary> students using the following methods?

Tick one box in each row.

a. Students are grouped more or less at random

b. Students are grouped according to similar ability levels

c. Students are grouped so that classes contain a mixture of ability levels

d. Students are assigned according to the special expertise of teachers

e. Students are assigned to classes composed of students of similar ages

f. Students are grouped according to their choice of program or subject (e.g., foreign language)

g. Students are grouped according to the requests of parents/ guardians

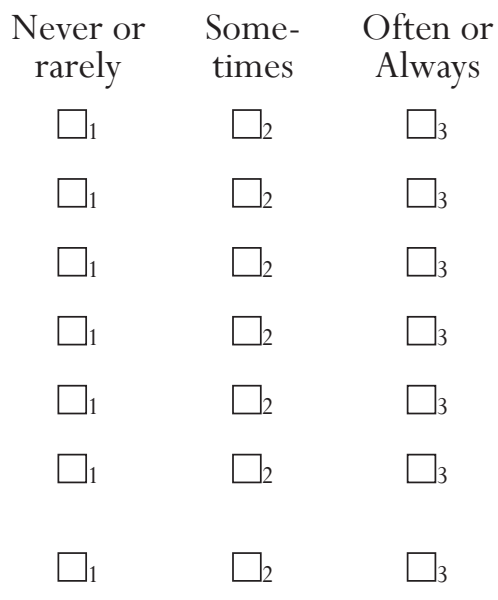

18. Does your school keep records for each <upper secondary> student during his/her entire stay for each of the following aspects?

Please indicate for each of the following aspects if such records are kept AND, if yes, whether teachers have access to them. Tick TWO BOXES in each row that you marked 'Yes' in column 1.

a. The student's choice of subjects/modules

Records kept centrally in the school?

All teachers

Yes No have access?

b. Student performance in school (e.g., scores on tests and assignments)

$\square_{1} \quad \square_{2}$ If yes, Yes No

$\square_{1} \quad \square_{2}$ If yes, 
c. Behavioral problems like bullying, drug addiction, etc.

\begin{tabular}{|c|c|c|}
\hline$\square_{2}$ & If yes, & $\square_{1}$ \\
\hline$\square_{2}$ & If yes, & $\square_{1}$ \\
\hline$\square_{2}$ & If yes, & $\square_{1}$ \\
\hline$\square_{2}$ & If yes, & $\square_{1}$ \\
\hline
\end{tabular}

19. Does your school receive information on its functioning from one or more of the following groups?

Tick one box in each row.

Not

e. Student performance out of school (e.g., in community projects or internships)

f. Results of final examinations

plicable/

a. Regional, national education authorities (e.g., inspectorates)

Yes

No

Don't know

b. The local school authority or the maintainer of the school

c. Employers (e.g., where the students spend their internship)

d. Parent groups (e.g., School Board, Teacher Parent Association)

e. Teacher groups (e.g., Staff Association, trade union)

f. Student groups (e.g., Student Association, youth organization)

g. External examination boards (students' results)

$\begin{array}{lll}\square_{1} & \square_{2} & \square_{3} \\ \square_{1} & \square_{2} & \square_{3} \\ \square_{1} & \square_{2} & \square_{3} \\ \square_{1} & \square_{2} & \square_{3} \\ \square_{1} & \square_{2} & \square_{3} \\ \square_{1} & \square_{2} & \square_{3} \\ \square_{1} & \square_{2} & \square_{3}\end{array}$

\section{Questions 20 to 28 ask about the use of information technology in your school.}

'Computers' in this section include computers capable of supporting other multimedia equipment such as a CD ROM and a sound card. Pocket computers or computers used only for recreation should be excluded from the answers.

Educational purpose' in this section means the use of computers in planning, organizing, and evaluating student learning, and the use of computers as a teaching and learning tool. E.g., retrieving demonstration material from the $<$ Internet $>$, editing of information, preparing demonstration material, preparing tasks and tests, correcting student work, demonstration and practicing of information search on the $<$ Internet/wwW $>$, etc.

20. Does your school provide computers (workstations) for students and/or the staff for educational purposes?

If your answer to this question is 'No', tick the 'No' box and skip to Question 29

$$
\square_{1} \text { Yes } \quad \square_{2} \text { No } \rightarrow \text { Skip to }
$$


21. Excluding computers only for recreation, about how many computers (workstations) are in your school...

Write a number in each row. If 'none', write 0.

a. available in the school altogether?

b. available for students altogether?

c. available only for < upper secondary> students?

d. available only for teachers' use?

e. available only for the administrative staff?

f. connected to the Internet/World Wide Web?

g. connected to a local area network (LAN, Intranet)?

h. portable (excluding pocket computers)?

22. In which year were the following technologies first used in your school for educational purposes?

Tick one box in each row.

Not applicable/

a. Standard word processing and spreadsheet applications like Word Year Not in use Don't know or Excel

b. < World Wide Web $>$ (Internet)

c. <e-mail accessible for teachers and students>

23. What percentage of the teachers at the <upper secondary level> in your school use...

Write a percentage or tick the box in each row. If 'none', write $0 \%$.

a. computers for educational purposes at least once a month? e.g., use computer in classroom as a medium of instruction, for demonstration purposes, as a learning tool, etc.

b. the $<W W W>$ for educational purposes at least once a month? e.g., to collect demonstration material, to teach information search, to network students with students in other schools, etc.

of teachers Don't know

c. $<$ e-mail $>$ for educational purposes regularly (at least once a month)? e.g., to send and receive homework, give feedback to students, etc.

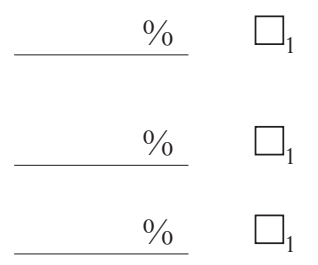


24. Are the following computer-related activities a regular part of students' assignments in <upper secondary education $>$ in your school?

By 'regular part' we mean that such assignments are given at least once a month.

Tick one box in each row.

Not applicable/

a. operating a computer (saving files, printing, etc.)

b. writing documents with a word processor (typing, editing, layout)

c. making illustrations with graphical programs

d. Calculating with spreadsheet programs (sheet creation, use of formulas, organising information)

e. Writing programs (in e.g., <logo, pascal, etc. $>$ )

f. Communicating via e-mail with teachers and other students

g. Sending, searching for, and using electronic forms of information

h. Using educational software (e.g., taking tests, exercises)
Yes

No

Don't know<smiles></smiles><smiles>[GeH2]</smiles><smiles></smiles><smiles>[GeH2]</smiles>

$\square 2$

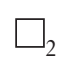

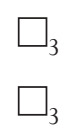

25. At the <upper secondary level>, how much are computers used on a regular basis to ...

Tick one box in each row.

a. develop skills of independent learning

Not at all A little A lot

b. provide additional instruction and practicing opportunities for students with special needs

c. allow students to learn/work at their own pace during lessons

$\square$

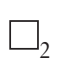

$\square$

d. combine parts of schools subjects with one another (multidisciplinary approach)

e. create opportunities for learning by simulation (using real-world simulation programs)

f. obtain information from the Internet

26. In which fields of information and communication technology use does your school work together with educational institutions, private companies or other organizations?

'Other organizations' include ministries, local authorities, municipal libraries, etc.

Check 'no' if your school does not work together with any other organisation in a particular field.

Tick one box in each row.

Cooperation with

$\begin{array}{cc}\text { Other } & \text { Other } \\ \text { educational Private } & \begin{array}{c}\text { organi- } \\ \text { Nations }\end{array}\end{array}$

a. Donation, exchange and/or joint purchase of ICT-related items (e.g., software, hardware, ICT learning materials) 
b. Joint educational experience through ICT (e.g., communication and exchange of information, joint research projects)

c. Professional development with regard to ICT

d. Other development activities with regard to ICT (e.g., development of software, computer networks, learning environments, learning materials)

e. Joint computer network and/or joint system/network maintenance

f. Delivery of instruction (e.g., on-line courses)

g. Other

27. Do you consider any of the following an obstacle to reaching your school's information technology related goals?

Tick one box in each row.

Obstacle Not an obstacle

a. Insufficient number of computers for teachers' use

b. Insufficient number of computers for students' use

c. Outdated computers (older than 3 years)

d. Shortage of maintenance and technical support

e. Not enough copies of software for instructional purposes

f. Not enough variety (types) of software

g. Poor quality of available software

h. Insufficient time for teachers to prepare lessons in which computers are used

i. Difficult to integrate computers into classroom instruction practices

j. Not enough staff to supervise students using computers

k. Problems in scheduling enough computer time for different classes

l. Internet connection not available

m. Difficult to use with low achieving students

n. No time in the school schedule for using the $<$ Internet/WWW $>$

o. No time in teachers' schedule to explore opportunities for using the <Internet/WWW $>$

p. Not enough space to locate computers appropriately

q. Lack of interest/willingness of teachers to use computers 
r. Teachers' lack of knowledge/skills in using computers for instructional purposes

s. Not enough training opportunities for teachers

t. Insufficient plans and/or resources to prevent theft and vandalism of computers

u. Lack of support from the governing body or community

v. Weak infrastructure (telecommunications, electricity, etc.)

28. Consider the list in Question 27. Which are the three most serious obstacles to using $\langle\mathrm{ICT}\rangle$ in teaching?

Write the letter of the first three most important obstacles on the lines (see Question 27).

a. The first most serious obstacle is

b. The second most serious obstacle is

c. The third most serious obstacle is

The questions in the following section (Questions 29 to 33) refer to the broad <upper secondary> program types listed in Question 1.

These last five questions should be answered separately for each of the <ISCED 3> program types offered at your school site. If you have more than one <ISCED 3> program type in your school, fill in a Part III form separately for each program type you offer in your school.

Below you find the checklist of Part III forms attached to the school questionnaire. Tick the box of the ones you fill out.

a. $<$ Country name for ISCED 3 Program 1>

b. <Country name for ISCED 3 Program 2>

c. <Country name for ISCED 3 Program 3>

d. < Country name for ISCED 3 Program 4>

e. $<$ Country name for ISCED 3 Program 5>, etc.

Country ID: $\square \square \square \quad$ Stratum ID: $\square \square \quad$ School ID: $\square \square \square \square$

Program ID: $\square \square$ : 
29. The following questions ask about students in the final school grade/year of <this program>. Consider the last school year.

Even if you do not have an official record, please provide your best estimate, if you have information.

Write in the number or tick the Not applicable/Don't know box in each row.

Not

Number of applicable/ students Don't know

a. How many students were ENROLLED in the final year of this program last school year?

b. How many students COMPLETED THE PROGRAM successfully (including examination requirements)?

c. How many students LEFT THE SCHOOL WITHOUT COMPLETING this or any other program successfully?

d. How many students continue their STUDIES IN $<$ ISCED 5 $>$ programs?

e. How many students continue their studies in $<$ ISCED $4>$ programs?

f. How many students continue their STUDIES IN OTHER < ISCED 3> LEVEL programs?

g. How many students continue their STUDIES IN THE WORK-BASED part of THIS PROGRAM but no longer as student of this school?

h. How many students sought EMPLOYMENT as a primary activity after leaving this school?
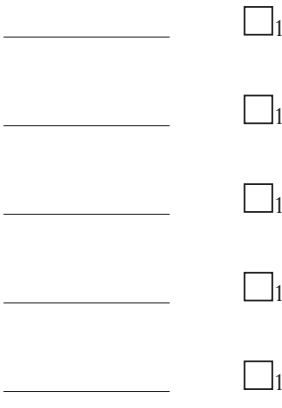

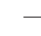

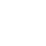


d. Information about possible careers is provided to all students through occasional classes or lectures

e. Personal guidance is provided by a tutor and/or school counselor

f. Informal guidance is given to students

g. The school invites employers and/or practitioners to talk to students within or outside instruction time

h. The school invites representatives of further education institutions to talk to students

i. The school organises visits for students to employment organisations and/or counseling services

j. The school organises visits to institutes of further education

31. Consider the last school year. What percentage of the students in the final school grade/year of $<$ this program> received individual career counseling?

Write a percentage or tick the box. If 'none', write $0 \%$.

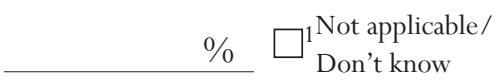

32. The following questions refer to different aspects of instruction time in this program.

$<$ Grades $>$ are counted from the $1^{\text {st }}$ year of primary education. Fill in the table from the column which corresponds to the first year of this program for a typical student. Leave blank the columns of grades which belong to another level of education. $>$

If there are different time schedules within this program, choose the one in which most students are enrolled or which is typical.

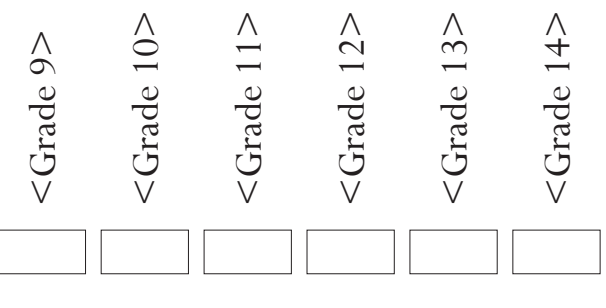

a. How many WEEKS students normally attend school in this program? (Do not count out-of-school learning or training time.)

b. How many DAYS A WEEK do students get instruction? (Do not count out-of-school training time.)

c. How many CLASS PERIODS A WEEK students normally have in this program? (Include within school vocational training here.)

$<$ Class period is the length of time each lesson runs for on a normal day. Some classes may run for 'double periods' or even more, but the class period refers to the basic unit of time used to break up the teaching day $>$.

d. How many MINUTES are there in a regular class period in this program?

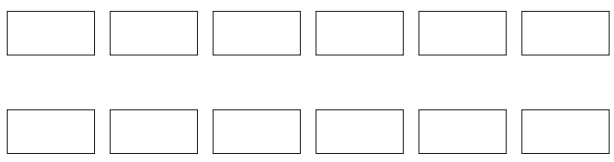


33. The following questions refer to out-of-school activities as part of the scheduled learning time in this program.

A day in this context should be counted as six or more clock hours.

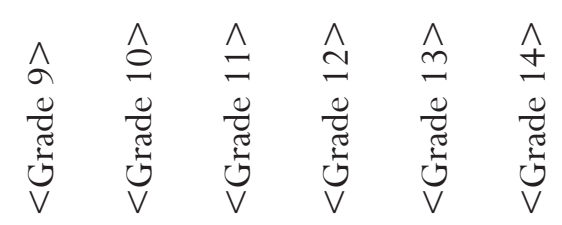

a. How many - if any - DAYS OF $<$ WORK-BASED LEARNING $>$ does a student normally have in this program? (Write 0 , if it is a general program, or if practical/vocational training takes place in the school.)

$<$ Work-based learning refers to the out-of-school training time (apprenticeship) spent in a work organization. It does not include instruction time within the school. $>$

b. How many DAYS OF ORGANIZED WORK EXPERIENCE - if any - does a student normally have in this program? (Write

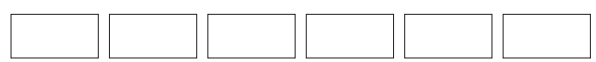
0 , if it there is no authentic work experience is organised by your school for the students in this program. (Do not count work based learning here)

$<$ Organized work experience can include any out-of-school activity that is planned in the curriculum and involves sustained effort to complete a task in an authentic work environment.

It may include participation in community services, and within school services done on a regular basis. $>$

\section{END OF PART III}


Annex

2

LIST OF UPPER SECONDARY PROGRAMMES

INCLUDED IN THE ISUSS STUDY 
List of upper secondary programmes included in the ISUSS study

\begin{tabular}{|c|c|c|c|c|c|c|c|c|c|c|}
\hline & \multirow[b]{2}{*}{ ISCED Level } & \multirow[b]{2}{*}{ Destination } & \multirow[b]{2}{*}{ Orientation } & \multicolumn{6}{|c|}{$\begin{array}{l}\text { Minimum cumulative years of education } \\
\text { from entry to primary education (grade) }\end{array}$} & \multirow{2}{*}{$\begin{array}{c}\text { Entry } \\
\text { requirement } \\
\text { (ISCED level) }\end{array}$} \\
\hline & & & & 9 & 10 & 11 & 12 & 13 & 14 & \\
\hline \multicolumn{11}{|l|}{ Belgium (Fl.) ${ }^{1}$} \\
\hline $\operatorname{ASO}(3 e \mathrm{lj}-6 \mathrm{e} l \mathrm{j})$ & 3 & A & G & 9 & 10 & 11 & 12 & & & ISCED 2 \\
\hline $\operatorname{BSO}\left(3^{e} \mathrm{lj}-6^{e} \mathrm{lj}\right)$ & 3 & $\mathrm{C}$ & $\mathrm{V}$ & 9 & 10 & 11 & 12 & & & ISCED 2 \\
\hline $\operatorname{TSO}(3 e \mathrm{lj}-6 \mathrm{e}$ lj $)$ & 3 & A & $\mathrm{V}$ & 9 & 10 & 11 & 12 & & & ISCED 2 \\
\hline \multicolumn{11}{|l|}{ Denmark } \\
\hline Alment gymnasium & 3 & A & G & & 10 & 11 & 12 & & & ISCED 2 \\
\hline Højere forberedelseseksamen (HF) & 3 & A & G & & & 11 & 12 & & & ISCED 2 \\
\hline Højere handelseksamen (HHX) & 3 & A & G & & 10 & 11 & 12 & & & ISCED 2 \\
\hline Højere teknisk eksamen (HTX) & 3 & A & G & & 10 & 11 & 12 & & & ISCED 2 \\
\hline $\begin{array}{l}\text { Erhvervsfaglige merkantile uddannelser } \\
\text { (EUD merkantile) }\end{array}$ & 3 & $\mathrm{C}$ & $\mathrm{V}$ & & 10 & 11 & 12 & 13 & & ISCED 2 \\
\hline $\begin{array}{l}\text { Erhvervsfaglige tekniske uddannelser } \\
\text { (EUD Teknisk) }\end{array}$ & 3 & $\mathrm{C}$ & $\mathrm{V}$ & & 10 & 11 & 12 & 13 & & ISCED 2 \\
\hline Social- og sundhedsuddannelser (SOSU) & 3 & $\mathrm{C}$ & $\mathrm{V}$ & & 10 & 11 & 12 & & & ISCED 2 \\
\hline $\begin{array}{l}\text { Landbrugs-, gartner- og } \\
\text { skovbrugsuddannelser }\end{array}$ & 3 & $\mathrm{C}$ & $\mathrm{V}$ & & 10 & 11 & 12 & 13 & & ISCED 2 \\
\hline \multicolumn{11}{|l|}{ Finland } \\
\hline Lukio & 3 & A & G & & 10 & 11 & 12 & 13 & & ISCED 2 \\
\hline Ammatillinen koulu & 3 & A & $\mathrm{V}$ & & 10 & 11 & 12 & & & ISCED 2 \\
\hline \multicolumn{11}{|l|}{ France } \\
\hline Second cycle général du second degré & 3 & A & G & & 10 & 11 & 12 & & & ISCED 2 \\
\hline $\begin{array}{l}\text { Second cycle technologique du second } \\
\text { degré }\end{array}$ & 3 & A & G & & 10 & 11 & 12 & & & ISCED 2 \\
\hline $\begin{array}{l}\text { Second cycle professionnel du second } \\
\text { degré niveau CAP, BEP } \\
\text { (sous statut scolaire) }\end{array}$ & 3 & $\mathrm{C}$ & $\mathrm{V}$ & & 10 & 11 & & & & ISCED 2 \\
\hline $\begin{array}{l}\text { Second cycle professionnel du second } \\
\text { degré niveau CAP, BEP (en apprentissage) }\end{array}$ & 3 & $\mathrm{C}$ & $\mathrm{V}$ & & 10 & 11 & & & & ISCED 2 \\
\hline $\begin{array}{l}\text { Second cycle professionnel du second } \\
\text { degré niveau bac (sous statut scolaire) }\end{array}$ & 3 & B & $\mathrm{V}$ & & & & 12 & 13 & & ISCED $3 \mathrm{CV}$ \\
\hline $\begin{array}{l}\text { Second cycle professionnel du second } \\
\text { degré niveau bac (en apprentissage) }\end{array}$ & 3 & B & $\mathrm{V}$ & & & & 12 & 13 & & ISCED $3 \mathrm{CV}$ \\
\hline \multicolumn{11}{|l|}{ Hungary } \\
\hline Gimnázium (9-12. évfolyam) & 3 & A & G & 9 & 10 & 11 & 12 & & & ISCED 2 \\
\hline Szakközépiskola (9-12. évfolyam) & 3 & A & $\mathrm{P}$ & 9 & 10 & 11 & 12 & & & ISCED 2 \\
\hline Szakiskola (9-10. évfolyam) & 3 & $\mathrm{C}$ & G & 9 & 10 & & & & & ISCED 2 \\
\hline $\begin{array}{l}\text { Szakiskola szakképzö évfolyamai (11-12. } \\
\text { évfolyam) }\end{array}$ & 3 & C & $\mathrm{V}$ & & & 11 & 12 & & & ISCED 3CG \\
\hline \multicolumn{11}{|l|}{ Ireland $^{2}$} \\
\hline Leaving Certificate programme & 3 & A & G & & 10 & 11 & 12 & & & ISCED 2 \\
\hline Leaving Certificate Vocational programme & 3 & A & $P$ & & 10 & 11 & 12 & & & ISCED 2 \\
\hline Transition Year programme & 3 & $\mathrm{C}$ & G & & 10 & & & & & ISCED 2 \\
\hline Leaving Certificate Applied programme & 3 & $\mathrm{C}$ & $\mathrm{P}$ & & 10 & 11 & 12 & & & ISCED 2 \\
\hline \multicolumn{11}{|l|}{ Italy } \\
\hline Liceo classico, scientifico, linguistico & 3 & A & G & 9 & 10 & 11 & 12 & 13 & & ISCED 2 \\
\hline 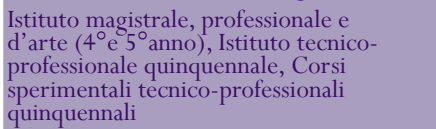 & 3 & A & $\mathrm{V}$ & & & & 12 & 13 & & ISCED 3CV \\
\hline Liceo artistico & 3 & A & G & 9 & 10 & 11 & 12 & 13 & & ISCED 2 \\
\hline $\begin{array}{l}\text { Istituto professionale e d'arte } \\
\text { (I,II e IIl anno) }\end{array}$ & 3 & $\mathrm{C}$ & $\mathrm{V}$ & 9 & 10 & 11 & & & & ISCED 2 \\
\hline \multicolumn{11}{|l|}{ Korea } \\
\hline General high school & 3 & A & G & & 10 & 11 & 12 & & & ISCED 2 \\
\hline $\begin{array}{l}\text { Vocational high school (including } \\
\text { comprehensive high school) }\end{array}$ & 3 & $\mathrm{C}$ & $\mathrm{V}$ & & 10 & 11 & 12 & & & ISCED 2 \\
\hline
\end{tabular}


List of upper secondary programmes included in the ISUSS study

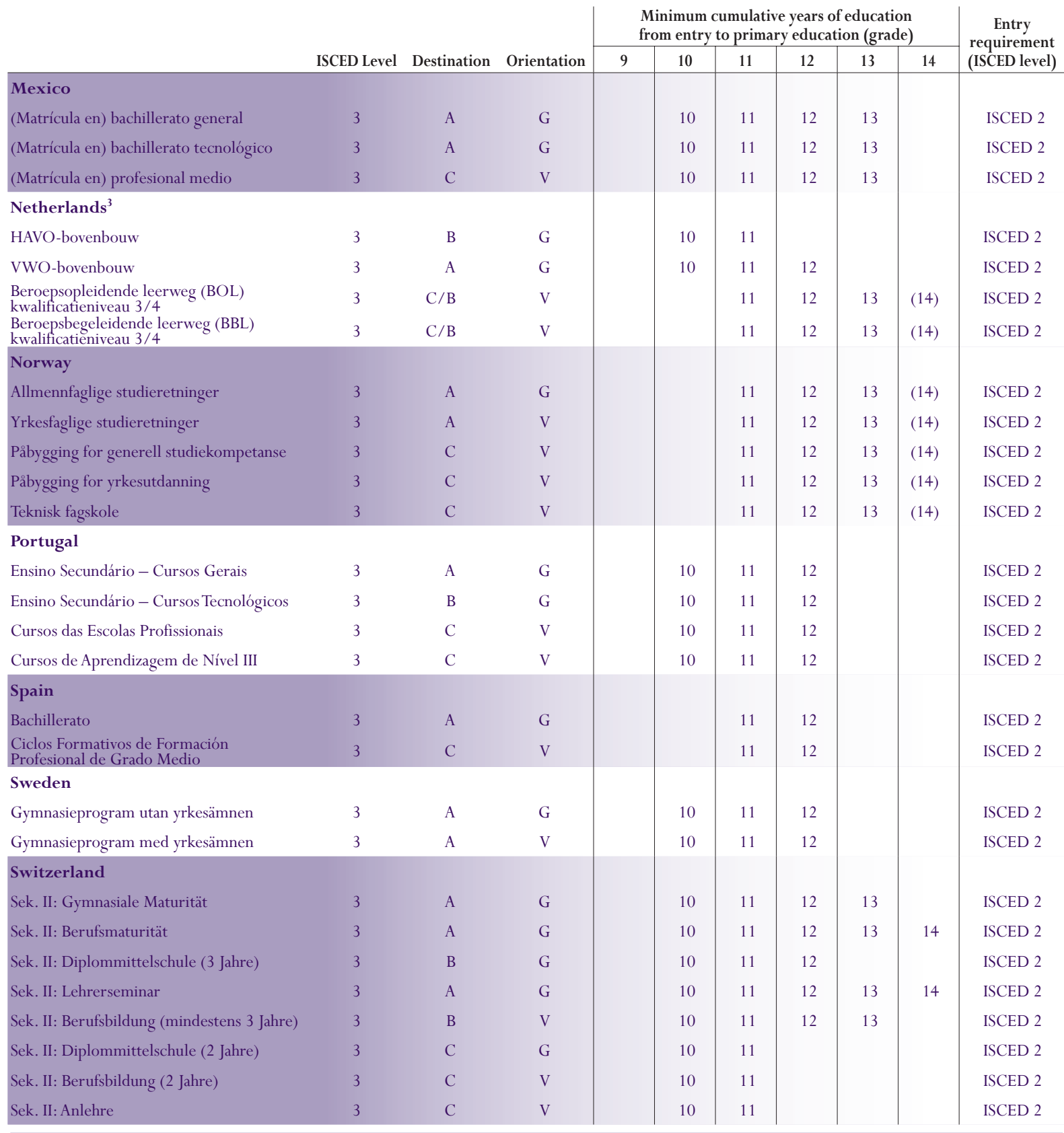

Note: Programmes with a destination 'A' prepare for higher education of all types, programmes with a destination 'B' prepare for specific kinds of higher education, programmes with a destination 'C' prepare for the labour market or for another ISCED 3 programme. Programmes with an orientation ' $\mathrm{G}$ ' are classified as general programmes, 'P' as pre-vocational programmes and 'V' as vocational programmes.

1. In Belgium (Fl.), there are four mainstream programmes in upper secondary education: ASO (general upper secondary education), BSO (vocational upper secondary education), KSO (artistic upper secondary education) and TSO (technical upper secondary education). Only schools providing ASO, BSO and TSO have participated to the ISUSS study.

2. The Leaving Certificate, Leaving Certificate Vocational and Leaving Certificate Applied programmes each have a 2 year duration wich can begin in either year 10 or 11, depending on wheter or not the transition year program is offered in year 10.

3. Vocational programs (BOL, BBL) as well as general programmes are flexible in the sense that they give different levels of qualification depending on when a student leaves the programme. Thus, there is a transition from HAVO to VWO in the case of general programmes. BOL and BBL qualifications are considered $3 \mathrm{C}$ or $3 \mathrm{~B}$ level qualification as depending on the hierarchical course modules the student takes and the level of qualification examination taken. 


\section{Annex}

\section{3}

\section{SAMPLING FORMS}

This Annex contains copies of all Sampling Forms needed to document the sampling procedures:

- Sampling Form 1: National Desired Target Population

- Sampling Form 2: National Defined Target Population

- Sampling Form 3: Stratification

- Sampling Form 4: $\quad$ Small Schools

- Sampling Form 5: $\quad$ Sampling Frame Description

- Sampling Form 6: School Tracking Form

- Sampling Form 7: $\quad$ Excluded Schools

- Sampling Form 8: Population Counts by Strata

- Sampling Form 9: Sample Allocation by Explicit Strata

- Sampling Form 10: School Sample Selection

- Sampling Form 11: School Sampling Frame

- Sampling Form 12: Response Rate

- Sampling Form 13: Calculating the School Weights 
OECD International Survey of Schools at the Upper Secondary Level

\section{Country:}

National Project Manager:

1. Total national enrollment in upper secondary programs listed in Phase I Classification Study:

2. Describe the population(s) to be excluded from the national desired target population (if applicable):

3. Total enrollment excluded from the national desired target population (corresponding to the exclusions listed in the previous item):

4. Total enrollment in the national desired target population: box $[a]-$ box $[b]$

5. Percentage of coverage in the national desired target population: box $[c] \div$ box $[a]$

6. Describe your data source (provide copies of relevant tables): 
OECD International Survey of Schools at the Upper Secondary Level

Sampling Form 2 National Defined Target Population

Country:

National Project Manager:

1. Total national enrollment in the national desired target population:

[a] From box [c] on Sampling Form 1

2. School-level exclusions:

\begin{tabular}{l|l}
\hline Description of exclusions & \# of students \\
\hline & \\
\hline & \\
\hline & \\
\hline TOTAL & \\
\hline
\end{tabular}

Percentage of school-level exclusions:

box $[b] \div$ box $[a]$

3. Total enrollment in the national defined target population:

box $[a]-$ box $[b]$

4. Describe your data source (provide copies of relevant tables): 
OECD International Survey of Schools at the Upper Secondary Level

Sampling Form 3 Stratification

Country:

National Project Manager:

\section{Explicit Stratification}

1. List and describe the variables used for explicit stratification.

\begin{tabular}{l|l|l}
\hline Explicit stratification variables & \# of levels \\
\hline 1 & & \\
\hline 2 & & \\
\hline 3 & & \\
\hline 4 & & \\
\hline 5 & & \\
\hline
\end{tabular}

2. Total number of explicit strata:

\section{Implicit Stratification}

3. List and describe the variables used for implicit stratification.

\begin{tabular}{l|l|l}
\hline Implicit stratification variables & \# of levels \\
\hline 1 & & \\
\hline 2 & & \\
\hline 3 & & \\
\hline 4 & & \\
\hline 5 & & \\
\hline
\end{tabular}

4. Total number of implicit strata: 
OECD International Survey of Schools at the Upper Secondary Level

Country:

National Project Manager:

\begin{tabular}{l|l}
\hline Total enrollment & \\
\hline Total \# of schools & \\
\hline ASEC & \\
\hline ASEC4 & \\
\hline
\end{tabular}

1. Enrollment in small schools:

\begin{tabular}{l|l|l}
\hline Type of school based on enrollment & \# of students & Percentage \\
\hline In-program school enrollment $<$ ASEC4 & & {$[\mathrm{a}]$} \\
\hline In-program school enrollment $\geq$ ASEC4 and $<$ ASEC & & {$[\mathrm{b}]$} \\
\hline In-program school enrollment $\geq$ ASEC & & {$[\mathrm{c}]$} \\
\hline TOTAL & & $100 \%$ \\
\hline
\end{tabular}

2. If the percentage in box [a] is less than $2 \%$, then these small schools can be excluded from the national defined target population. Be sure to record this exclusion on Sampling Form 2, item 2.

box $[\mathrm{e}]<2 \%$ ?

Yes $\square$ or No $\square$

3. If the percentage in box [c] is $90 \%$ or more, then all schools should remain in the national defined target population and be subject to normal school sampling.

box $[c] \geq 90 \%$ ?

Yes $\square$ or No $\square$

4. If the percentage in box [c] is less than $90 \%$, then small schools (enrollment < ASEC4) should form an explicit stratum. Be sure to record this level of explicit stratification in Sampling Form 3, Item 1. Please consult with AIR to determine an appropriate sample for this stratum of small schools. 


\section{Country:}

National Project Manager:

1. Specify the type of school sampling frame to be used.

Single-level sampling frame

Double-level sampling frame

Other (please describe):

2. Specify the school measure of size (MOS) to be used.

Total student enrollment in the target programs in the given school

Total student enrollment in the target school

Average student enrollment per grade

Number of classrooms in the target school

Other (please describe):

3. Specify the school year for which enrollment data will be used for the school MOS.

4. If a double-level sampling frame is to be used, please provide a preliminary description of the information available to construct this frame. Please consult with AIR for support and advice in the construction and use of a double-level sampling frame. 
OECD International Survey of Schools at the Upper Secondary Level

Country:

National Project Manager:

Explicit Stratum:

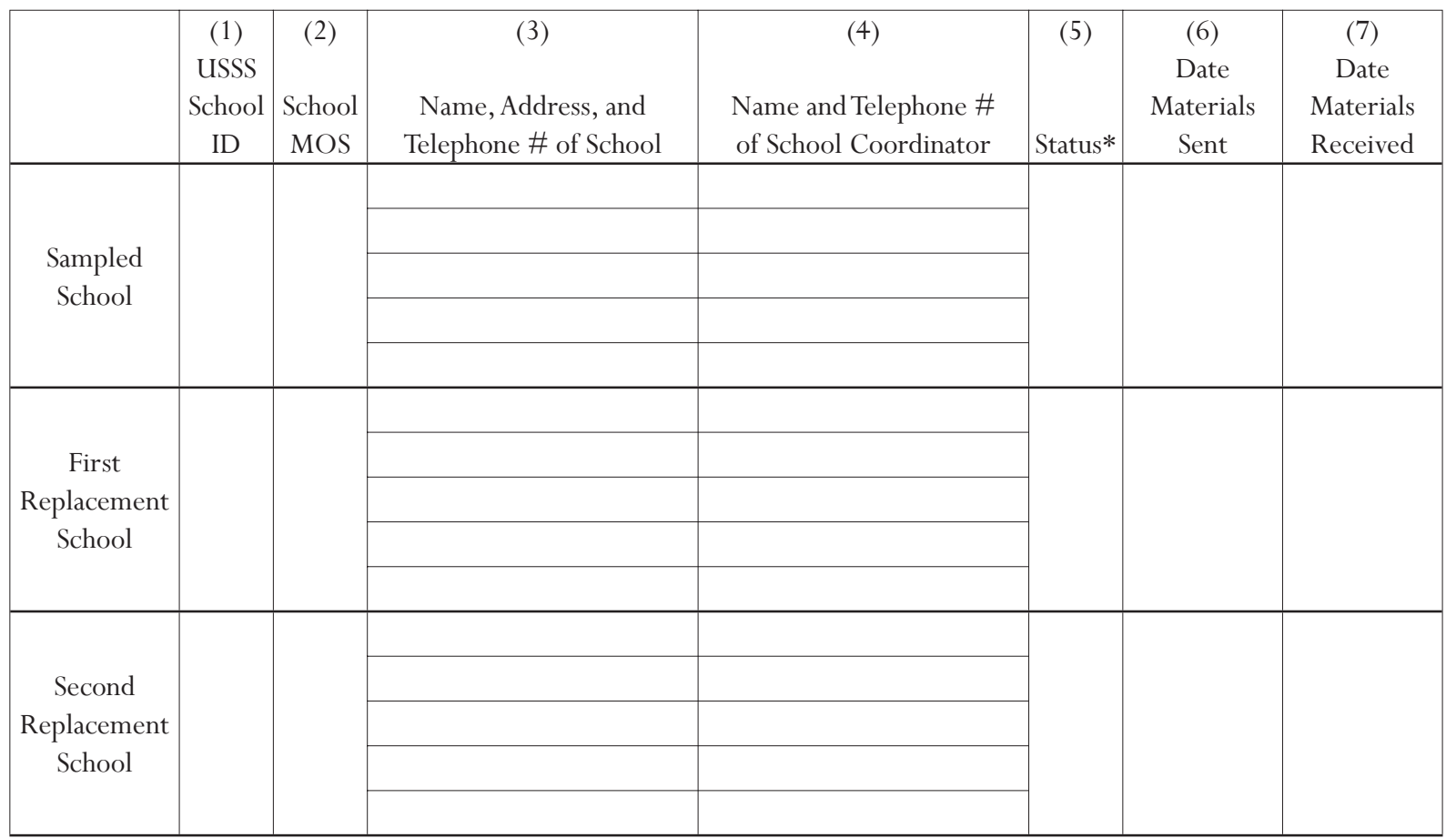

* Enter "N" for non-participating schools. A check mark $(\sqrt{ })$ indicates the participating school. 
ANNEX 3

OECD International Survey of Schools at the Upper Secondary Level

Sampling Form 7 Excluded Schools

Country:

National Project Manager:

\begin{tabular}{|c|c|c|}
\hline $\begin{array}{c}(1) \\
\text { School ID }\end{array}$ & $\begin{array}{c}(2) \\
\text { Reason for exclusion }\end{array}$ & $\begin{array}{c}\text { (3) } \\
\text { School MOS }\end{array}$ \\
\hline & & \\
\hline & & \\
\hline & & \\
\hline & & \\
\hline & & \\
\hline & & \\
\hline & & \\
\hline & & \\
\hline & & \\
\hline & & \\
\hline & & \\
\hline & & \\
\hline & & \\
\hline & & \\
\hline & & \\
\hline & & \\
\hline & & \\
\hline & & \\
\hline & & \\
\hline & & \\
\hline & & \\
\hline & & \\
\hline
\end{tabular}


OECD International Survey of Schools at the Upper Secondary Level

Sampling Form 8 Population Counts by Strata

Country:

National Project Manager:

\begin{tabular}{|c|c|c|c|}
\hline (1) & (2) & (3) & (4) \\
\hline \multirow[b]{2}{*}{ Explicit Strata } & \multirow[b]{2}{*}{ Implicit Strata } & \multicolumn{2}{|c|}{ Population Counts } \\
\hline & & Schools & Students \\
\hline & & & \\
\hline & & & \\
\hline & & & \\
\hline & & & \\
\hline & & & \\
\hline & & & \\
\hline & & & \\
\hline & & & \\
\hline & & & \\
\hline & & & \\
\hline & & & \\
\hline & & & \\
\hline & & & \\
\hline & & & \\
\hline & & & \\
\hline & & & \\
\hline & & & \\
\hline & & & \\
\hline & & & \\
\hline & & & \\
\hline & & & \\
\hline & & & \\
\hline & & & \\
\hline
\end{tabular}


ANNEX 3

OECD International Survey of Schools at the Upper Secondary Level

Sampling Form 9 Sample Allocation by Explicit Strata

Country:

National Project Manager:

\begin{tabular}{|c|c|c|}
\hline (1) & (2) & (3) \\
\hline \multirow[b]{2}{*}{ Explicit Strata } & \multicolumn{2}{|c|}{ Sample Allocation } \\
\hline & Schools & Students \\
\hline & & \\
\hline & & \\
\hline & & \\
\hline & & \\
\hline & & \\
\hline & & \\
\hline & & \\
\hline & & \\
\hline & & \\
\hline & & \\
\hline & & \\
\hline & & \\
\hline & & \\
\hline & & \\
\hline & & \\
\hline & & \\
\hline & & \\
\hline & & \\
\hline & & \\
\hline & & \\
\hline & & \\
\hline & & \\
\hline
\end{tabular}


OECD International Survey of Schools at the Upper Secondary Level

Sampling Form 10 School Sample Selection

Country:

National Project Manager:

Explicit Stratum:

\begin{tabular}{|l|l|l|l|}
\hline $\begin{array}{l}\text { S } \\
{[\text { a]Total Measure of Size }}\end{array}$ & $\begin{array}{l}\text { D } \\
\text { [b] Desired Sample Size }\end{array}$ & $\begin{array}{l}\text { I } \\
\text { [c] Sampling Interval }\end{array}$ & $\begin{array}{l}\text { RN } \\
\text { [d] Random Number }\end{array}$ \\
\hline
\end{tabular}

\begin{tabular}{|l|l|}
\hline \multicolumn{1}{|c|}{$(1)$} & $(2)$ \\
\hline Line Numbers & Selection Numbers \\
\hline & \\
\hline & \\
\hline & \\
\hline & \\
\hline & \\
\hline & \\
\hline & \\
\hline & \\
\hline & \\
\hline & \\
\hline
\end{tabular}


ANNEX 3

OECD International Survey of Schools at the Upper Secondary Level

Sampling Form 11 School Sampling Frame

Country:

National Project Manager:

Explicit Stratum:

\begin{tabular}{|c|c|c|c|c|c|c|}
\hline $\begin{array}{c}\text { (1) } \\
\text { School List ID }\end{array}$ & $\begin{array}{c}\text { (2) } \\
\text { Implicit Stratum }\end{array}$ & $\begin{array}{c}\text { (3) } \\
\text { MOS } \\
\text { (measure of size) } \\
\end{array}$ & $\begin{array}{c}\text { (4) } \\
\text { Cumulative } \\
\text { MOS }\end{array}$ & $\begin{array}{c}\text { (5) } \\
\text { Line Number }\end{array}$ & $\begin{array}{c}(6) \\
\text { Sample Status }\end{array}$ & $\begin{array}{c}\text { (7) } \\
\text { USSS School ID }\end{array}$ \\
\hline & & & & & & \\
\hline & & & & & & \\
\hline & & & & & & \\
\hline & & & & & & \\
\hline & & & & & & \\
\hline & & & & & & \\
\hline & & & & & & \\
\hline & & & & & & \\
\hline & & & & & & \\
\hline & & & & & & \\
\hline & & & & & & \\
\hline & & & & & & \\
\hline & & & & & & \\
\hline & & & & & & \\
\hline & & & & & & \\
\hline & & & & & & \\
\hline & & & & & & \\
\hline & & & & & & \\
\hline & & & & & & \\
\hline & & & & & & \\
\hline & & & & & & \\
\hline & & & & & & \\
\hline & & & & & & \\
\hline
\end{tabular}


OECD International Survey of Schools at the Upper Secondary Level

Sampling Form 12 Response Rate

Country:

National Project Manager:

1. Originally selected schools

\begin{tabular}{|c|c|c|}
\hline & & \\
\hline [a]Total selected schools & [b] Original participating schools & $\begin{array}{c}\text { [c] School response rate } \\
{[\mathrm{c}]=[\mathrm{b}] \div[\mathrm{a}]}\end{array}$ \\
\hline
\end{tabular}

2. Total sample

\begin{tabular}{|c|c|c|}
\hline [d] Total selected schools & $\begin{array}{c}\text { [e] Total participating schools } \\
\text { including replacements }\end{array}$ & $\begin{array}{c}\text { [f] Study response rate } \\
{[\mathrm{f}]=[\mathrm{e}] \div[\mathrm{d}]}\end{array}$ \\
\hline
\end{tabular}


OECD International Survey of Schools at the Upper Secondary Level

Sampling Form 13 Calculating the School Weights

Country:

National Project Manager:

Explicit Stratum:

L

[a] Number of selected schools

\section{L'}

[b] Number of responding schools [c] Adjustment factor ( L'/L ) [d] Sum of weights $\left(\sum \mathrm{w}_{\mathrm{i}}\right)$

\begin{tabular}{|c|c|c|c|c|c|c|}
\hline $\begin{array}{c}(1) \\
\text { School ID }\end{array}$ & $\begin{array}{c}(2) \\
\text { Participated } \\
(\mathrm{Y} / \mathrm{N})\end{array}$ & $\begin{array}{c}(3) \\
\text { MOS }\end{array}$ & $\begin{array}{c}(4) \\
\text { AMOS }\end{array}$ & $\begin{array}{c}(5) \\
\text { School } \\
\text { probability, } \mathrm{P}_{\mathrm{i}}\end{array}$ & $\begin{array}{c}(6) \\
\text { Adjusted school- } \\
\text { probability, } \mathrm{H}_{\mathrm{i}}\end{array}$ & $\begin{array}{c}\quad(7) \\
\text { Final school } \\
\text { Weight, } \mathrm{W}_{\mathrm{i}}\end{array}$ \\
\hline & & & & & & \\
\hline & & & & & & \\
\hline & & & & & & \\
\hline & & & & & & \\
\hline & & & & & & \\
\hline & & & & & & \\
\hline & & & & & & \\
\hline & & & & & & \\
\hline & & & & & & \\
\hline & & & & & & \\
\hline & & & & & & \\
\hline & & & & & & \\
\hline
\end{tabular}


Annex

4

CODEBOOK 
The codebook gives a full and complete description of the 'raw' variables included in both ACCESS and SPSS databases and of the derived variables used in the report 'Completing the Foundation for Lifelong Learning - An OECD Survey of Upper Secondary Schools'.

\section{Codebook Part A: Questionnaire data}

This gives a full description of the 'raw' variables that were included in the questionnaire and which are included in both ACCESS and SPSS databases. It shows for each variable its variable short name, its variable name, its source (the corresponding question on the Questionnaire), its value (the valid values that the variables could take in the questionnaire), its label (the description of these values) and description/ notes. Missing values could be coded as follows: M/R (multiple or ambiguous response), N/ADM (not administered response) or MIS (item level non-response). Section III.4 of the Technical Report gives a full description of these missing values.

\section{Codeboook Part B: Derived variables}

The list of derived variables used in the following report 'Completing the Foundation for Lifelong Learning - An OECD Survey of Upper Secondary School' is detailed in the next pages. It shows for each derived variable its name, its short name, its source (reference to one or more questions of the ISUSS questionnaire), its value and label as well as its description and its correspondence with the ISUSS tables provided in the ISUSS report. 
Codebook Part A: Questionnaire data

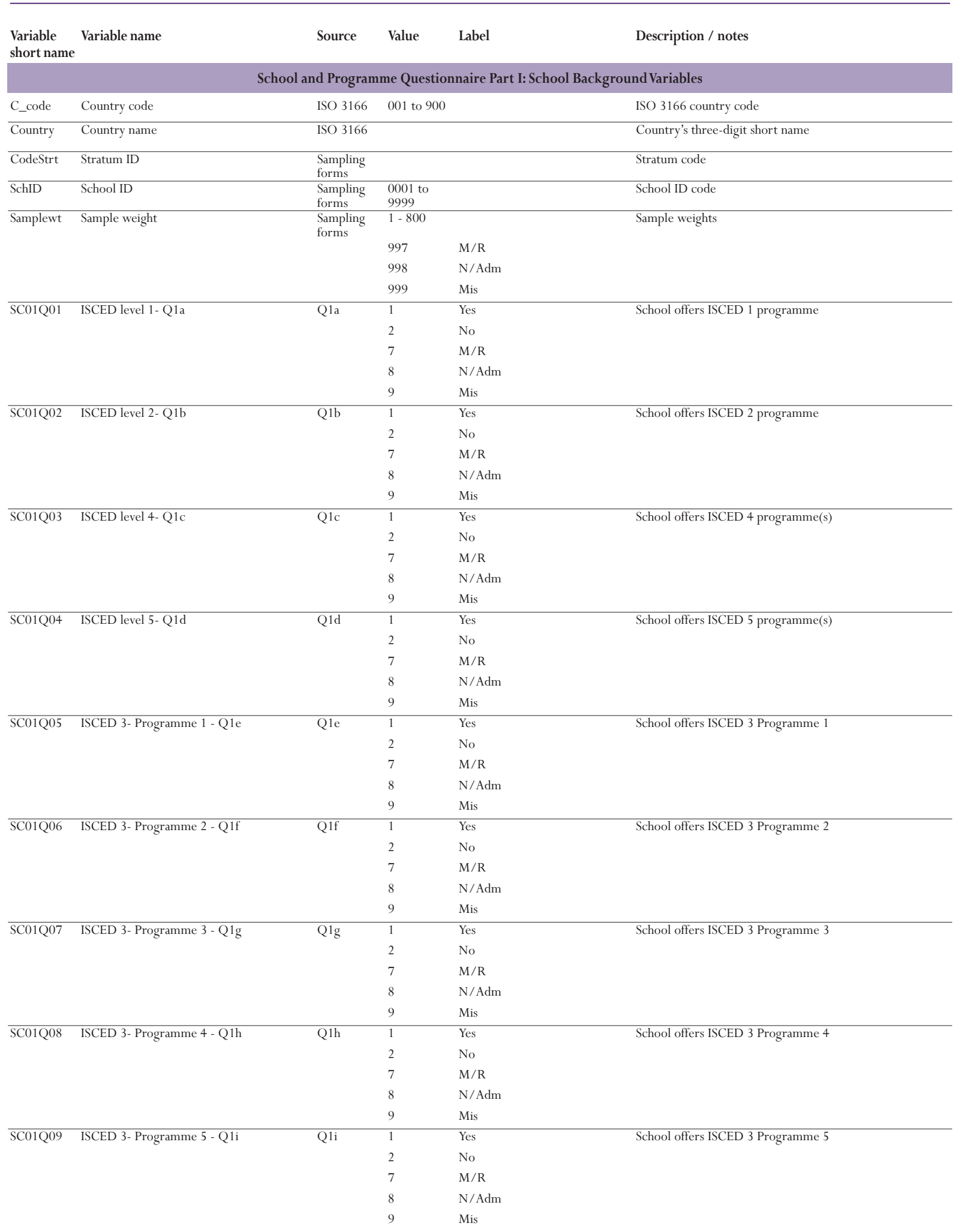


ANNEX 4

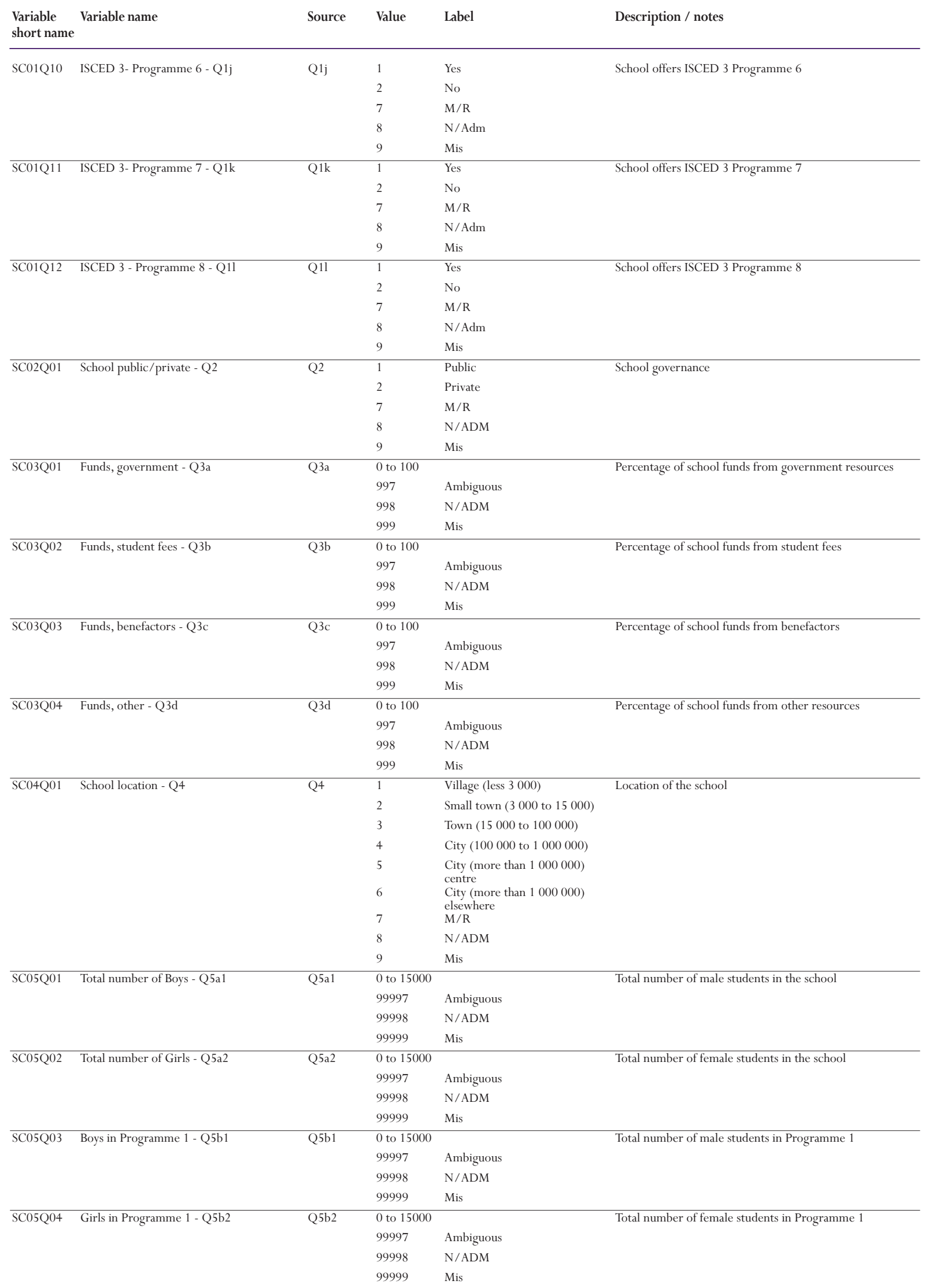




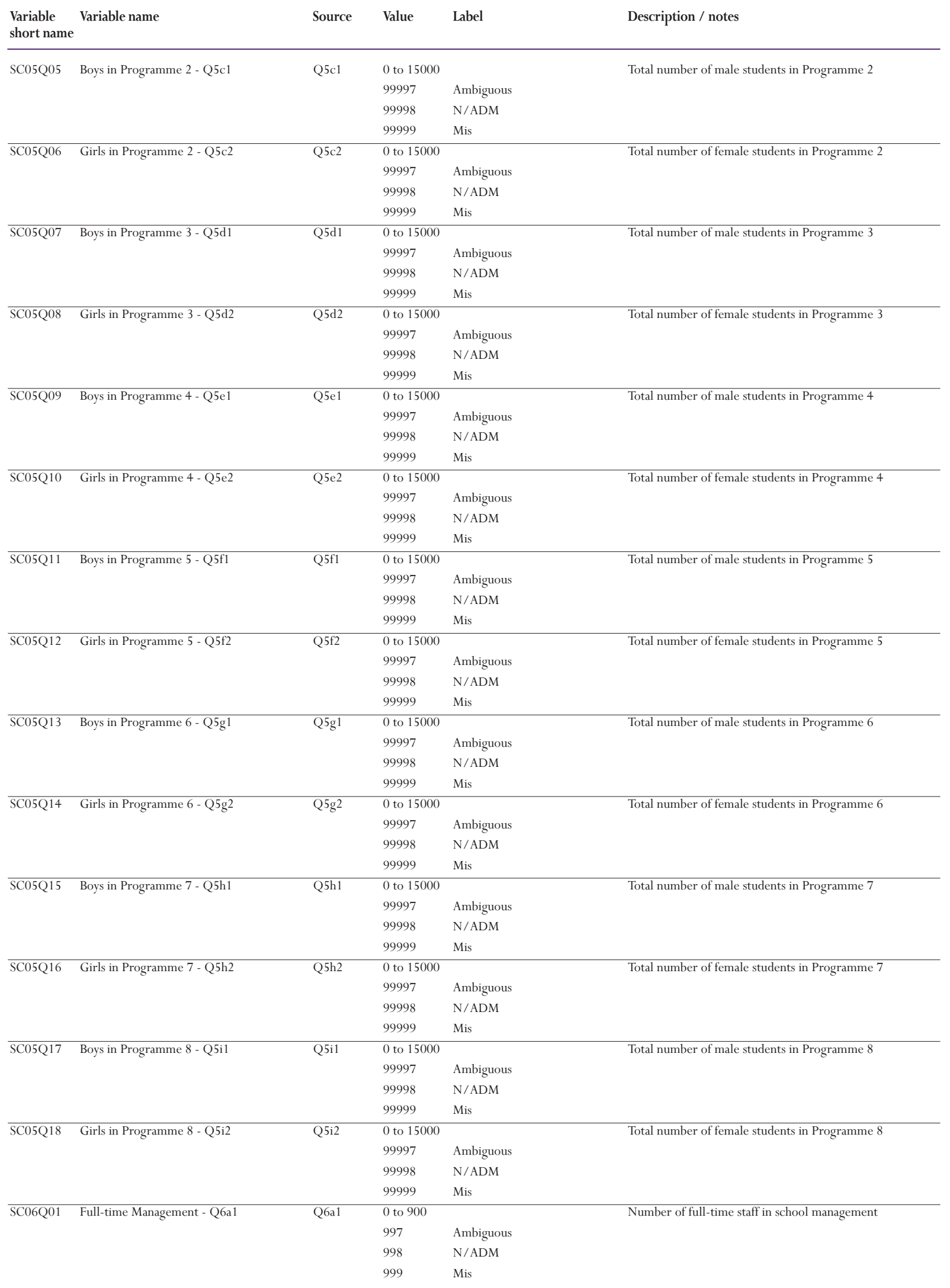


ANNEX 4

\begin{tabular}{|c|c|c|c|c|c|}
\hline $\begin{array}{l}\text { Variable } \\
\text { short name }\end{array}$ & Variable name & Source & Value & Label & Description / notes \\
\hline \multirow[t]{3}{*}{ SC06Q02 } & Part-time Management - Q6a2 & Q6a2 & 0 to 900 & & Number of part-time staff in school management \\
\hline & & & 998 & N/ADM & \\
\hline & & & 999 & Mis & \\
\hline \multirow[t]{3}{*}{$\overline{\mathrm{SC06Q03}}$} & Full-time classroom teachers - Q6b1 & Q6b1 & 0 to 900 & & Number of full-time classroom teachers \\
\hline & & & 998 & N/ADM & \\
\hline & & & 999 & Mis & \\
\hline \multirow[t]{4}{*}{$\overline{\text { SC06Q04 }}$} & Part-time classroom teachers - Q6b2 & Q6b2 & 0 to 900 & & Number of part-time classroom teachers \\
\hline & & & 997 & Ambiguous & \\
\hline & & & 998 & N/ADM & \\
\hline & & & 999 & Mis & \\
\hline \multirow[t]{3}{*}{$\overline{\text { SC06Q05 }}$} & Full-time teacher aides - Q6c1 & Q6c1 & 0 to 900 & & Number of full-time teacher aids \\
\hline & & & 998 & N/ADM & \\
\hline & & & 999 & Mis & \\
\hline \multirow[t]{4}{*}{ SC06Q06 } & Part-time teacher aides - Q6c2 & Q6c2 & 0 to 900 & & Number of part-time teacher aids \\
\hline & & & 997 & Ambiguous & \\
\hline & & & 998 & N/ADM & \\
\hline & & & 999 & Mis & \\
\hline \multirow[t]{4}{*}{ SC06Q07 } & Full-time professional support - Q6d1 & Q6d1 & 0 to 900 & & Number of full-time professional support \\
\hline & & & 997 & Ambiguous & \\
\hline & & & 998 & N/ADM & \\
\hline & & & 999 & Mis & \\
\hline \multirow[t]{4}{*}{$\overline{S C 06 Q 08}$} & Part-time professional support- Q6d2 & Q6d2 & 0 to 900 & & Number of part-time professional support \\
\hline & & & 997 & Ambiguous & \\
\hline & & & 998 & N/ADM & \\
\hline & & & 999 & Mis & \\
\hline \multirow{3}{*}{ SC06Q09 } & & & 997 & Ambiguous & \\
\hline & & & 998 & $\mathrm{~N} / \mathrm{ADM}$ & \\
\hline & & & 999 & Mis & \\
\hline \multirow[t]{4}{*}{ SC06Q10 } & Part-time other support- Q6e2 & Q6e2 & 0 to 900 & & Number of other part-time support personnel \\
\hline & & & 997 & Ambiguous & \\
\hline & & & 998 & N/ADM & \\
\hline & & & 999 & Mis & \\
\hline
\end{tabular}

\begin{tabular}{|c|c|c|c|c|c|}
\hline \multicolumn{6}{|c|}{ School and Programme Questionnaire Part II: Questions on Upper Secondary Education } \\
\hline \multirow[t]{3}{*}{ SC07Q01 } & \multirow[t]{3}{*}{ Full-time temporary teachers - Q7a1 } & \multirow[t]{3}{*}{ Q07a1 } & $\begin{array}{l}0 \text { to } 100 \\
997\end{array}$ & Ambiguous & \multirow[t]{3}{*}{ Percentage of full-time teachers who are temporaries } \\
\hline & & & 998 & N/ADM & \\
\hline & & & 999 & Mis & \\
\hline \multirow[t]{3}{*}{$\overline{\mathrm{SC} 07 \mathrm{Q} 02}$} & \multirow[t]{3}{*}{ Part-time temporary teachers - Q7a2 } & \multirow[t]{3}{*}{ Q07a2 } & 0 to 100 & & \multirow[t]{3}{*}{ Percentage of part-time teachers who are temporaries } \\
\hline & & & 997 & Ambiguous & \\
\hline & & & 999 & Mis & \\
\hline \multirow[t]{4}{*}{$\overline{\mathrm{SC} 07 \mathrm{Q} 03}$} & \multirow[t]{4}{*}{ Full-time fully qualified teachers - Q7b1 } & \multirow[t]{4}{*}{ Q07b1 } & 0 to 100 & & \multirow[t]{4}{*}{ Percentage of full-time teachers who are fully qualified } \\
\hline & & & 997 & Ambiguous & \\
\hline & & & 998 & N/ADM & \\
\hline & & & 999 & Mis & \\
\hline \multirow[t]{3}{*}{$\overline{\mathrm{SC} 07 \mathrm{Q} 04}$} & \multirow[t]{3}{*}{ Part-time fully qualified teachers - Q7b2 } & \multirow[t]{3}{*}{ Q07b2 } & 0 to 100 & & \multirow[t]{3}{*}{ Percentage of part-time teachers who are fully qualified } \\
\hline & & & 997 & Ambiguous & \\
\hline & & & 999 & Mis & \\
\hline \multirow[t]{5}{*}{$\overline{\text { SC08Q01 }}$} & \multirow[t]{5}{*}{ Teacher hiring responsibility - Q8 } & \multirow[t]{5}{*}{ Q08 } & 1 & Yes & \multirow[t]{5}{*}{ School has responsibility in hiring teachers } \\
\hline & & & 2 & No & \\
\hline & & & 7 & $\mathrm{M} / \mathrm{R}$ & \\
\hline & & & 8 & N/ADM & \\
\hline & & & 9 & Mis & \\
\hline \multirow[t]{4}{*}{$\overline{\text { SC09Q01 }}$} & \multirow[t]{4}{*}{ Teaching vacancies - Q9 } & \multirow[t]{4}{*}{ Q09 } & 0 to 500 & & \multirow{4}{*}{$\begin{array}{l}\text { Number of vacant posts to be filled at the beginning of the } \\
\text { school year }\end{array}$} \\
\hline & & & 997 & Ambiguous & \\
\hline & & & 998 & N/ADM & \\
\hline & & & 999 & Mis & \\
\hline
\end{tabular}




\begin{tabular}{|c|c|c|c|c|c|}
\hline $\begin{array}{l}\text { Variable } \\
\text { short name }\end{array}$ & Variable name & Source & Value & Label & Description / notes \\
\hline \multirow[t]{4}{*}{ SC10Q01 } & \multirow[t]{4}{*}{ Fully qualified teacher - Q10a } & \multirow[t]{4}{*}{ Q10a } & 1 & Yes & \multirow[t]{4}{*}{ Vacancy was covered by employing a fully qualified teacher } \\
\hline & & & 7 & $\mathrm{M} / \mathrm{R}$ & \\
\hline & & & 8 & N/ADM & \\
\hline & & & 9 & Mis & \\
\hline \multirow{4}{*}{ SC10Q02 } & \multirow{4}{*}{ Less than full qualification - Q10b } & \multirow{4}{*}{ Q10b } & 2 & No & \multirow{4}{*}{$\begin{array}{l}\text { Vacancy was covered by employing a less than fully qualified } \\
\text { teacher }\end{array}$} \\
\hline & & & 7 & $\mathrm{M} / \mathrm{R}$ & \\
\hline & & & 8 & N/ADM & \\
\hline & & & 9 & Mis & \\
\hline \multirow[t]{4}{*}{ SC10Q03 } & \multirow[t]{4}{*}{ Course was cancelled - Q10c } & \multirow[t]{4}{*}{ Q10d } & 1 & Yes & \multirow[t]{4}{*}{ Planned course was cancelled to manage vacancies } \\
\hline & & & 2 & No & \\
\hline & & & 8 & N/ADM & \\
\hline & & & 9 & Mis & \\
\hline \multirow[t]{5}{*}{$\overline{\mathrm{SC} 10 \mathrm{Q} 04}$} & \multirow[t]{5}{*}{ Class sizes were expanded - Q10d } & \multirow[t]{5}{*}{ Q10d } & 1 & Yes & \multirow[t]{5}{*}{ Class sizes were expanded to manage vacancies } \\
\hline & & & 2 & No & \\
\hline & & & 7 & $\mathrm{M} / \mathrm{R}$ & \\
\hline & & & 8 & N/ADM & \\
\hline & & & 9 & Mis & \\
\hline$\overline{\text { SC10Q05 }}$ & Courses were added - Q10e & Q10e & 1 & Yes & Sections (courses) were added to other teachers' normal \\
\hline & & & 2 & No & teaching hours to manage vacancies \\
\hline & & & 7 & $\mathrm{M} / \mathrm{R}$ & \\
\hline & & & 8 & N/ADM & \\
\hline & & & 9 & Mis & \\
\hline$\overline{S C 11 Q 01}$ & Mother tongue - Q11a & Q11a & 1 & Yes & Mother tongue - Principal perceives difficulty to hire a fully \\
\hline & & & 2 & No & qualified upper secondary teacher \\
\hline & & & 9 & Mis & \\
\hline$\overline{S C 11 Q 02}$ & Mathematics - Q11b & Q11b & 1 & Yes & Mathematics - Principal perceives difficulty to hire a fully \\
\hline & & & 2 & No & qualified upper secondary teacher \\
\hline & & & 7 & $\mathrm{M} / \mathrm{R}$ & \\
\hline & & & 8 & N/ADM & \\
\hline & & & 9 & Mis & \\
\hline$\overline{S C 11 Q 03}$ & Foreign languages - Q11c & Q11c & 1 & Yes & Foreign languages - Principal perceives difficulty to hire a \\
\hline & & & 2 & No & fully qualified upper secondary teacher \\
\hline & & & 7 & $\mathrm{M} / \mathrm{R}$ & \\
\hline & & & 8 & $\mathrm{~N} / \mathrm{ADM}$ & \\
\hline & & & 9 & Mis & \\
\hline SC11Q04 & Social studies - Q11d & Q11d & 1 & Yes & Social studies - Principal perceives difficulty to hire a fully \\
\hline & & & 2 & No & qualified upper secondary teacher \\
\hline & & & 7 & $\mathrm{M} / \mathrm{R}$ & \\
\hline & & & 8 & N/ADM & \\
\hline & & & 9 & Mis & \\
\hline$\overline{\mathrm{SC} 11 \mathrm{Q} 05}$ & Sciences - Q11e & Q11e & 1 & Yes & Sciences - Principal perceives difficulty to hire a fully qualified \\
\hline & & & 2 & No & upper secondary teacher \\
\hline & & & 7 & $\mathrm{M} / \mathrm{R}$ & \\
\hline & & & 8 & N/ADM & \\
\hline & & & 9 & Mis & \\
\hline$\overline{\text { SC11Q06 }}$ & Technology - Q11f & Q11f & 1 & Yes & Technology - Principal perceives difficulty to hire a fully \\
\hline & & & 2 & No & qualified upper secondary teacher \\
\hline & & & 7 & $\mathrm{M} / \mathrm{R}$ & \\
\hline & & & 8 & N/ADM & \\
\hline & & & 9 & Mis & \\
\hline$\overline{\mathrm{SC} 11 \mathrm{Q} 07}$ & Arts - Q11g & Q11g & 1 & Yes & Arts - Principal perceives difficulty to hire a fully qualified \\
\hline & & & 2 & No & upper secondary teacher \\
\hline
\end{tabular}


ANNEX 4

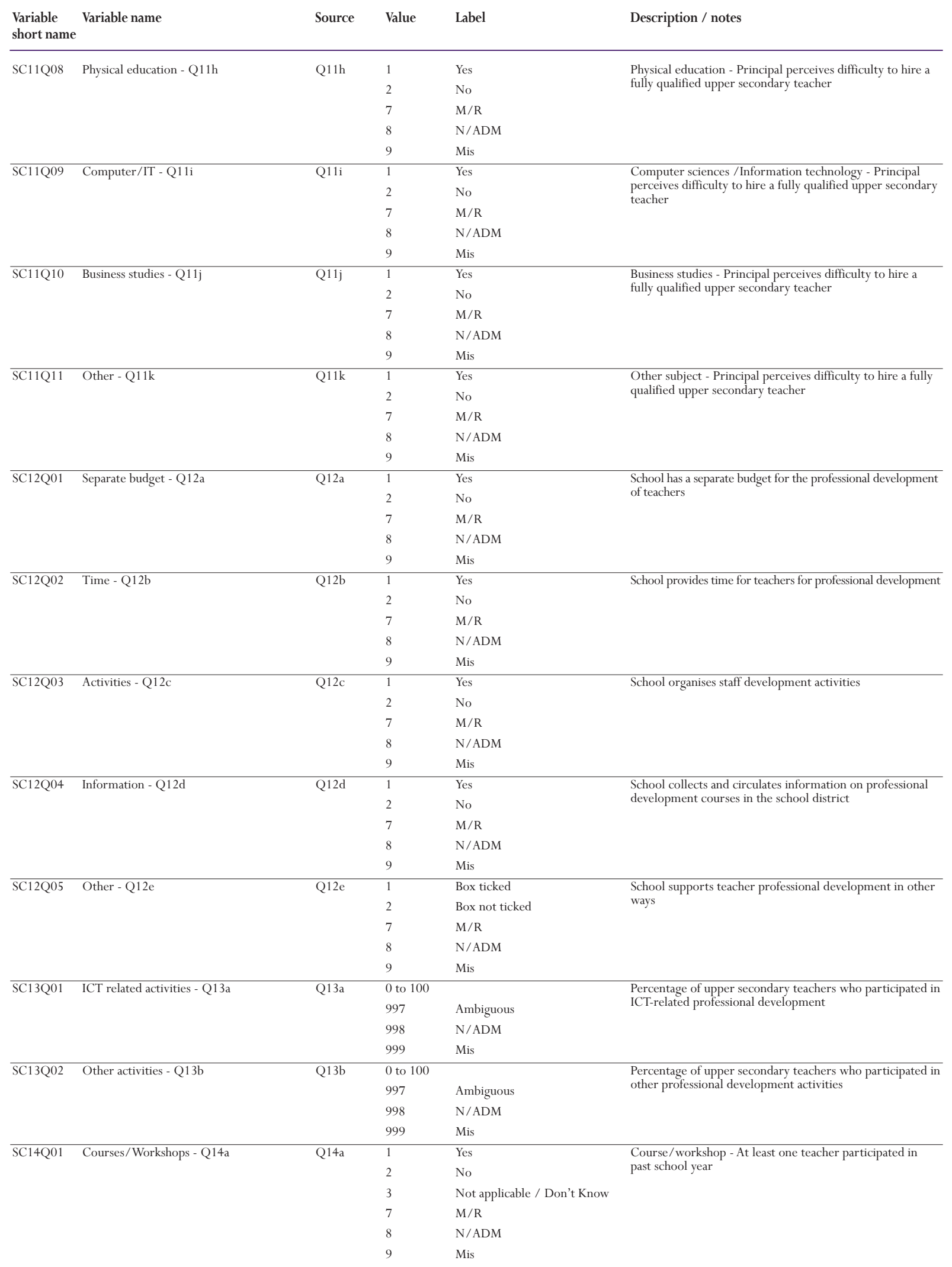




\begin{tabular}{|c|c|c|c|c|c|}
\hline $\begin{array}{l}\text { Variable } \\
\text { short name }\end{array}$ & Variable name & Source & Value & Label & Description / notes \\
\hline \multirow[t]{4}{*}{ SC14Q02 } & \multirow[t]{4}{*}{ Conferences - Q14b } & \multirow[t]{4}{*}{$\mathrm{Q} 14 \mathrm{~b}$} & 1 & Yes & \multirow{4}{*}{$\begin{array}{l}\text { Methodological or research conferences - At least one } \\
\text { teacher participated in past school year }\end{array}$} \\
\hline & & & 3 & Not applicable / Don't Know & \\
\hline & & & 7 & $\mathrm{M} / \mathrm{R}$ & \\
\hline & & & 8 & $\mathrm{~N} / \mathrm{ADM}$ & \\
\hline \multirow[t]{6}{*}{$\overline{\mathrm{SC} 14 \mathrm{Q} 03}$} & \multirow[t]{6}{*}{ Degree program - Q14c } & \multirow[t]{6}{*}{ Q14c } & 1 & Yes & \multirow{6}{*}{$\begin{array}{l}\text { Qualification or degree programme - At least one teacher } \\
\text { participated in past school year }\end{array}$} \\
\hline & & & 2 & No & \\
\hline & & & 3 & Not applicable / Don’t Know & \\
\hline & & & 7 & $\mathrm{M} / \mathrm{R}$ & \\
\hline & & & 8 & N/ADM & \\
\hline & & & 9 & Mis & \\
\hline \multirow[t]{5}{*}{ SC14Q04 } & \multirow[t]{5}{*}{ Visits to other schools - Q14d } & \multirow[t]{5}{*}{ Q14d } & 1 & Yes & \multirow{5}{*}{$\begin{array}{l}\text { Observational visits to other schools - At least one teacher } \\
\text { participated in past school year }\end{array}$} \\
\hline & & & 3 & Not applicable / Don't Know & \\
\hline & & & 7 & $\mathrm{M} / \mathrm{R}$ & \\
\hline & & & 8 & N/ADM & \\
\hline & & & 9 & Mis & \\
\hline \multirow[t]{6}{*}{$\overline{\mathrm{SC} 14 \mathrm{Q} 05}$} & \multirow[t]{6}{*}{ Regularly-scheduled collaboration - Q14e } & \multirow[t]{6}{*}{ Q14e } & 1 & Yes & \multirow{6}{*}{$\begin{array}{l}\text { Regularly scheduled collaboration among teachers - At least } \\
\text { one teacher participated in past school year }\end{array}$} \\
\hline & & & 2 & No & \\
\hline & & & 3 & Not applicable / Don't Know & \\
\hline & & & 7 & $\mathrm{M} / \mathrm{R}$ & \\
\hline & & & 8 & N/ADM & \\
\hline & & & 9 & Mis & \\
\hline \multirow[t]{4}{*}{$\overline{\text { SC14Q06 }}$} & \multirow[t]{4}{*}{$\begin{array}{l}\text { Mentoring/peer observation/coaching } \\
\text { - Q14f }\end{array}$} & Q14f & 1 & Yes & $\begin{array}{l}\text { Mentoring and/or peer observation - At least one teacher } \\
\text { participated in past school year }\end{array}$ \\
\hline & & & 2 & No & \\
\hline & & & 3 & Not applicable / Don’t Know & \\
\hline & & & 9 & Mis & \\
\hline$\overline{\mathrm{SC} 14 \mathrm{Q} 07}$ & Research/development - Q14g & Q14g & 1 & Yes & Mentoring and/or peer observation and coaching - At least \\
\hline & & & 2 & No & one teacher participated in past school year \\
\hline & & & 3 & Not applicable / Don’t Know & \\
\hline & & & 7 & $\mathrm{M} / \mathrm{R}$ & \\
\hline & & & 8 & $\mathrm{~N} / \mathrm{ADM}$ & \\
\hline & & & 9 & Mis & \\
\hline$\overline{\mathrm{SC} 14 \mathrm{Q} 08}$ & Participation in a network - Q14h & Q14h & 1 & Yes & Participation in a network of teachers - At least one teacher \\
\hline & & & 2 & No & participated in past school year \\
\hline & & & 3 & Not applicable / Don't Know & \\
\hline & & & 7 & $\mathrm{M} / \mathrm{R}$ & \\
\hline & & & 8 & N/ADM & \\
\hline & & & 9 & Mis & \\
\hline$\overline{\text { SC14Q09 }}$ & Visits to companies/employers - Q14i & Q14i & 1 & Yes & Visit to companies/employers - At least one teacher par- \\
\hline & & & 2 & No & ticipated in past school year \\
\hline & & & 3 & Not applicable / Don’t Know & \\
\hline & & & 7 & $\mathrm{M} / \mathrm{R}$ & \\
\hline & & & 8 & N/ADM & \\
\hline & & & 9 & Mis & \\
\hline$\overline{\text { SC15Q01 }}$ & Cancelled (not held) - Q15a & Q15a & 0 to 100 & & Percentage of of class periods cancelled because of the \\
\hline & & & 997 & Ambiguous & absence of the assigned teacher \\
\hline & & & 998 & N/ADM & \\
\hline & & & 999 & Mis & \\
\hline$\overline{\mathrm{SC} 15 \mathrm{Q} 02}$ & Covered by other teacher - Q15b & Q15b & 0 to 100 & & Percentage of of class periods covered by another teacher \\
\hline & & & 997 & Ambiguous & because of the absence of the assigned teacher \\
\hline & & & 998 & N/ADM & \\
\hline & & & 999 & Mis & \\
\hline
\end{tabular}


ANNEX 4

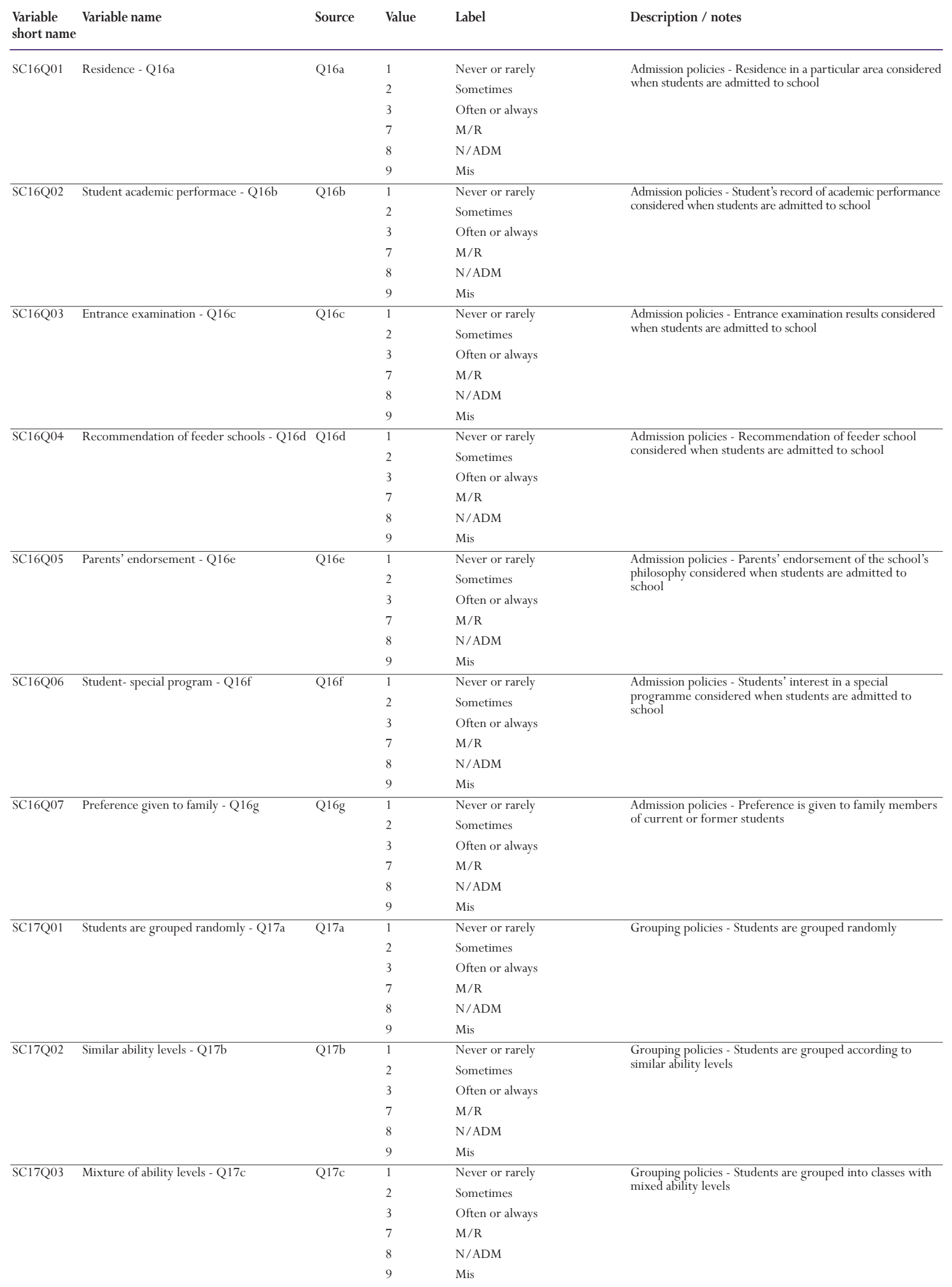




\begin{tabular}{|c|c|c|c|c|c|}
\hline $\begin{array}{l}\text { Variable } \\
\text { short name }\end{array}$ & Variable name & Source & Value & Label & Description / notes \\
\hline \multirow[t]{4}{*}{ SC17Q04 } & \multirow[t]{4}{*}{ Special expertise of teachers - Q17d } & \multirow[t]{4}{*}{$\mathrm{Q} 17 \mathrm{~d}$} & 1 & Never or rarely & \multirow{4}{*}{$\begin{array}{l}\text { Grouping policies - Students are assigned to classes according } \\
\text { to the special expertise of teachers }\end{array}$} \\
\hline & & & 3 & Often or always & \\
\hline & & & 7 & $\mathrm{M} / \mathrm{R}$ & \\
\hline & & & 8 & $\mathrm{~N} / \mathrm{ADM}$ & \\
\hline \multirow[t]{6}{*}{$\overline{\text { SC17Q05 }}$} & \multirow[t]{6}{*}{ Similar ages - Q17e } & \multirow[t]{6}{*}{ Q17e } & 1 & Never or rarely & \multirow{6}{*}{$\begin{array}{l}\text { Grouping policies - Students are assigned to classes composed } \\
\text { of students of similar ages }\end{array}$} \\
\hline & & & 2 & Sometimes & \\
\hline & & & 3 & Often or always & \\
\hline & & & 7 & $\mathrm{M} / \mathrm{R}$ & \\
\hline & & & 8 & N/ADM & \\
\hline & & & 9 & Mis & \\
\hline \multirow[t]{5}{*}{ SC17Q06 } & \multirow[t]{5}{*}{ Choice of program/subjects - Q17f } & \multirow[t]{5}{*}{ Q17f } & 1 & Never or rarely & \multirow{5}{*}{$\begin{array}{l}\text { Grouping policies - Students are assigned to classed according } \\
\text { to choice of programme or subject }\end{array}$} \\
\hline & & & 3 & Often or always & \\
\hline & & & 7 & $\mathrm{M} / \mathrm{R}$ & \\
\hline & & & 8 & N/ADM & \\
\hline & & & 9 & Mis & \\
\hline \multirow[t]{6}{*}{$\overline{\mathrm{SC} 17 \mathrm{Q} 07}$} & \multirow[t]{6}{*}{ Requests of parents/guardians - Q17g } & \multirow[t]{6}{*}{ Q17g } & 1 & Never or rarely & \multirow{6}{*}{$\begin{array}{l}\text { Grouping policies - Students are grouped according to the } \\
\text { request of parents }\end{array}$} \\
\hline & & & 2 & Sometimes & \\
\hline & & & 3 & Often or always & \\
\hline & & & 7 & $\mathrm{M} / \mathrm{R}$ & \\
\hline & & & 8 & N/ADM & \\
\hline & & & 9 & Mis & \\
\hline SC18Q01 & Student's choice of S/M - Q18a1 & Q18a1 & 1 & Yes & Student's choice of subjects/modules - Record kept \\
\hline & & & 2 & No & centrally \\
\hline & & & 7 & $\mathrm{M} / \mathrm{R}$ & \\
\hline & & & 8 & N/ADM & \\
\hline SC18Q02 & Teachers-acccess to student's choice - & Q18a2 & 1 & Yes & Student's choice of subjects/modules - All teachers have \\
\hline & Q18a2 & & 2 & No & access to records \\
\hline & & & 7 & $\mathrm{M} / \mathrm{R}$ & \\
\hline & & & 8 & N/ADM & \\
\hline & & & 9 & Mis & \\
\hline SC18Q03 & Student performance - Q18b1 & Q18b1 & 1 & Yes & Student's performance in school - Record kept centrally \\
\hline & & & 2 & No & \\
\hline & & & 7 & $\mathrm{M} / \mathrm{R}$ & \\
\hline & & & 8 & N/ADM & \\
\hline & & & 9 & Mis & \\
\hline$\overline{\mathrm{SC} 18 \mathrm{Q} 04}$ & Teachers access - Std. performance - & Q18b2 & 1 & Yes & Student's performance in school - All teachers have access \\
\hline & Q18b2 & & 2 & No & to records \\
\hline & & & 7 & $\mathrm{M} / \mathrm{R}$ & \\
\hline & & & 8 & N/ADM & \\
\hline & & & 9 & Mis & \\
\hline$\overline{S C 18 Q 05}$ & Behavioural problems - Q18c1 & Q18c1 & 1 & Yes & Behavioural problems - Record kept centrally \\
\hline & & & 2 & No & \\
\hline & & & 7 & $\mathrm{M} / \mathrm{R}$ & \\
\hline & & & 8 & N/ADM & \\
\hline & & & 9 & Mis & \\
\hline$\overline{\text { SC18Q06 }}$ & Teachers access - behavioural problems - & Q18c2 & 1 & Yes & Behavioural problems - All teachers have access to records \\
\hline & Q18c2 & & 2 & No & \\
\hline & & & 7 & $\mathrm{M} / \mathrm{R}$ & \\
\hline & & & 8 & N/ADM & \\
\hline & & & 9 & Mis & \\
\hline$\overline{\text { SC18Q07 }}$ & Student absenteeism - Q18d1 & Q18d1 & 1 & Yes & Student's absenteeism - Record kept centrally \\
\hline & & & 2 & No & \\
\hline & & & 7 & $\mathrm{M} / \mathrm{R}$ & \\
\hline & & & 8 & $\mathrm{~N} / \mathrm{ADM}$ & \\
\hline
\end{tabular}


ANNEX 4

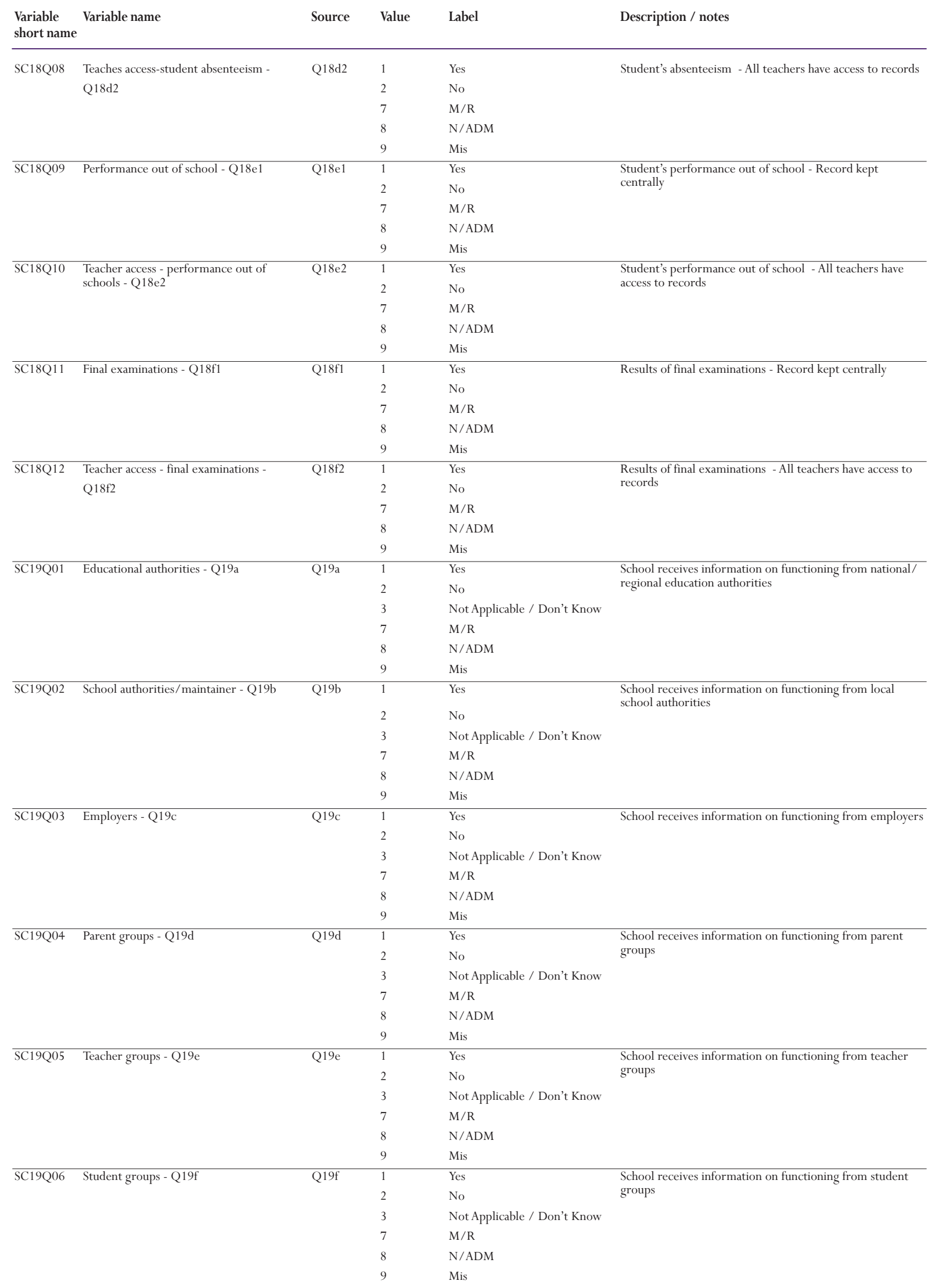




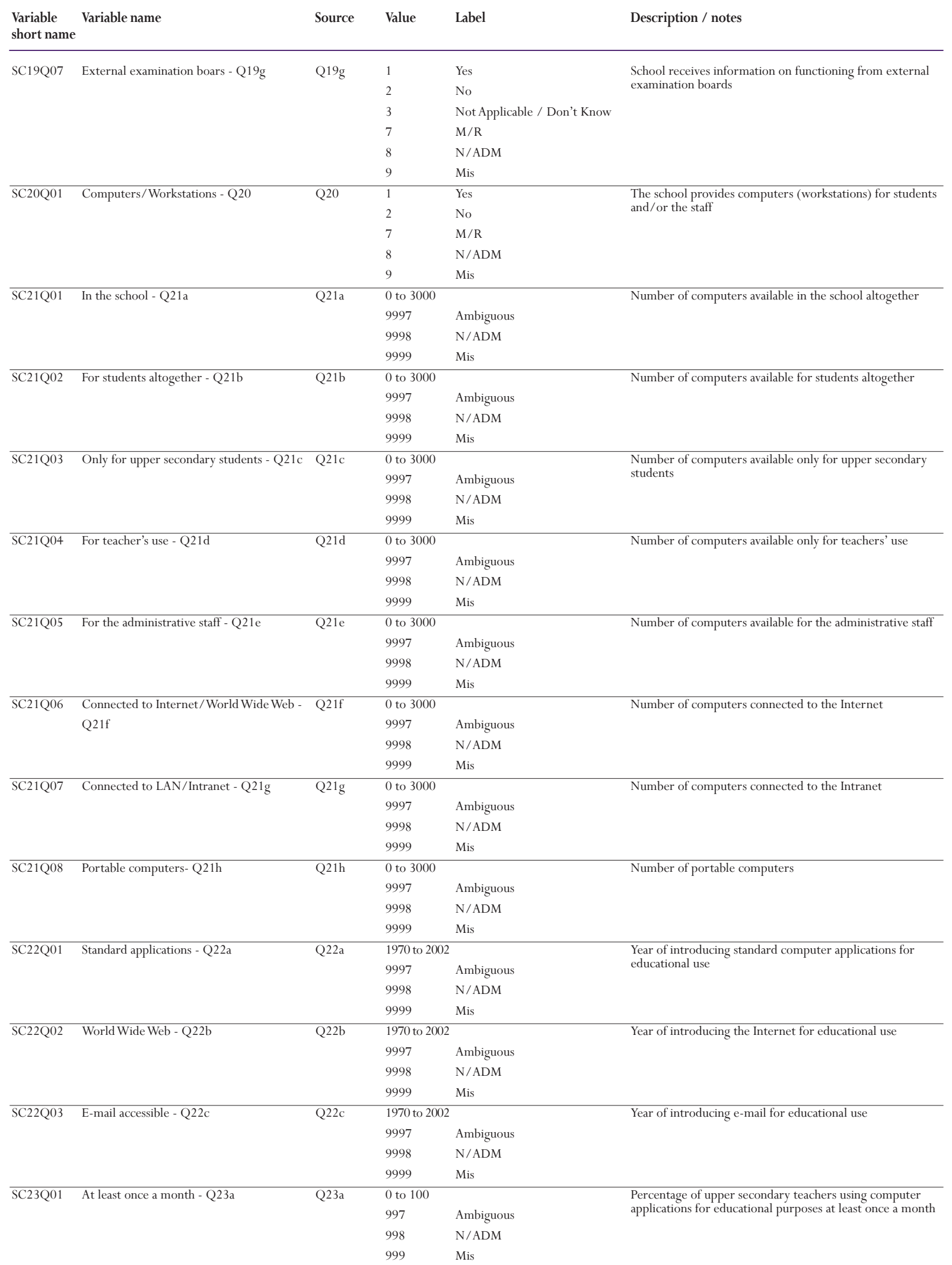


ANNEX 4

\begin{tabular}{|c|c|c|c|c|c|}
\hline $\begin{array}{l}\text { Variable } \\
\text { short name }\end{array}$ & Variable name & Source & Value & Label & Description / notes \\
\hline \multirow[t]{4}{*}{ SC23Q02 } & \multirow[t]{4}{*}{ The WWW - Q23b } & \multirow[t]{4}{*}{ Q23b } & 0 to 100 & & \multirow{4}{*}{$\begin{array}{l}\text { Percentage of upper secondary teachers using the Internet } \\
\text { for educational purposes at least once a month }\end{array}$} \\
\hline & & & 997 & Ambiguous & \\
\hline & & & 998 & N/ADM & \\
\hline & & & 999 & Mis & \\
\hline \multirow[t]{4}{*}{$\overline{\mathrm{SC} 23 \mathrm{Q} 03}$} & \multirow[t]{4}{*}{ E-mail for educational purposes - Q23c } & \multirow[t]{4}{*}{ Q23c } & 0 to 100 & & \multirow{4}{*}{$\begin{array}{l}\text { Percentage of upper secondary teachers using e-mail for } \\
\text { educational purposes at least once a month }\end{array}$} \\
\hline & & & 997 & Ambiguous & \\
\hline & & & 998 & N/ADM & \\
\hline & & & 999 & Mis & \\
\hline \multirow[t]{6}{*}{$\overline{\mathrm{SC} 24 \mathrm{Q} 01}$} & \multirow[t]{6}{*}{ Operating a computer - Q24a } & \multirow[t]{6}{*}{ Q24a } & 1 & Yes & \multirow{6}{*}{$\begin{array}{l}\text { Operating a computer - Part of students' assignment at } \\
\text { least once a month }\end{array}$} \\
\hline & & & 2 & No & \\
\hline & & & 3 & Not applicable / Don't Know & \\
\hline & & & 7 & $\mathrm{M} / \mathrm{R}$ & \\
\hline & & & 8 & N/ADM & \\
\hline & & & 9 & Mis & \\
\hline \multirow[t]{6}{*}{$\overline{\text { SC24Q02 }}$} & \multirow[t]{6}{*}{ With a word processor - Q24b } & \multirow[t]{6}{*}{ Q24b } & 1 & Yes & \multirow{6}{*}{$\begin{array}{l}\text { Writing documents with a word processor - Part of students' } \\
\text { assignment at least once a month }\end{array}$} \\
\hline & & & 2 & No & \\
\hline & & & 3 & Not applicable / Don't Know & \\
\hline & & & 7 & $\mathrm{M} / \mathrm{R}$ & \\
\hline & & & 8 & $\mathrm{~N} / \mathrm{ADM}$ & \\
\hline & & & 9 & Mis & \\
\hline \multirow[t]{6}{*}{$\overline{\mathrm{SC} 24 \mathrm{Q} 03}$} & \multirow[t]{6}{*}{ With graphical program - Q24c } & Q24c & 1 & Yes & Making illustrations with graphical programmes - Part of \\
\hline & & & 2 & No & students' assignment at least once a month \\
\hline & & & 3 & Not applicable / Don't Know & \\
\hline & & & 7 & $\mathrm{M} / \mathrm{R}$ & \\
\hline & & & 8 & N/ADM & \\
\hline & & & 9 & Mis & \\
\hline$\overline{\mathrm{SC} 24 Q 04}$ & With spreadsheet programs - Q24d & Q24d & 1 & Yes & Calculating with spreadsheet programmes - Part of students' \\
\hline & & & 2 & No & assignment at least once a month \\
\hline & & & 3 & Not applicable / Don't Know & \\
\hline & & & 7 & $\mathrm{M} / \mathrm{R}$ & \\
\hline & & & 8 & $\mathrm{~N} / \mathrm{ADM}$ & \\
\hline & & & 9 & Mis & \\
\hline$\overline{\text { SC24Q05 }}$ & Writing programs - Q24e & Q24e & 1 & Yes & Writing programmes - Part of students' assignment at least \\
\hline & & & 2 & No & once a month \\
\hline & & & 3 & Not applicable / Don't Know & \\
\hline & & & 7 & $\mathrm{M} / \mathrm{R}$ & \\
\hline & & & 8 & $\mathrm{~N} / \mathrm{ADM}$ & \\
\hline & & & 9 & Mis & \\
\hline$\overline{\text { SC24Q06 }}$ & Communicating via e-mail - Q24f & Q24f & 1 & Yes & Communicating via e-mail with teachers and other students \\
\hline & & & 2 & No & - Part of students' assignment at least once a month \\
\hline & & & 3 & Not applicable / Don't Know & \\
\hline & & & 7 & $\mathrm{M} / \mathrm{R}$ & \\
\hline & & & 8 & N/ADM & \\
\hline & & & 9 & Mis & \\
\hline$\overline{S C 24 Q 07}$ & Electronic forms of information - Q24g & Q24g & 1 & Yes & Sending, searching for and using electronic forms of information \\
\hline & & & 2 & No & - Part of students' assignment at least once a month \\
\hline & & & 3 & Not applicable / Don't Know & \\
\hline & & & 7 & $\mathrm{M} / \mathrm{R}$ & \\
\hline & & & 8 & N/ADM & \\
\hline & & & 9 & Mis & \\
\hline$\overline{\text { SC24Q08 }}$ & Using educational software - Q24h & Q24h & 1 & Yes & Using educational software (e.g., taking tests) - Part of \\
\hline & & & 2 & No & students' assignment at least once a month \\
\hline & & & 3 & Not applicable / Don't Know & \\
\hline & & & 7 & $\mathrm{M} / \mathrm{R}$ & \\
\hline & & & 8 & N/ADM & \\
\hline & & & 9 & Mis & \\
\hline
\end{tabular}




\begin{tabular}{|c|c|c|c|c|c|}
\hline $\begin{array}{l}\text { Variable } \\
\text { short name }\end{array}$ & Variable name & Source & Value & Label & Description / notes \\
\hline \multirow[t]{6}{*}{ SC25Q01 } & \multirow[t]{6}{*}{$\begin{array}{l}\text { Develop skill of independent learning } \\
\text { - Q25a }\end{array}$} & \multirow[t]{6}{*}{ Q25a } & 1 & Not at all & \multirow[t]{6}{*}{$\begin{array}{l}\text { Educational purposes of ICT use - Computers used to } \\
\text { develop skills of independent learning }\end{array}$} \\
\hline & & & 2 & A little & \\
\hline & & & 3 & A lot & \\
\hline & & & 7 & $\mathrm{M} / \mathrm{R}$ & \\
\hline & & & 8 & N/ADM & \\
\hline & & & 9 & Mis & \\
\hline \multirow[t]{6}{*}{$\overline{\mathrm{SC} 25 \mathrm{Q} 02}$} & \multirow{6}{*}{ Provide additional instruction...- Q25b } & \multirow[t]{6}{*}{ Q25b } & 1 & Not at all & \multirow{6}{*}{$\begin{array}{l}\text { Educational purposes of ICT use - Computers used to } \\
\text { provide additional instruction and practising opportunities } \\
\text { for students with special needs }\end{array}$} \\
\hline & & & 2 & A little & \\
\hline & & & 3 & A lot & \\
\hline & & & 7 & $\mathrm{M} / \mathrm{R}$ & \\
\hline & & & 8 & N/ADM & \\
\hline & & & 9 & Mis & \\
\hline \multirow{5}{*}{$\overline{\mathrm{SC} 25 \mathrm{Q} 03}$} & \multirow{5}{*}{ Allow students to learn/work ... - Q25c } & \multirow{5}{*}{ Q25c } & 2 & A little & \multirow{5}{*}{$\begin{array}{l}\text { Educational purposes of ICT use - Computers used to allow } \\
\text { students to learn/work at their own pace during lessons }\end{array}$} \\
\hline & & & 3 & A lot & \\
\hline & & & 7 & $\mathrm{M} / \mathrm{R}$ & \\
\hline & & & 8 & N/ADM & \\
\hline & & & 9 & Mis & \\
\hline \multirow[t]{6}{*}{$\overline{\mathrm{SC} 25 \mathrm{Q} 04}$} & \multirow[t]{6}{*}{ Combine parts of school subjects - Q25d } & \multirow[t]{6}{*}{ Q25d } & 1 & Not at all & \multirow{6}{*}{$\begin{array}{l}\text { Educational purposes of ICT use - Computers used to } \\
\text { combine parts of school subjects with one another }\end{array}$} \\
\hline & & & 2 & A little & \\
\hline & & & 3 & A lot & \\
\hline & & & 7 & $\mathrm{M} / \mathrm{R}$ & \\
\hline & & & 8 & N/ADM & \\
\hline & & & 9 & Mis & \\
\hline \multirow[t]{4}{*}{$\overline{\mathrm{SC} 25 \mathrm{Q} 05}$} & \multirow[t]{4}{*}{ Learning by simulation - Q25e } & Q25e & 1 & Not at all & Educational purposes of ICT use - Computers used to to \\
\hline & & & 2 & A little & create opportunities for learning by simulation \\
\hline & & & 3 & A lot & \\
\hline & & & 9 & Mis & \\
\hline$\overline{\mathrm{SC} 25 \mathrm{Q} 06}$ & Obtain information from the internet - Q25f & Q25f & 1 & Not at all & Educational purposes of ICT use - Computers used to \\
\hline & & & 2 & A little & obtain information from the Internet \\
\hline & & & 3 & A lot & \\
\hline & & & 7 & $\mathrm{M} / \mathrm{R}$ & \\
\hline & & & 8 & N/ADM & \\
\hline & & & 9 & Mis & \\
\hline$\overline{\mathrm{SC} 26 \mathrm{Q} 01}$ & Donation/exchange/joint purchase & Q26a1 & 1 & Ticked & Donation, exchange and/or joint purchase of ICT-related \\
\hline & $\begin{array}{l}\text { - None - } \\
\text { Q26a1 }\end{array}$ & & 2 & Not Ticked & items - School has NO co-operation \\
\hline & & & 8 & $\mathrm{~N} / \mathrm{ADM}$ & \\
\hline & & & 9 & Mis & \\
\hline$\overline{S C 26 Q 02}$ & Donation/exchange/joint purchase & Q26a2 & 1 & Ticked & Donation, exchange and/or joint purchase of ICT-related \\
\hline & - other education institution Q26a2 & & 2 & Not Ticked & items - School co-operates with other education institutions \\
\hline & & & 8 & N/ADM & \\
\hline & & & 9 & Mis & \\
\hline$\overline{\mathrm{SC} 26 \mathrm{Q} 03}$ & Donation/exchange/joint purchase & Q26a3 & 1 & Ticked & Donation, exchange and/or joint purchase of ICT-related \\
\hline & - Private companies - Q26a3 & & 2 & Not Ticked & items - School co-operates with private companies \\
\hline & & & 8 & $\mathrm{~N} / \mathrm{ADM}$ & \\
\hline & & & 9 & Mis & \\
\hline$\overline{\mathrm{SC} 26 \mathrm{Q} 04}$ & Donation/exchange/joint purchase & Q26a4 & 1 & Ticked & Donation, exchange and/or joint purchase of ICT-related \\
\hline & - other organisations - Q26a4 & & 2 & Not Ticked & items - School co-operates with other organisations \\
\hline & & & 8 & N/ADM & \\
\hline & & & 9 & Mis & \\
\hline$\overline{\mathrm{SC} 26 \mathrm{Q} 05}$ & Joint educational experience - None & Q26b1 & 1 & Ticked & Joint educational experience through ICT - School has NO \\
\hline & Q26b1 & & 2 & Not Ticked & co-operation \\
\hline & & & 8 & N/ADM & \\
\hline & & & 9 & Mis & \\
\hline
\end{tabular}


ANNEX 4

\begin{tabular}{|c|c|c|c|c|c|}
\hline $\begin{array}{l}\text { Variable } \\
\text { short name }\end{array}$ & Variable name & Source & Value & Label & Description / notes \\
\hline \multirow[t]{4}{*}{ SC26Q06 } & \multirow{4}{*}{$\begin{array}{l}\text { Joint educational experience } \\
\text { - other education institution - Q26b2 }\end{array}$} & \multirow[t]{4}{*}{ Q26b2 } & 1 & Ticked & \multirow{4}{*}{$\begin{array}{l}\text { Joint educational experience through ICT - School co-operates } \\
\text { with other education institutions }\end{array}$} \\
\hline & & & 2 & Not Ticked & \\
\hline & & & 8 & N/ADM & \\
\hline & & & 9 & Mis & \\
\hline \multirow[t]{4}{*}{ SC26Q07 } & \multirow{4}{*}{$\begin{array}{l}\text { Joint educational experience } \\
\text { - Private companies - Q26b3 }\end{array}$} & \multirow[t]{4}{*}{ Q26b3 } & 1 & Ticked & \multirow{4}{*}{$\begin{array}{l}\text { Joint educational experience through ICT - School co-operates } \\
\text { with private companies }\end{array}$} \\
\hline & & & 2 & Not Ticked & \\
\hline & & & 8 & N/ADM & \\
\hline & & & 9 & Mis & \\
\hline \multirow[t]{4}{*}{ SC26Q08 } & \multirow{4}{*}{$\begin{array}{l}\text { Joint educational experience } \\
\text { - other organisations - Q26b4 }\end{array}$} & \multirow[t]{4}{*}{ Q26b4 } & 1 & Ticked & \multirow{4}{*}{$\begin{array}{l}\text { Joint educational experience through ICT - School co-operates } \\
\text { with other organisations }\end{array}$} \\
\hline & & & 2 & Not Ticked & \\
\hline & & & 8 & N/ADM & \\
\hline & & & 9 & Mis & \\
\hline \multirow{3}{*}{$\overline{S C 26 Q 09}$} & \multirow{3}{*}{$\begin{array}{l}\text { Professional development ICT - None } \\
\text { Q26c1 }\end{array}$} & \multirow{3}{*}{ Q26c1 } & 2 & Not Ticked & \multirow{3}{*}{ Professional development in ICT - School has NO co-operation } \\
\hline & & & 8 & N/ADM & \\
\hline & & & 9 & Mis & \\
\hline \multirow[t]{4}{*}{$\overline{S C 26 Q 10}$} & \multirow{4}{*}{$\begin{array}{l}\text { Professional development ICT } \\
\text { - other education institutions - Q26c2 }\end{array}$} & Q26c2 & 1 & Ticked & Professional development in ICT - School co-operates with \\
\hline & & & 2 & Not Ticked & \\
\hline & & & 8 & N/ADM & \\
\hline & & & 9 & Mis & \\
\hline SC26Q11 & Professional development ICT & Q26c3 & 1 & Ticked & Professional development in ICT - School co-operates with \\
\hline & & & 2 & Not Ticked & \\
\hline & & & 8 & N/ADM & \\
\hline & & & 9 & Mis & \\
\hline SC26Q12 & Professional development ICT & Q26c4 & 1 & Ticked & Professional development in ICT - School co-operates with \\
\hline & - other organisations - Q26c4 & & 2 & Not Ticked & other organisations \\
\hline & & & 8 & N/ADM & \\
\hline & & & 9 & Mis & \\
\hline & Q26d1 & & 2 & Not Ticked & has NO co-operation \\
\hline & & & 8 & $\mathrm{~N} / \mathrm{ADM}$ & \\
\hline & & & 9 & Mis & \\
\hline SC26Q14 & Other development activities ICT & Q26d2 & 1 & Ticked & Other development activities with regard to ICT - School \\
\hline & - other education institutions - Q26d2 & & 2 & Not Ticked & co-operates with other education institutions \\
\hline & & & 8 & N/ADM & \\
\hline & & & 9 & Mis & \\
\hline SC26Q15 & Other development activities ICT & Q26d3 & 1 & Ticked & Other development activities with regard to ICT - School \\
\hline & - Private companies - Q26d3 & & 2 & Not Ticked & co-operates with private companies \\
\hline & & & 8 & N/ADM & \\
\hline & & & 9 & Mis & \\
\hline$\overline{S C 26 Q 16}$ & Other development activities ICT & Q26d4 & 1 & Ticked & Other development activities with regard to ICT - School \\
\hline & & & 2 & Not Ticked & co-operates with other organisations \\
\hline & & & 8 & $\mathrm{~N} / \mathrm{ADM}$ & \\
\hline & & & 9 & Mis & \\
\hline SC26Q17 & $\begin{array}{l}\text { Joint computer network...- None } \\
\text { Q26e1 }\end{array}$ & Q26e1 & 1 & Ticked & $\begin{array}{l}\text { Joint computer network or system maintenance - School } \\
\text { has NO co-operation }\end{array}$ \\
\hline & & & 2 & Not Ticked & \\
\hline & & & 8 & N/ADM & \\
\hline & & & 9 & Mis & \\
\hline SC26Q18 & Joint computer network. & Q26e2 & 1 & Ticked & Joint computer network or system maintenance - School \\
\hline & - other education institutions - Q26e2 & & 2 & Not Ticked & co-operates with other education institutions \\
\hline & & & 8 & N/ADM & \\
\hline & & & 9 & Mis & \\
\hline SC26Q19 & Joint computer network. & Q26e3 & 1 & Ticked & Joint computer network or system maintenance - School \\
\hline & - Private companies - Q26e3 & & 2 & Not Ticked & co-operates with private companies \\
\hline & & & 8 & N/ADM & \\
\hline & & & 9 & Mis & \\
\hline
\end{tabular}




\begin{tabular}{|c|c|c|c|c|c|}
\hline $\begin{array}{l}\text { Variable } \\
\text { short name }\end{array}$ & Variable name & Source & Value & Label & Description / notes \\
\hline \multirow[t]{4}{*}{ SC26Q20 } & \multirow{4}{*}{$\begin{array}{l}\text { Joint computer network. } \\
\text { - other organisations - Q26e4 }\end{array}$} & \multirow[t]{4}{*}{ Q26e4 } & 1 & Ticked & \multirow{4}{*}{$\begin{array}{l}\text { Joint computer network or system maintenance - School } \\
\text { co-operates with other organisations }\end{array}$} \\
\hline & & & 2 & NotTicked & \\
\hline & & & 8 & N/ADM & \\
\hline & & & 9 & Mis & \\
\hline \multirow[t]{4}{*}{$\overline{S C 26 Q 21}$} & \multirow[t]{4}{*}{ Delivery of instruction - None - Q26f1 } & \multirow[t]{4}{*}{ Q26f1 } & 1 & Ticked & \multirow[t]{4}{*}{ Delivery of instruction - School has NO co-operation } \\
\hline & & & 2 & Not Ticked & \\
\hline & & & 8 & N/ADM & \\
\hline & & & 9 & Mis & \\
\hline \multirow{4}{*}{$\overline{S C 26 Q 22}$} & \multirow{4}{*}{$\begin{array}{l}\text { Delivery of instruction - other education } \\
\text { institutions - Q26f2 }\end{array}$} & \multirow[t]{4}{*}{ Q26f2 } & 1 & Ticked & \multirow{4}{*}{$\begin{array}{l}\text { Delivery of instruction - School co-operates with other } \\
\text { education institutions }\end{array}$} \\
\hline & & & 2 & Not Ticked & \\
\hline & & & 8 & $\mathrm{~N} / \mathrm{ADM}$ & \\
\hline & & & 9 & Mis & \\
\hline \multirow{3}{*}{$\overline{S C 26 Q 23}$} & \multirow{3}{*}{$\begin{array}{l}\text { Delivery of instruction- Private companies } \\
\text { - Q26f3 }\end{array}$} & \multirow{3}{*}{ Q26f3 } & 2 & Not Ticked & \multirow{3}{*}{$\begin{array}{l}\text { Delivery of instruction - School co-operates with private } \\
\text { companies }\end{array}$} \\
\hline & & & 8 & N/ADM & \\
\hline & & & 9 & Mis & \\
\hline \multirow[t]{4}{*}{$\overline{\text { SC26Q24 }}$} & Delivery of instruction & Q26f4 & 1 & Ticked & Delivery of instruction - School co-operates with other \\
\hline & - other organisations - Q26f4 & & 2 & Not Ticked & organisations \\
\hline & & & 8 & N/ADM & \\
\hline & & & 9 & Mis & \\
\hline SC26Q25 & Other - Q26g & Q26g & 1 & None & Other \\
\hline & & & 8 & N/ADM & \\
\hline & & & 9 & Mis & \\
\hline$\overline{\mathrm{SC} 27 \mathrm{Q} 01}$ & Insufficient number of computers for & Q27a & 1 & Obstacle & Obstacle to reaching the school's ICT related goals: \\
\hline & teacher - Q27a & & 2 & Not an obstacle & insufficient number of computers for teachers' use \\
\hline & & & 7 & $\mathrm{M} / \mathrm{R}$ & \\
\hline & & & 8 & N/ADM & \\
\hline & & & 9 & Mis & \\
\hline & & & 2 & Not an obstacle & \\
\hline & & & 7 & $\mathrm{M} / \mathrm{R}$ & \\
\hline & & & 8 & N/ADM & \\
\hline & & & 9 & Mis & \\
\hline$\overline{\mathrm{SC} 27 \mathrm{Q} 03}$ & Outdated computers - Q27c & Q27c & 1 & Obstacle & Obstacle to reaching the school's ICT related goals: \\
\hline & & & 2 & Not an obstacle & outdated computers \\
\hline & & & 7 & $\mathrm{M} / \mathrm{R}$ & \\
\hline & & & 8 & N/ADM & \\
\hline & & & 9 & Mis & \\
\hline$\overline{\mathrm{SC} 27 \mathrm{Q} 04}$ & Shortage of maintenance/technical support & Q28d & 1 & Obstacle & Obstacle to reaching the school's ICT related goals: \\
\hline & - Q27d & & 2 & Not an obstacle & shortage of maintenance and technical support \\
\hline & & & 7 & $\mathrm{M} / \mathrm{R}$ & \\
\hline & & & 8 & N/ADM & \\
\hline & & & 9 & Mis & \\
\hline SC27Q05 & Not enough copies of software - Q27e & Q27e & 1 & Obstacle & Obstacle to reaching the school's ICT related goals: not \\
\hline & & & 2 & Not an obstacle & enough copies of software for educational purposes \\
\hline & & & 7 & $\mathrm{M} / \mathrm{R}$ & \\
\hline & & & 8 & N/ADM & \\
\hline & & & 9 & Mis & \\
\hline$\overline{\mathrm{SC} 27 \mathrm{Q} 06}$ & Not enough variety of software - Q27f & Q27f & 1 & Obstacle & Obstacle to reaching the school's ICT related goals: not \\
\hline & & & 2 & Not an obstacle & enough variety of software \\
\hline & & & 7 & $\mathrm{M} / \mathrm{R}$ & \\
\hline & & & 8 & N/ADM & \\
\hline & & & 9 & Mis & \\
\hline SC27Q07 & Poor quality of available software - Q27g & Q27g & 1 & Obstacle & Obstacle to reaching the school's ICT related goals: poor \\
\hline & & & 2 & Not an obstacle & quality of available software \\
\hline & & & 7 & $\mathrm{M} / \mathrm{R}$ & \\
\hline & & & 8 & N/ADM & \\
\hline
\end{tabular}


ANNEX 4

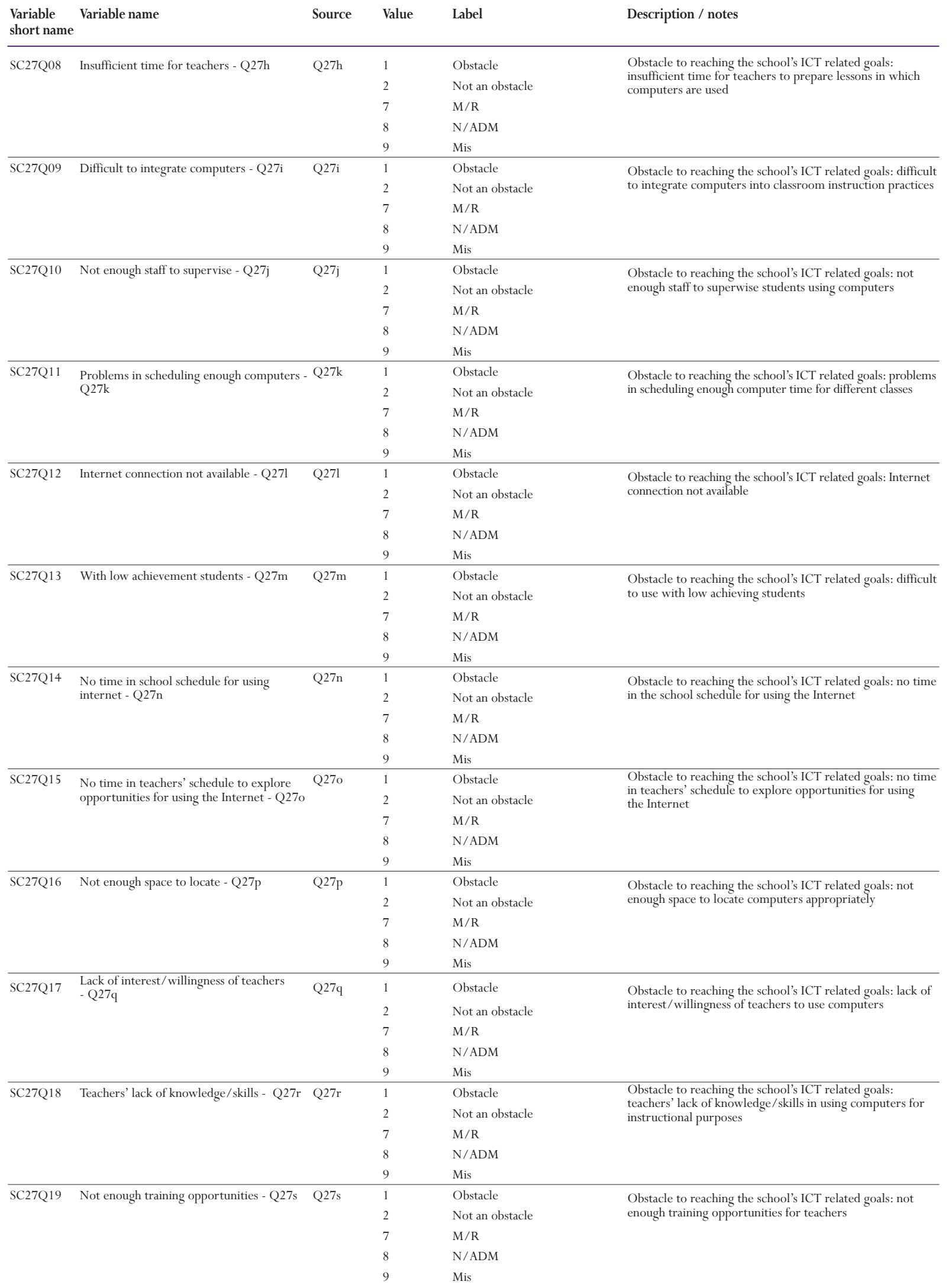




\begin{tabular}{|c|c|c|c|c|c|}
\hline $\begin{array}{l}\text { Variable } \\
\text { short name }\end{array}$ & Variable name & Source & Value & Label & Description / notes \\
\hline \multirow[t]{5}{*}{ SC27Q20 } & \multirow{5}{*}{$\begin{array}{l}\text { Insufficient plans/resource to prevent } \\
\text { - Q27t }\end{array}$} & \multirow[t]{5}{*}{ Q27t } & 1 & Obstacle & \multirow{5}{*}{$\begin{array}{l}\text { Obstacle to reaching the school's ICT related goals: insufficient } \\
\text { plans and/or resources to prevent theft and vandalism of } \\
\text { computers }\end{array}$} \\
\hline & & & 2 & Not an obstacle & \\
\hline & & & 7 & $\mathrm{M} / \mathrm{R}$ & \\
\hline & & & 8 & N/ADM & \\
\hline & & & 9 & Mis & \\
\hline \multirow[t]{5}{*}{ SC27Q21 } & \multirow{5}{*}{$\begin{array}{l}\text { Lack of support from governing/ } \\
\text { community - Q27u }\end{array}$} & \multirow[t]{5}{*}{ Q27u } & 1 & Obstacle & \multirow{5}{*}{$\begin{array}{l}\text { Obstacle to reaching the school's ICT related goals: lack of } \\
\text { support from the governing body or community }\end{array}$} \\
\hline & & & 2 & Not an obstacle & \\
\hline & & & 7 & $\mathrm{M} / \mathrm{R}$ & \\
\hline & & & 8 & N/ADM & \\
\hline & & & 9 & Mis & \\
\hline \multirow[t]{5}{*}{ SC27Q22 } & \multirow[t]{5}{*}{ Weak infrastructure Q27v } & \multirow[t]{5}{*}{ Q27v } & 1 & Obstacle & \multirow{5}{*}{$\begin{array}{l}\text { Obstacle to reaching the school's ICT related goals: weak } \\
\text { infrastructure (telecommunications, electricity, etc.) }\end{array}$} \\
\hline & & & 2 & Not an obstacle & \\
\hline & & & 7 & $M / R$ & \\
\hline & & & 8 & $\mathrm{~N} / \mathrm{ADM}$ & \\
\hline & & & 9 & Mis & \\
\hline \multirow[t]{4}{*}{ SC28Q01 } & \multirow[t]{4}{*}{ The first most serious obstacle - Q28a } & \multirow[t]{4}{*}{ Q28a } & 01 to 22 & Number of obstacle in Q27 & \multirow[t]{4}{*}{ The most serious obstacle (from the list in Question 27) } \\
\hline & & & 97 & $\mathrm{M} / \mathrm{R}$ & \\
\hline & & & 98 & N/ADM & \\
\hline & & & 99 & Mis & \\
\hline \multirow[t]{4}{*}{$\begin{array}{l}\mathrm{SC} 28 \mathrm{Q} 02 \\
\mathrm{~A}\end{array}$} & \multirow[t]{4}{*}{ The second most serious obstacle - Q28b } & \multirow[t]{4}{*}{ Q28b } & 01 to 22 & Number of obstacle in Q27 & \multirow{4}{*}{ The second most serious obstacle (from the list in Question 27) } \\
\hline & & & 97 & $\mathrm{M} / \mathrm{R}$ & \\
\hline & & & 98 & $\mathrm{~N} / \mathrm{ADM}$ & \\
\hline & & & 99 & Mis & \\
\hline \multirow[t]{4}{*}{$\begin{array}{l}\mathrm{SC} 28 \mathrm{Q} 03 \\
\mathrm{~S}\end{array}$} & \multirow[t]{4}{*}{ The third most serious obstacle - Q28c } & \multirow[t]{4}{*}{ Q28c } & 01 to 22 & Number of obstacle in Q27 & \multirow{4}{*}{ The third most serious obstacle (from the list in Question 27) } \\
\hline & & & 97 & $\mathrm{M} / \mathrm{R}$ & \\
\hline & & & 98 & $\mathrm{~N} / \mathrm{ADM}$ & \\
\hline & & & 99 & Mis & \\
\hline
\end{tabular}

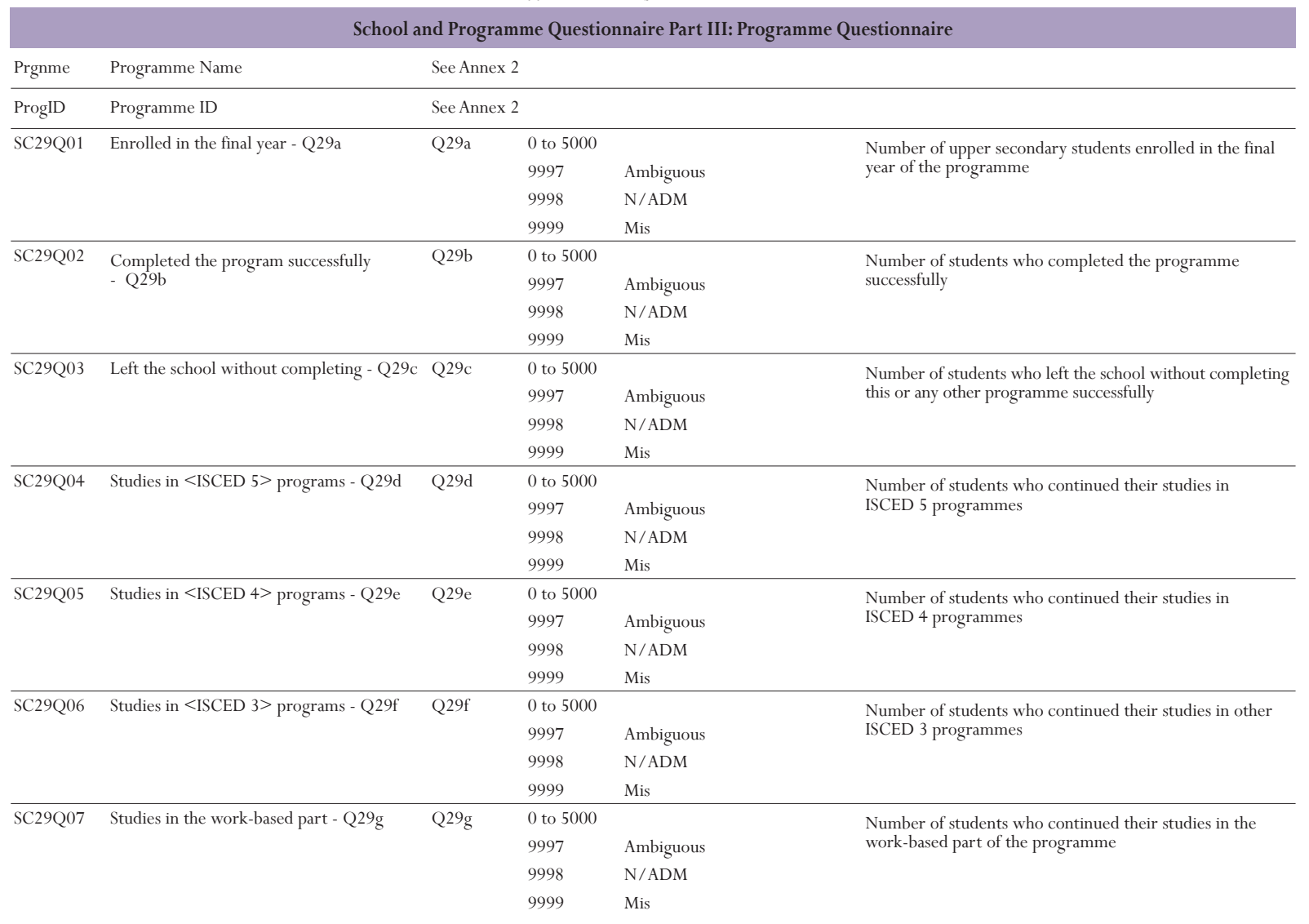


ANNEX 4

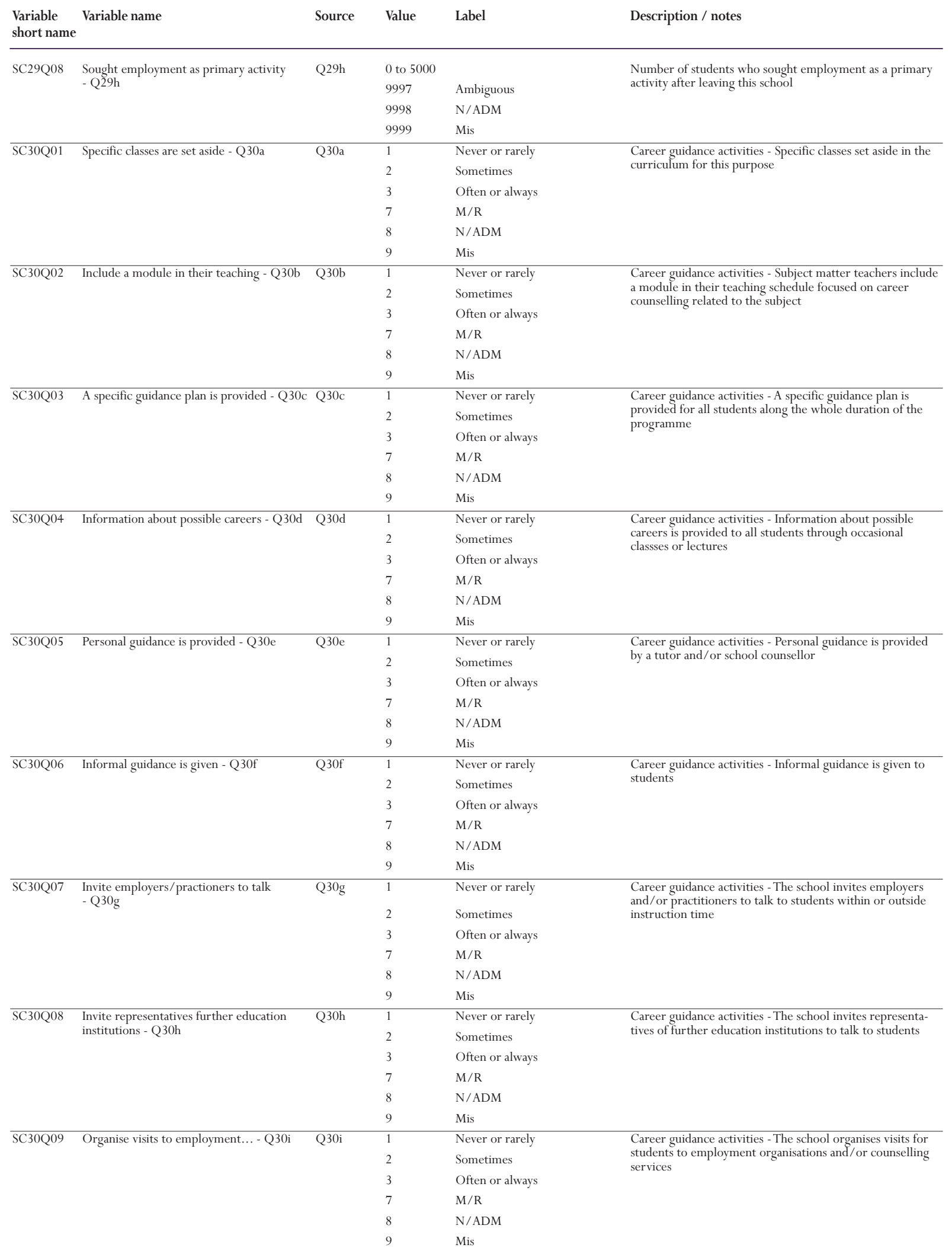




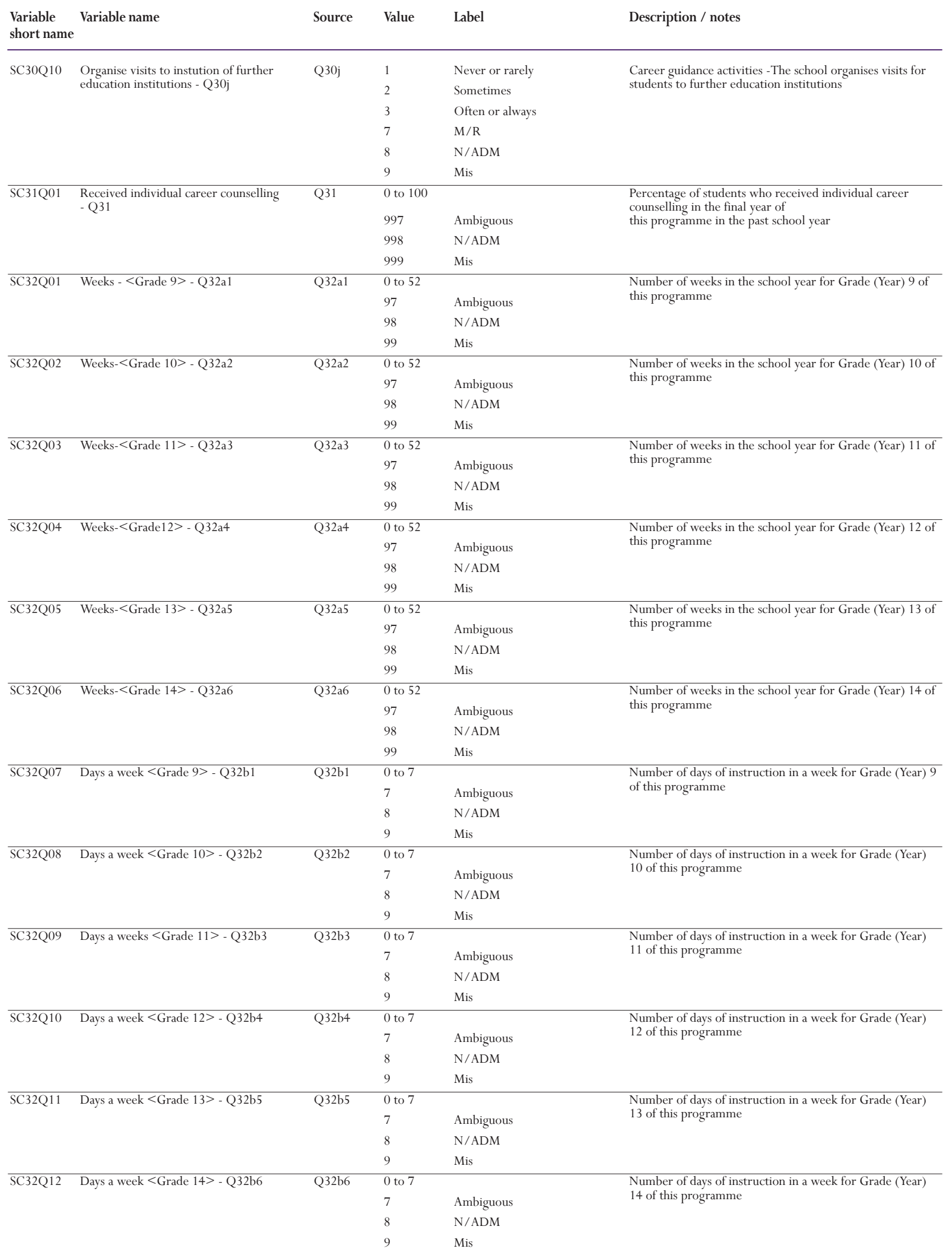


ANNEX 4

\begin{tabular}{|c|c|c|c|c|c|}
\hline $\begin{array}{l}\text { Variable } \\
\text { short name }\end{array}$ & Variable name & Source & Value & Label & Description / notes \\
\hline \multirow[t]{4}{*}{ SC32Q13 } & \multirow[t]{4}{*}{ Class periods a week < Grade 9> - Q32c1 } & \multirow[t]{4}{*}{ Q32c1 } & 0 to 90 & & \multirow{4}{*}{$\begin{array}{l}\text { Number of class periods a week for (Year) } 9 \text { of this } \\
\text { programme }\end{array}$} \\
\hline & & & 97 & Ambiguous & \\
\hline & & & 98 & N/ADM & \\
\hline & & & 99 & Mis & \\
\hline \multirow[t]{4}{*}{$\overline{S C 32 Q 14}$} & \multirow[t]{4}{*}{ Class periods a week $<$ Grade $10>-$ Q32c2 } & \multirow[t]{4}{*}{ Q32c2 } & 0 to 90 & & \multirow{4}{*}{$\begin{array}{l}\text { Number of class periods a week for Grade (Year) } 10 \text { of this } \\
\text { programme }\end{array}$} \\
\hline & & & 97 & Ambiguous & \\
\hline & & & 98 & N/ADM & \\
\hline & & & 99 & Mis & \\
\hline \multirow[t]{4}{*}{ SC32Q15 } & \multirow[t]{4}{*}{ Class periods a week $<$ Grade $11>-$ Q 32c3 } & \multirow[t]{4}{*}{ Q32c3 } & 0 to 90 & & \multirow{4}{*}{$\begin{array}{l}\text { Number of class periods a week for Grade (Year) } 11 \text { of this } \\
\text { programme }\end{array}$} \\
\hline & & & 97 & Ambiguous & \\
\hline & & & 98 & N/ADM & \\
\hline & & & 99 & Mis & \\
\hline \multirow{3}{*}{ SC32Q16 } & \multirow{3}{*}{ Class periods a week < Grade 12> - Q32c4 } & \multirow{3}{*}{ Q32c4 } & 97 & Ambiguous & \multirow{3}{*}{$\begin{array}{l}\text { Number of class periods a week for Grade (Year) } 12 \text { of this } \\
\text { programme }\end{array}$} \\
\hline & & & 98 & N/ADM & \\
\hline & & & 99 & Mis & \\
\hline \multirow[t]{4}{*}{$\overline{S C 32 Q 17}$} & \multirow{4}{*}{ Class periods a week < Grade 13>-Q32c5 } & Q32c5 & 0 to 90 & & Number of class periods a week for Grade (Year) 13 of this \\
\hline & & & 97 & Ambiguous & programme \\
\hline & & & 98 & N/ADM & \\
\hline & & & 99 & Mis & \\
\hline SC32Q18 & Class periods a week < Grade 14> - Q32c6 & Q32c6 & 0 to 90 & & Number of class periods a week for Grade (Year) 14 of this \\
\hline & & & 97 & Ambiguous & programme \\
\hline & & & 98 & N/ADM & \\
\hline & & & 99 & Mis & \\
\hline SC32Q19 & Minutes in a period < Grade $9>-$ Q $32 \mathrm{~d} 1$ & Q32d1 & 0 to 240 & & Number of minutes in a regular class period for Grade \\
\hline & & & 997 & Ambiguous & (Year) 9 of this programme \\
\hline & & & 998 & N/ADM & \\
\hline & & & 999 & Mis & \\
\hline & & & 997 & Ambiguous & (Year) 10 of this programme \\
\hline & & & 998 & N/ADM & \\
\hline & & & 999 & Mis & \\
\hline SC32Q21 & Minutes in a period $<$ Grade $11>-$ Q $32 \mathrm{~d} 3$ & Q32d3 & 0 to 240 & & Number of minutes in a regular class period for Grade \\
\hline & & & 997 & Ambiguous & (Year) 11 of this programme \\
\hline & & & 998 & N/ADM & \\
\hline & & & 999 & Mis & \\
\hline$\overline{S C 32 Q 22}$ & Minutes in a period $<$ Grade $12>-$ Q32d4 & Q32d4 & 0 to 240 & & Number of minutes in a regular class period for Grade \\
\hline & & & 997 & Ambiguous & (Year) 12 of this programme \\
\hline & & & 998 & N/ADM & \\
\hline & & & 999 & Mis & \\
\hline SC32Q23 & Minutes in a period $<$ Grade $13>$ - Q32d5 & Q32d5 & 0 to 240 & & Number of minutes in a regular class period for Grade \\
\hline & & & 997 & Ambiguous & (Year) 13 of this programme \\
\hline & & & 998 & N/ADM & \\
\hline & & & 999 & Mis & \\
\hline$\overline{S C 32 Q 24}$ & Minutes in a period $<$ Grade $14>$. & Q32d6 & 0 to 240 & & Number of minutes in a regular class period for Grade \\
\hline & Q32d6 & & 997 & Ambiguous & (Year) 14 of this programme \\
\hline & & & 998 & N/ADM & \\
\hline & & & 999 & Mis & \\
\hline$\overline{S C 33 Q 01}$ & Days of < work based learning $>$ & Q33a1 & 0 to 300 & & Number of days of work based learning in this programme \\
\hline & $<$ Grade 9>-Q33a1 & & 997 & Ambiguous & -Year 9 \\
\hline & & & 998 & N/ADM & \\
\hline & & & 999 & Mis & \\
\hline $\begin{array}{l}\text { SC33Q02 } \\
\end{array}$ & Days of < work based learning $>$ & Q33a2 & 0 to 300 & & Number of days of work based learning in this programme \\
\hline & $<$ Grade 10>-Q33a2 & & 997 & Ambiguous & -Year 10 \\
\hline & & & 998 & N/ADM & \\
\hline & & & 999 & Mis & \\
\hline
\end{tabular}




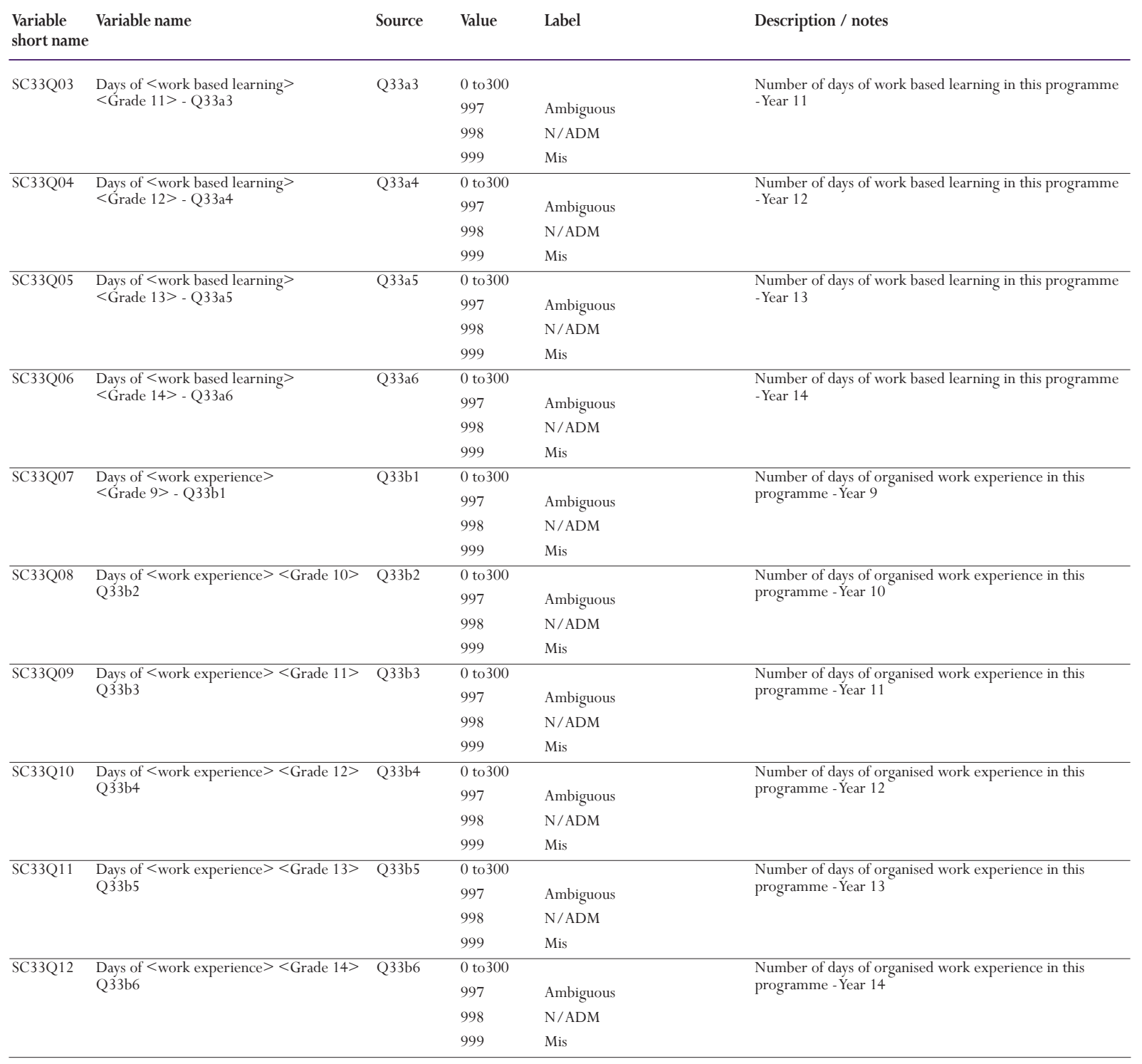


Codeboook Part B: Derived variables

\begin{tabular}{|c|c|c|c|c|c|c|}
\hline $\begin{array}{l}\text { Variable short } \\
\text { name }\end{array}$ & Variable name & Source & Value & Label & Description / notes & Table reference \\
\hline \multicolumn{7}{|c|}{ Weights (used in all ISUSS Tables) } \\
\hline IS3ENRWT & Weights by upper secondary enrolments & & numeric & & See detailed notes in the Technical report & \\
\hline IS3TOTWT & $\begin{array}{l}\text { Weights by upper secondary enrolments } \\
\text { (to calculate standardised indices) }\end{array}$ & & numeric & & See detailed notes in the Technical report & \\
\hline PRGENRWT & Weights by programme enrolments & & numeric & & See detailed notes in the Technical report & \\
\hline PRGTOTWT & $\begin{array}{l}\text { Weights by programme enrolments (to } \\
\text { calculate standardised indices) }\end{array}$ & & numeric & & See detailed notes in the Technical report & \\
\hline \multicolumn{7}{|c|}{ Institution and programme-related variables } \\
\hline \multirow[t]{3}{*}{ DEST } & Programme destination & Table A2.1 & & Programme destination & & $\mathrm{T} 2.4 \mathrm{a}, \mathrm{T} 2.4 \mathrm{~b}, \mathrm{~T} 2.5, \mathrm{~T} 2.6$ \\
\hline & & & 1 & A (Higher education) & & \\
\hline & & & 3 & $\mathrm{C}$ (Labour market) & & \\
\hline \multirow[t]{4}{*}{ ORIENT } & Programme orientation & Table A2.1 & & Programme orientation & & $\mathrm{T} 2.4 \mathrm{a}, \mathrm{T} 2.4 \mathrm{~b}, \mathrm{~T} 2.5, \mathrm{~T} 2.6$ \\
\hline & & & 1 & General & & \\
\hline & & & 2 & Pre-vocational & & \\
\hline & & & 3 & Vocational & & \\
\hline \multirow[t]{5}{*}{ TYPROG } & Programme type & & & Programme type & & $\mathrm{T} 2.4 \mathrm{a}, \mathrm{T} 2.4 \mathrm{~b}, \mathrm{~T} 2.5, \mathrm{~T} 2.6$ \\
\hline & & & 1 & $\begin{array}{l}\text { Academic general } \\
\text { programme }\end{array}$ & $\mathrm{IF}(\mathrm{DEST}=1$ and ORIENT $=1)$ & \\
\hline & & & 2 & $\begin{array}{l}\text { Academic vocational } \\
\text { programme }\end{array}$ & $\begin{array}{l}\text { IF(DEST }=1 \text { and }(\text { ORIENT }=2 \text { or ORIENT } \\
=3))\end{array}$ & \\
\hline & & & 3 & $\begin{array}{l}\text { Non-academic general } \\
\text { programme }\end{array}$ & $\begin{array}{l}\mathrm{IF}((\mathrm{DEST}=2 \text { or DEST }=3) \text { and ORIENT } \\
=1)\end{array}$ & \\
\hline & & & 4 & $\begin{array}{l}\text { Non-academic (pre-) } \\
\text { vocational programme }\end{array}$ & $\begin{array}{l}\mathrm{IF}((\mathrm{DEST}=2 \text { or DEST }=3) \text { and }(\text { ORIENT } \\
=2 \text { or ORIENT }=3))\end{array}$ & \\
\hline$\overline{\text { PROVSMLT }}$ & & & 2 & $\begin{array}{l}\text { Multiple programme } \\
\text { provider }\end{array}$ & $\begin{array}{l}\text { At least two of SCQ0105 to SC01Q14 = 1, } \\
\text { all others } 2 \text { or } 8\end{array}$ & \\
\hline \multirow[t]{10}{*}{$\begin{array}{l}\text { PG_TYPn } \\
\mathrm{n}=1 \text { to } 8\end{array}$} & ISCED programme type & Table A2.1 & & ISCED programme type & & A2.2 \\
\hline & & & 311 & $3 \mathrm{AG}$ & Academic general & \\
\hline & & & 312 & $3 \mathrm{AP}$ & $\begin{array}{l}\text { Academic programmes with prevocational } \\
\text { orientation }\end{array}$ & \\
\hline & & & 313 & $3 \mathrm{AV}$ & $\begin{array}{l}\text { Academic programmes with vocational } \\
\text { orientation }\end{array}$ & \\
\hline & & & 321 & 3BG & Higher non-academic general & \\
\hline & & & 322 & 3BP & Higher non-academic prevocational & \\
\hline & & & 323 & $3 \mathrm{BV}$ & Higher non-academic vocational & \\
\hline & & & 331 & 3CG & Lower general (transition) programmes & \\
\hline & & & 332 & $3 \mathrm{CP}$ & Lower pre-vocational programmes & \\
\hline & & & 333 & $3 \mathrm{CV}$ & $\begin{array}{l}\text { Labour market oriented vocational pro- } \\
\text { grammes }\end{array}$ & \\
\hline \multicolumn{7}{|c|}{ Note:Table A2.1 is available from the following report 'Completing the Foundation for Lifelong Learning - An OECD Survey of Upper Secondary Schools'. } \\
\hline \multirow[t]{5}{*}{$\overline{\text { PROVLEVL }}$} & Providers by levels taught together & Q1 & & Programme levels offered & & $\mathrm{A} 2.3$ \\
\hline & & & 1 & Upper secondary school & $\begin{array}{l}\text { Only ISCED } 3 \text { programmes (SC01Q01 } \\
\text { to SC01Q04 }=2 \text { or } 8 \text { and at least one of } \\
\text { SC01Q05 to SC01Q } 14=1 \text { ) }\end{array}$ & \\
\hline & & & 2 & Secondary school & $\begin{array}{l}\text { ISCED } 2 \text { and ISCED } 3 / 4 \text { programmes } \\
\text { (SC01Q01 } 2 \text { or } 8, \text { SC01Q02 and at least } \\
\text { one of SC01Q05 to SC01Q14 = 1) }\end{array}$ & \\
\hline & & & 3 & $\begin{array}{l}\text { Upper secondary and post- } \\
\text { secondary }\end{array}$ & $\begin{array}{l}\text { ISCED } 3 \text { and ISCED } 4 / 5 \text { programmes } \\
\text { (SC01Q01 and SC01Q02 = } 2 \text { or } 8 \text {, } \\
\text { SC01Q03 and /or SC01 = 1, and at least one } \\
\text { of SC01Q05 to SC01Q } 14=1 \text { ) }\end{array}$ & \\
\hline & & & 4 & Primary and secondary & $\begin{array}{l}\text { ISCED } 1 \text { to } 3 / 4 \text { programmes }(S C 01 Q 01 \text { and } \\
\text { SC01Q02 and at least one of SC01Q05 to } \\
\text { SC01Q14 = 1) }\end{array}$ & \\
\hline
\end{tabular}




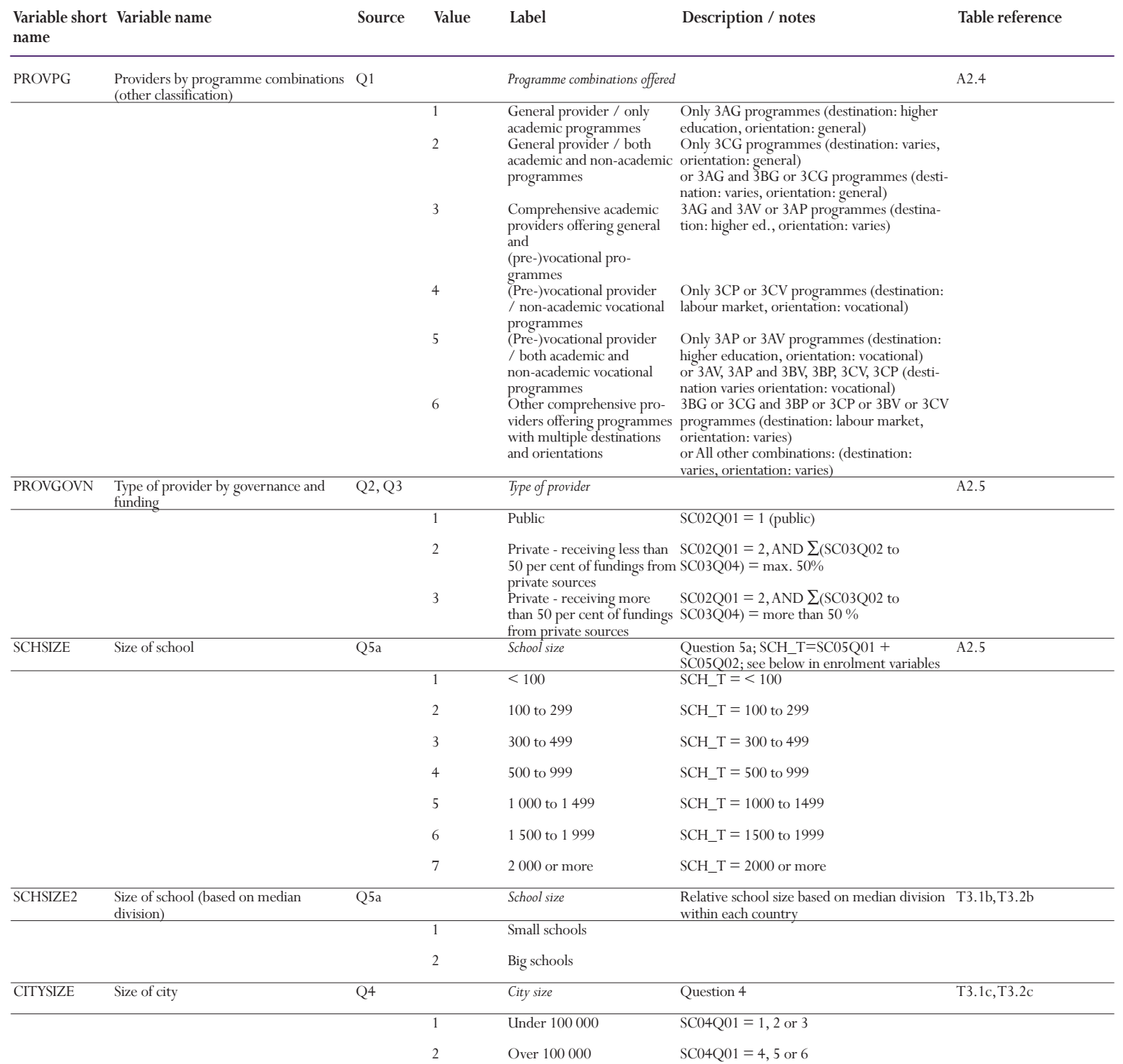

Enrolment variables (used in all ISUSS Tables)

\begin{tabular}{|c|c|c|c|c|c|}
\hline SCH_B & Total number of boys in schools & Q5b & numeric & $\begin{array}{l}\text { Total number of boys in } \\
\text { school }\end{array}$ & Calculation: SC05Q01 \\
\hline$\overline{\text { SCH_G }}$ & Total number of girls in schools & Q5b & numeric & $\begin{array}{l}\text { Total number of girls in } \\
\text { school }\end{array}$ & Calculation: SC05Q02 \\
\hline$\overline{\mathrm{SCH}} \_\mathrm{T}$ & Total number of students in schools & Q5a & numeric & Total enrolment in school & Calculation: SC05Q01 + SC05Q02 \\
\hline ISCED3_B & $\begin{array}{l}\text { Total number of boys in upper second- } \\
\text { ary (ISCED 3) programmes }\end{array}$ & Q5b to $5 \mathrm{k}$ & numeric & $\begin{array}{l}\text { Total number of boys in } \\
\text { ISCED } 3 \text { programmes }\end{array}$ & $\begin{array}{l}\text { Calculation: } \sum(\mathrm{SC} 05 \mathrm{Q} 03, \mathrm{SC} 05 \mathrm{Q} 05, \\
\text { SC05Q07, SC05Q09, SC05Q11, SC05Q13, } \\
\text { SC05Q15, SC05Q17, SC05Q19, SC05Q21) }\end{array}$ \\
\hline ISCED3_G & $\begin{array}{l}\text { Total number of girls in upper second- } \\
\text { ary (ISCED 3) programmes }\end{array}$ & Q5b to $5 \mathrm{k}$ & numeric & $\begin{array}{l}\text { Total number of girls in } \\
\text { ISCED } 3 \text { programmes }\end{array}$ & $\begin{array}{l}\text { Calculation: } \sum \text { (SC05Q04, SC05Q06, } \\
\text { SC05Q08, SC05Q10, SC05Q12, SC05Q14, } \\
\text { SC05Q16, SC05Q18, SC05Q20, SC05Q22) }\end{array}$ \\
\hline$\overline{\text { ISCED3_T }}$ & $\begin{array}{l}\text { Total number of students in ISCED } 3 \\
\text { programmes }\end{array}$ & Q5b to $5 \mathrm{k}$ & numeric & $\begin{array}{l}\text { Total enrolment in ISCED } 3 \\
\text { programmes }\end{array}$ & Calculation: $\sum(\mathrm{SC} 05 \mathrm{Q} 03$ to SC05Q22) \\
\hline$\overline{\text { PRG_B }}$ & Number of boys in programme & Q5b-h & numeric & $\begin{array}{l}\text { Number of boys in the } \\
\text { programme }\end{array}$ & $\begin{array}{l}\text { Taken from } \mathrm{SC} 05 \mathrm{Q} 03 \text { or } \mathrm{SC} 05 \mathrm{Q} 05 \text { or } \\
\text { SC05Q07, etc. depending on the programme } \\
\text { number }\end{array}$ \\
\hline$\overline{\text { PRG_G }}$ & Number of girls in programme & Q5b-h & numeric & $\begin{array}{l}\text { Number of girls in the } \\
\text { programme }\end{array}$ & $\begin{array}{l}\text { Taken from SC05Q04 or SC05Q06 or } \\
\text { SC05Q08, etc. depending on the programme } \\
\text { number }\end{array}$ \\
\hline PRG_T & Total number of students in programme & Q5b-h & numeric & $\begin{array}{l}\text { Total number of students in } \\
\text { the programme }\end{array}$ & Calculation: prg_b + prg_g \\
\hline
\end{tabular}




\begin{tabular}{|c|c|c|c|c|c|c|}
\hline \multicolumn{7}{|c|}{ Personnel variables } \\
\hline PERSFTE & $\begin{array}{l}\text { Total number of school personnel (full- } \\
\text { time equivalents) }\end{array}$ & Q6a to 6e & numeric & $\begin{array}{l}\text { Total school personnel } \\
\text { (FTE) }\end{array}$ & $\begin{array}{l}\text { Calculation: } \sum(\text { SC06Q01, SC06Q03, } \\
\text { SC06Q05, SC06Q07, SC06Q09)+ } \\
\sum(\text { SC06Q02, SC06Q04, SC06Q06, } \\
\text { SC06Q08, SC06Q10)*0,5 }\end{array}$ & $\begin{array}{l}\text { (T3.2a, T3.2b, T3.2c, } \\
\text { T3.2d) }\end{array}$ \\
\hline PERSHDC & $\begin{array}{l}\text { Total number of school personnel } \\
\text { (headcounts) }\end{array}$ & Q6a to 6e & numeric & $\begin{array}{l}\text { Total school personnel } \\
\text { (headcounts) }\end{array}$ & Calculation: $\sum$ (S06Q01 to S06Q10) & \\
\hline STAFFFTE & $\begin{array}{l}\text { Number of professional staff (full-time } \\
\text { equivalents) }\end{array}$ & Q6a, b, d & numeric & Professional staff (FTE) & $\begin{array}{l}\text { Calculation: } \sum \text { (SC06Q01, SC06Q03, } \\
\text { SC06Q07) }+\sum \text { (SC06Q02, SC06Q04, } \\
\text { SC06Q08)*0,5 }\end{array}$ & $\begin{array}{l}\text { (T3.2a, T3.2b, T3.2c, } \\
\text { T3.2d) }\end{array}$ \\
\hline STAFFHDC & $\begin{array}{l}\text { Number of professional staff (head- } \\
\text { counts) }\end{array}$ & Q6a, b, d & numeric & $\begin{array}{l}\text { Professional staff (head- } \\
\text { counts) }\end{array}$ & $\begin{array}{l}\text { Calculation: } \sum \text { (SC06Q01, SC06Q03, } \\
\text { SC06Q07) + } \sum \text { (SC06Q02, SC06Q04, } \\
\text { SC06Q08) }\end{array}$ & \\
\hline MNGFTE & $\begin{array}{l}\text { Number of school management } \\
\text { personnel (full-time equivalents) }\end{array}$ & Q6a & numeric & $\begin{array}{l}\text { School management } \\
\text { personnel (FTE) }\end{array}$ & Calculation: SC06Q01 + (SC06Q02 *0,5) & $\begin{array}{l}\text { (T3.2a, T3.2b, T3.2c, } \\
\text { T3.2d) }\end{array}$ \\
\hline MNGHDC & $\begin{array}{l}\text { Number of school management } \\
\text { personnel (headcounts) }\end{array}$ & Q6a & numeric & $\begin{array}{l}\text { School management } \\
\text { personnel (headcounts) }\end{array}$ & Calculation: SC06Q01 + SC06Q02 & \\
\hline TCHFTE & $\begin{array}{l}\text { Number of classroom teachers (full- } \\
\text { time equivalents) }\end{array}$ & Q6b & numeric & Classroom teachers (FTE) & Calculation: SC06Q03 + (SC06Q04 * 0,5) & $\begin{array}{l}\text { (T3.2a, T3.2b, T3.2c, } \\
\text { T3.2d) }\end{array}$ \\
\hline TCHHDC & $\begin{array}{l}\text { Number of classroom teachers } \\
\text { (headcounts) }\end{array}$ & Q6b & numeric & $\begin{array}{l}\text { Classroom teachers } \\
\text { (headcounts) }\end{array}$ & Calculation: SC06Q03 + SC06Q04 & \\
\hline AIDFTE & $\begin{array}{l}\text { Number of teacher aids (full-time } \\
\text { equivalents) }\end{array}$ & Q6c & numeric & Teacher aids (FTE) & Calculation: SC06Q05 + (SC06Q06*0,5) & $\begin{array}{l}\text { (T3.2a, T3.2b, T3.2c, } \\
\text { T3.2d) }\end{array}$ \\
\hline AIDHDC & Number of teacher aids (headcounts) & Q6c & numeric & Teacher aids (headcounts) & Calculation: SC06Q05 + SC06Q06 & \\
\hline PRSUPFTE & $\begin{array}{l}\text { Number of professional support } \\
\text { personnel (full-time equivalents) }\end{array}$ & Q6d & numeric & $\begin{array}{l}\text { Professional support } \\
\text { personnel (FTE) }\end{array}$ & Calculation: SC06Q07 + (SC06Q08 * 0,5) & $\begin{array}{l}\text { (T3.2a, T3.2b, T3.2c, } \\
\text { T3.2d) }\end{array}$ \\
\hline PRSUPHDC & $\begin{array}{l}\text { Number of professional support } \\
\text { personnel (headcounts) }\end{array}$ & Q6d & numeric & $\begin{array}{l}\text { Professional support } \\
\text { personnel (headcounts) }\end{array}$ & Calculation: SC06Q07 + SC06Q08 & \\
\hline OTHERFTE & $\begin{array}{l}\text { Number of other support } \\
\text { personnel (full-time equivalents) }\end{array}$ & Q6e & numeric & $\begin{array}{l}\text { Other support personnel } \\
\text { (FTE) }\end{array}$ & Calculation: SC06Q09 + (SC06Q10 * 0,5) & $\begin{array}{l}\text { (T3.2a, T3.2b, T3.2c, } \\
\text { T3.2d) }\end{array}$ \\
\hline OTHERHDC & $\begin{array}{l}\text { Number of other support personnel } \\
\text { (headcounts) }\end{array}$ & Q6e & numeric & $\begin{array}{l}\text { Other support personnel } \\
\text { (headcounts) }\end{array}$ & Calculation: SC06Q09 + SC06Q10 & \\
\hline MNGPERFT & $\begin{array}{l}\text { Management personnel to total } \\
\text { personnel (full-time equivalents) }\end{array}$ & $\begin{array}{l}\text { Q6a, } \\
\text { Q6a to 6e }\end{array}$ & numeric & $\begin{array}{l}\text { Management personnel to } \\
\text { total personnel (FTE) }\end{array}$ & Calculation: MNGFTE/PERSFTE & $\begin{array}{l}\text { T3.2a, T3.2b, T3.2c, } \\
\text { T3.2d }\end{array}$ \\
\hline TCHPERFT & $\begin{array}{l}\text { Teachers to total personnel (full-time } \\
\text { equivalents) }\end{array}$ & $\begin{array}{l}\text { Q6b, } \\
\text { Q6a to 6e }\end{array}$ & numeric & $\begin{array}{l}\text { Teachers to total personnel } \\
\text { (FTE) }\end{array}$ & Calculation:TCHFTE/PERSFTE & $\begin{array}{l}\text { T3.2a, T3.2b, T3.2c, } \\
\text { T3.2d }\end{array}$ \\
\hline AIDPERFT & $\begin{array}{l}\text { Teacher aids to total personnel (full- } \\
\text { time equivalents) }\end{array}$ & $\begin{array}{l}\text { Q6c, } \\
\text { Q6a to 6e }\end{array}$ & numeric & $\begin{array}{l}\text { Teacher aids to total } \\
\text { personnel (FTE) }\end{array}$ & Calculation: AIDFTE/PERSFTE & $\begin{array}{l}\text { T3.2a,T3.2b, T3.2c, } \\
\text { T3.2d }\end{array}$ \\
\hline PSUPERFT & $\begin{array}{l}\text { Professional support staff to total } \\
\text { personnel (full-time equivalents) }\end{array}$ & $\begin{array}{l}\text { Q6d, } \\
\text { Q6a to 6e }\end{array}$ & numeric & $\begin{array}{l}\text { Professional support staff to } \\
\text { total personnel (FTE) }\end{array}$ & Calculation: PRSUFTE/PERSFTE & $\begin{array}{l}\text { T3.2a, T3.2b, T3.2c, } \\
\text { T3.2d }\end{array}$ \\
\hline OSUPERFT & $\begin{array}{l}\text { Other support personnel to total } \\
\text { personnel (full-time equivalents) }\end{array}$ & $\begin{array}{l}\text { Q6e, } \\
\text { Q6a to 6e }\end{array}$ & numeric & $\begin{array}{l}\text { Other support personnel to } \\
\text { total personnel (FTE) }\end{array}$ & Calculation: OTHERFTE/PERSFTE & $\begin{array}{l}\text { T3.2a,T3.2b, T3.2c, } \\
\text { T3.2d }\end{array}$ \\
\hline STAPERFT & $\begin{array}{l}\text { Professional staff to total personnel } \\
\text { (full-time equivalents) }\end{array}$ & $\begin{array}{l}\text { Q6a, b, d } \\
\text { Q6a to 6e }\end{array}$ & numeric & $\begin{array}{l}\text { Professional staff to total } \\
\text { personnel (FTE) }\end{array}$ & Calculation: STAFFFTE/PERSFTE & $\begin{array}{l}\text { T3.2a, T3.2b, T3.2c, } \\
\text { T3.2d }\end{array}$ \\
\hline SUPPERFT & $\begin{array}{l}\text { Aid teachers and other support } \\
\text { personnel to total personnel (full-time } \\
\text { equivalents) }\end{array}$ & $\begin{array}{l}\text { Q6 c, e } \\
\text { Q6a to 6e }\end{array}$ & numeric & $\begin{array}{l}\text { Professional staff to total } \\
\text { personnel (FTE) }\end{array}$ & Calculation: AIDPERFT + OSUPERFT & $\begin{array}{l}\text { T3.2a, T3.2b, T3.2c, } \\
\text { T3.2d }\end{array}$ \\
\hline RSTDPERS & $\begin{array}{l}\text { Ratio of students to total personnel } \\
\text { (FTE) }\end{array}$ & Q5a, Q6a & numeric & $\begin{array}{l}\text { Ratio of students to total } \\
\text { personnel (FTE) }\end{array}$ & Calculation:SCH_T/PERSFTE & $\begin{array}{l}\text { T3.1a,T3.1b, T3.1c, } \\
\text { T3.1d }\end{array}$ \\
\hline RSTDTCH & Ratio of students to teachers (FTE) & Q5a, Q6b & numeric & $\begin{array}{l}\text { Ratio of students to teachers } \\
\text { (FTE) }\end{array}$ & Calculation: SCH_T/TCHFTE & $\begin{array}{l}\text { T3.1a,T3.1b, T3.1c, } \\
\text { T3.1d }\end{array}$ \\
\hline$\overline{R S T D P R O F}$ & $\begin{array}{l}\text { Ratio of students to professional } \\
\text { personnel (FTE) }\end{array}$ & $\begin{array}{l}\text { Q5a, Q6a, } \\
\text { Q6b, Q6d }\end{array}$ & numeric & $\begin{array}{l}\text { Ratio of students to } \\
\text { professional personnel (FTE) }\end{array}$ & Calculation:SCH_T/STAFFFTE & $\begin{array}{l}\text { T3.1a,T3.1b, T3.1c, } \\
\text { T3.1d }\end{array}$ \\
\hline RTEMPFT & $\begin{array}{l}\text { Full-time temporary teachers as a } \\
\text { percentage of full-time teachers }\end{array}$ & Q7a & numeric & $\begin{array}{l}\text { Full-time temporary } \\
\text { teachers as a percentage of } \\
\text { full-time teachers }\end{array}$ & Calculation: SC07Q01 & $\begin{array}{l}\text { T3.1a,T3.1b, T3.1c, } \\
\text { T3.1d }\end{array}$ \\
\hline RTEMPPT & $\begin{array}{l}\text { Part-time temporary teachers as a } \\
\text { percentage of part-time teachers }\end{array}$ & Q7a & numeric & $\begin{array}{l}\text { Part-time temporary } \\
\text { teachers as a percentage of } \\
\text { part-time teachers }\end{array}$ & Calculation: SC07Q02 & $\begin{array}{l}\text { T3.1a,T3.1b,T3.1c, } \\
\text { T3.1d }\end{array}$ \\
\hline RNQUALFT & $\begin{array}{l}\text { Full-time not fully-qualified teachers } \\
\text { as a percentage of full-time teachers }\end{array}$ & Q7b & numeric & $\begin{array}{l}\text { Full-time not fully qualified } \\
\text { teachers as a percentage of } \\
\text { full-time teachers }\end{array}$ & Calculation: 1 - SC07Q03 & $\begin{array}{l}\text { T3.1a,T3.1b, T3.1c, } \\
\text { T3.1d }\end{array}$ \\
\hline RNQUALPT & $\begin{array}{l}\text { Part-time not fully-qualified teachers } \\
\text { as a percentage of part-time teachers }\end{array}$ & Q7b & numeric & $\begin{array}{l}\text { Part-time not fully qualified } \\
\text { teachers as a percentage of } \\
\text { part-time teachers }\end{array}$ & Calculation: 1 - SC07Q04 & T3.3 \\
\hline TCHPT & $\begin{array}{l}\text { Part-time teachers as a percentage of } \\
\text { total teachers }\end{array}$ & Q6 & numeric & $\begin{array}{l}\text { Part-time teachers as a } \\
\text { percentage of total teachers }\end{array}$ & $\begin{array}{l}\text { Calculation: SC06Q04 / (SC06Q03 + } \\
\text { SC06Q04) }\end{array}$ & T3.3 \\
\hline RTCHVAC & $\begin{array}{l}\text { Teacher vacancies as a percentage of } \\
\text { full-time equivalent teachers }\end{array}$ & Q6b, Q9 & numeric & $\begin{array}{l}\text { Teacher vacancies as a } \\
\text { percentage of full-time } \\
\text { equivalent teachers }\end{array}$ & Calculation: SC09Q01/TCHFTE & T3.4a \\
\hline \multirow[t]{2}{*}{ Q10VALID } & Number of valid values in Question 10 & $\begin{array}{l}\text { Q10a to } \\
10 \mathrm{e}\end{array}$ & numeric & $\begin{array}{l}\text { Number of valid values in } \\
\text { the range }\end{array}$ & $\begin{array}{l}\text { Number of non-missing values in the range } \\
\text { (Q10a-Q10e) }\end{array}$ & (T3.4b) \\
\hline & & & & Recode 2, $8=0$ & $\begin{array}{l}\text { Calculation: NVALID( SC10Q01, SC10Q02, } \\
\text {..., SC10Q05) }\end{array}$ & \\
\hline \multirow[t]{2}{*}{ Q10INDEX } & $\begin{array}{l}\text { Composite index for Q10 (or index of } \\
\text { difficulty to cover vacancies) }\end{array}$ & $\begin{array}{l}\text { Q10a, } \\
\text { Q10b, } \\
\text { Q11c, } \\
\text { Q10d, } \\
\text { Q10e }\end{array}$ & numeric & $\begin{array}{l}\text { Index of difficulty to cover } \\
\text { vacancies }\end{array}$ & $\begin{array}{l}\text { This index is calculated by summing Q10a, } \\
\text { Q10b, Q10c, Q10d and Q10e when } \\
\text { Q10VALID > 0 }\end{array}$ & T3.4b \\
\hline & & & & Recode $2,8=0$ & Calculation: $\sum$ ( SC10Q01 to SC10Q05) & \\
\hline$\overline{\text { CLP_CANC }}$ & $\begin{array}{l}\text { Percentage of class periods that had to } \\
\text { be cancelled }\end{array}$ & Q15a & numeric & $\begin{array}{l}\text { Percentage of class periods } \\
\text { that had to be cancelled }\end{array}$ & Calculation: SC15Q01 & T3.5 \\
\hline$\overline{C L P}$ COV & $\begin{array}{l}\text { Percentage of class periods that had to } \\
\text { be covered by another teacher }\end{array}$ & Q15b & numeric & $\begin{array}{l}\text { Percentage of class periods } \\
\text { that had to be covered by } \\
\text { another teacher }\end{array}$ & Calculation: SC15Q02 & T3.5 \\
\hline \multirow[t]{2}{*}{ Q11VALID } & Number of valid values in Question 11 & $\begin{array}{l}\text { Q11a to } \\
11 j\end{array}$ & numeric & $\begin{array}{l}\text { Number of valid values in } \\
\text { the range }\end{array}$ & $\begin{array}{l}\text { Number of non-missing values in the range } \\
\text { (Q11a-Q11j) }\end{array}$ & (T3.6b) \\
\hline & & & & Recode 2, $8=0$ & $\begin{array}{l}\text { Calculation: NVALID( SC11Q01, SC10Q02, } \\
\text {..., SC11Q10) }\end{array}$ & \\
\hline Q11INDEX & $\begin{array}{l}\text { Composite index for Q11 (or index of } \\
\text { difficulty by subject) }\end{array}$ & $\begin{array}{l}\text { Q11a to } \\
11 j\end{array}$ & numeric & Index of difficulty by subject & $\begin{array}{l}\text { This index is calculated by summing Q11a to } \\
\text { Q11j when Q11VALID }>0\end{array}$ & T3.6b \\
\hline
\end{tabular}




\section{Professional development variables}

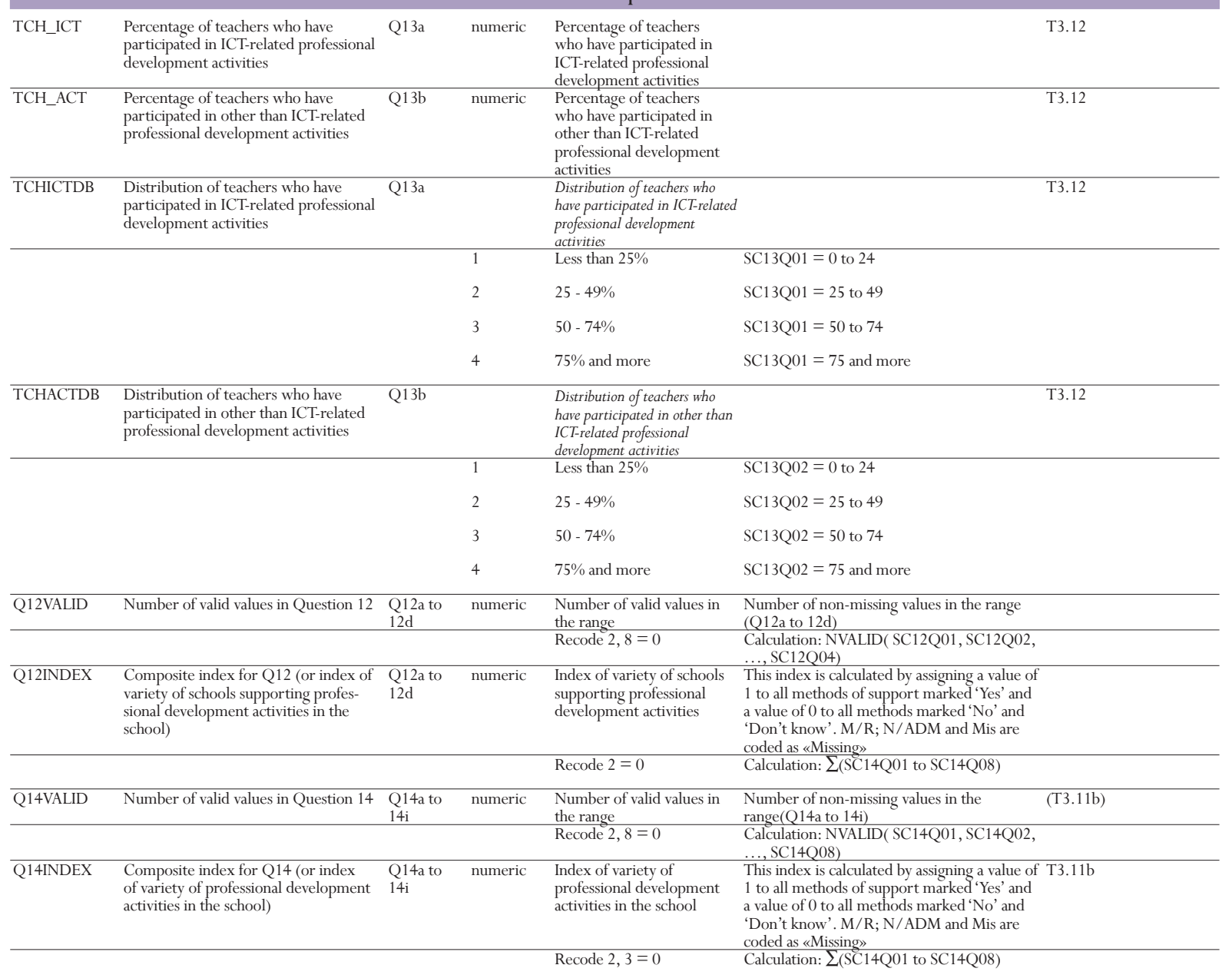

\begin{tabular}{|c|c|c|c|c|}
\hline \multicolumn{5}{|c|}{ Variables related to school functioning } \\
\hline Q16VAL1 & Number of valid values in Question 16 & $\begin{array}{l}\text { Q16b, 16c, numeric } \\
16 \mathrm{~d}\end{array}$ & $\begin{array}{l}\text { Number of valid values in } \\
\text { the range }\end{array}$ & $\begin{array}{l}\text { Number of non-missing values in the range } \quad(\mathrm{T} 2.1 \mathrm{~b}) \\
\text { (Q16b, 16c, 16d) }\end{array}$ \\
\hline & & & Recode $2,8=0$ & $\begin{array}{l}\text { Calculation: NVALID( SC16Q02, SC16Q03, } \\
\text { SC16Q04) }\end{array}$ \\
\hline$\overline{\text { Q16ACHIE }}$ & $\begin{array}{l}\text { Index of achievement related admission } \\
\text { policy }\end{array}$ & $\begin{array}{l}\text { Q16b, 16c, numeric } \\
\text { 16d }\end{array}$ & $\begin{array}{l}\text { Achievement related } \\
\text { admission policy }\end{array}$ & $\begin{array}{l}\text { This index is calculated by assigning a score } \\
\text { of } 2 \text { to all items marked 'Often', a score of } 1 \\
\text { to all marked 'Sometimes' and a score of } 0 \\
\text { marked 'Never'. M/R, N/ADM and Mis are } \\
\text { coded as «Missing» }\end{array}$ \\
\hline \multirow[t]{2}{*}{ Q16VAL2 } & Number of valid values in Question 16 & Q16e, 16g numeric & $\begin{array}{l}\text { Number of valid values in } \\
\text { the range }\end{array}$ & $\begin{array}{l}\text { Number of non-missing values in the range }(\mathrm{T} 2.1 \mathrm{~b}) \\
\text { (Q16e, } 16 \mathrm{~g})\end{array}$ \\
\hline & & & Recode $2,8=0$ & Calculation: NVALID( SC16Q05, SC16Q07) \\
\hline \multirow[t]{2}{*}{ Q16LOYAL } & Index of loyalty related admission policy & Q16e, 16g numeric & $\begin{array}{l}\text { Loyalty related admission } \\
\text { policy }\end{array}$ & $\begin{array}{l}\text { This index is calculated by assigning a score } \\
\text { of } 2 \text { to all items marked 'Often', a score of } 1 \\
\text { to all marked ' Sometimes' and a score of } 0 \\
\text { marked 'Never'. M/R, N/ADM and Mis are } \\
\text { coded as «Missing» }\end{array}$ \\
\hline & & & Recode $3=2,2=1,1=0$ & Calculation: $\sum(\mathrm{SC} 16 \mathrm{Q} 05+\mathrm{SC16Q07)}$ \\
\hline \multirow[t]{2}{*}{ Q17VALID } & Number of valid values in Question 17 & $\begin{array}{l}\text { Q17a, } 17 \mathrm{~b} \text {, numeric } \\
17 \mathrm{c}, 17 \mathrm{~g}\end{array}$ & $\begin{array}{l}\text { Number of valid values in } \\
\text { the range }\end{array}$ & $\begin{array}{l}\text { Number of non-missing values in the range } \\
(\mathrm{Q} 17 \mathrm{a}, 17 \mathrm{~b}, 17 \mathrm{c}, 17 \mathrm{~g})\end{array}$ \\
\hline & & & Recode $2,8=0$ & $\begin{array}{l}\text { Calculation: NVALID( SC17Q01, SC17Q02, } \\
\text {.., SC17Q05) }\end{array}$ \\
\hline
\end{tabular}


ANNEX 4

\begin{tabular}{|c|c|c|c|c|c|c|}
\hline $\begin{array}{l}\text { Variable short } \\
\text { name }\end{array}$ & Variable name & Source & Value & Label & Description / notes & Table reference \\
\hline \multirow[t]{3}{*}{ Q17INDEX } & $\begin{array}{l}\text { Composite index for Q17 (or index of } \\
\text { grouping policies within schools) }\end{array}$ & $\begin{array}{l}\text { Q17a, 17b, } \\
17 \mathrm{c}, 17 \mathrm{~g}\end{array}$ & numeric & $\begin{array}{l}\text { Index of streaming related } \\
\text { grouping policies within } \\
\text { schools }\end{array}$ & $\begin{array}{l}\text { This index is calculated by assigning a value of } \\
1 \text { to all methods of support marked 'Yes' and } \\
\text { a value of } 0 \text { to all methods marked ' No' or } \\
\text { 'Don't know'. M/R, N/ADM and Mis are } \\
\text { coded as «Missing» }\end{array}$ & $\mathrm{T} 2.2 \mathrm{~b}$ \\
\hline & & & & $\begin{array}{l}\text { For } Q 17 \mathrm{a}, 17 \mathrm{c}, \text { recode } \\
3=0,2=1,1=2 \\
\text { For } \mathrm{Q} 17 \mathrm{~b}, 17 \mathrm{~g}, \text { recode } \\
3=2,2=1,1=0\end{array}$ & Calculation: $\sum(\mathrm{SC} 19 \mathrm{Q} 01$ to SC19Q07) & \\
\hline & Student's choice of subjects/modules & Q18a & & $\begin{array}{l}\text { Kept centrally or Kept } \\
\text { centrally and teachers have } \\
\text { access }\end{array}$ & $\begin{array}{l}\text { First, recode both SC18Q01 and SC18Q02 } \\
\text { into Q18a } \\
\text { IF }(\mathrm{SC} 18 \mathrm{Q} 01=1 \text { and SC18Q02 = 1) Q18a } \\
=1 \\
\mathrm{IF}(\mathrm{SC} 18 \mathrm{Q} 01=1 \text { and SC18Q02 = 2) Q18a } \\
=2 \\
\mathrm{IF}(\mathrm{SC} 18 \mathrm{Q} 01=2) \mathrm{Q} 18 \mathrm{a}=3\end{array}$ & $\mathrm{~T} 2.3$ \\
\hline $\bar{Q} 18 \mathrm{a} 1$ & & & 1,0, Mis & Kept centrally & Q18a $(1=1)(2=1)(3=0)($ ELSE $=$ SYSMIS $)$ & \\
\hline \multirow[t]{2}{*}{ Q18a2 } & & & 1,0, Mis & $\begin{array}{l}\text { Kept centrally and teachers } \\
\text { have access }\end{array}$ & Q18a $(1=1)(2=0)(3=0)(E L S E=S Y S M I S)$ & \\
\hline & Student performance & Q18b & & $\begin{array}{l}\text { Kept centrally or Kept } \\
\text { centrally and teachers have } \\
\text { access }\end{array}$ & $\begin{array}{l}\text { First, recode both SC18Q03 and SC18Q04 } \\
\text { into Q18b } \\
\text { IF (SC18Q03 = } 1 \text { and SC18Q04=1) Q18b } \\
=1 \\
\mathrm{IF}(\mathrm{SC} 18 \mathrm{Q} 03=1 \text { and SC18Q04 = 2) Q18b } \\
=2 \\
\mathrm{IF}(\mathrm{SC} 18 \mathrm{Q} 03=2) \mathrm{Q} 18 \mathrm{~b}=3\end{array}$ & T2.3 \\
\hline Q18b1 & & & 1,0, Mis & Kept centrally & Q18b $(1=1)(2=1)(3=0)(E L S E=S Y S M I S)$ & \\
\hline \multirow[t]{2}{*}{ Q18b2 } & & & 1,0, Mis & $\begin{array}{l}\text { Kept centrally and teachers } \\
\text { have access }\end{array}$ & Q18b $(1=1)(2=0)(3=0)(E L S E=S Y S M I S)$ & \\
\hline & Behavioral problems & Q18c & & $\begin{array}{l}\text { Kept centrally or Kept } \\
\text { centrally and teachers have } \\
\text { access }\end{array}$ & $\begin{array}{l}\text { First, recode both SC18Q05 and SC18Q06 } \\
\text { into Q18c } \\
\text { IF }(\mathrm{SC} 18 \mathrm{Q} 05=1 \text { and SC18Q06 = 1) } \\
\text { Q18c }=1 \\
\mathrm{IF}(\mathrm{SC} 18 \mathrm{Q} 05=1 \text { and SC18Q06 = 2) } \\
\text { Q18c }=2 \\
\mathrm{IF}(\mathrm{SC} 18 \mathrm{Q} 05=2) \mathrm{Q} 18 \mathrm{c}=3\end{array}$ & $\mathrm{~T} 2.3$ \\
\hline Q18c1 & & & 1,0, Mis & Kept centrally & Q18c $(1=1)(2=1)(3=0)($ ELSE $=$ SYSMIS $)$ & \\
\hline \multirow[t]{2}{*}{ Q18c2 } & & & 1,0, Mis & $\begin{array}{l}\text { Kept centrally and teachers } \\
\text { have access }\end{array}$ & Q18c $(1=1)(2=0)(3=0)(E L S E=S Y S M I S)$ & \\
\hline & Student's absenteeism & Q18d & & $\begin{array}{l}\text { Kept centrally or Kept } \\
\text { centrally and teachers have } \\
\text { access }\end{array}$ & $\begin{array}{l}\text { First, recode both SC18Q07 and SC18Q08 } \\
\text { into Q18dIF (SC18Q07 = } 1 \text { and SC18Q08 = } \\
\text { 1) Q18d = 1IF (SC18Q07 = 1 and SC18Q08 } \\
=2) \text { Q18d = } 2 \mathrm{IF}(\mathrm{SC} 18 \mathrm{Q} 07=2) \mathrm{Q} 18 \mathrm{~d}=3\end{array}$ & $\mathrm{~T} 2.3$ \\
\hline Q18d1 & & & 1,0, Mis & Kept centrally & Q18d $(1=1)(2=1)(3=0)($ ELSE=SYSMIS $)$ & \\
\hline \multirow[t]{2}{*}{ Q18d2 } & & & 1,0, Mis & $\begin{array}{l}\text { Kept centrally and teachers } \\
\text { have access }\end{array}$ & Q18d $(1=1)(2=0)(3=0)($ ELSE $=$ SYSMIS $)$ & \\
\hline & $\begin{array}{l}\text { Community work (projects or intern- } \\
\text { ships) }\end{array}$ & Q18e & & $\begin{array}{l}\text { Kept centrally or Kept } \\
\text { centrally and teachers have } \\
\text { access }\end{array}$ & $\begin{array}{l}\text { First, recode both SC18Q09 and SC18Q10 } \\
\text { into Q18e } \\
\text { IF }(\mathrm{SC} 18 \mathrm{Q} 09=1 \text { and SC18Q10 = 1) } \\
\text { Q18e }=1 \\
\text { IF }(\mathrm{SC} 18 \mathrm{Q} 09=1 \text { and SC18Q10 = 2) } \\
\text { Q18e }=2 \\
\mathrm{IF}(\mathrm{SC} 18 \mathrm{Q} 09=2) \mathrm{Q} 18 \mathrm{e}=3\end{array}$ & $\mathrm{~T} 2.3$ \\
\hline Q18e1 & & & 1,0, Mis & Kept centrally & Q18e $(1=1)(2=1)(3=0)($ ELSE $=$ SYSMIS $)$ & \\
\hline \multirow[t]{2}{*}{ Q18e2 } & & & 1,0, Mis & $\begin{array}{l}\text { Kept centrally and teachers } \\
\text { have access }\end{array}$ & Q18e $(1=1)(2=0)(3=0)(E L S E=$ SYSMIS $)$ & \\
\hline & Examinations & Q18f & & $\begin{array}{l}\text { Kept centrally or Kept } \\
\text { centrally and teachers have } \\
\text { access }\end{array}$ & $\begin{array}{l}\text { First, recode both SC18Q11 and SC18Q12 } \\
\text { into Q18f } \\
\text { IF }(\mathrm{SC} 18 \mathrm{Q} 11=1 \text { and SC18Q12=1) } \\
\text { Q18f }=1 \\
\mathrm{IF}(\mathrm{SC} 18 \mathrm{Q} 11=1 \text { and SC18Q12 = }) \\
\text { Q18f }=2 \\
\mathrm{IF}(\mathrm{SC} 18 \mathrm{Q} 11=2) \mathrm{Q} 18 \mathrm{f}=3\end{array}$ & T2.3 \\
\hline Q18f1 & & & 1,0, Mis & Kept centrally & Q18f $(1=1)(2=1)(3=0)($ ELSE $=$ SYSMIS $)$ & \\
\hline Q18f2 & & & 1,0, Mis & $\begin{array}{l}\text { Kept centrally and teachers } \\
\text { have access }\end{array}$ & Q18f $(1=1)(2=0)(3=0)($ ELSE $=$ SYSMIS $)$ & \\
\hline \multirow[t]{2}{*}{ Q19VALID } & Number of valid values in Question 19 & $\begin{array}{l}\text { Q19a to } \\
19 f\end{array}$ & numeric & $\begin{array}{l}\text { Number of valid values in } \\
\text { the range }\end{array}$ & $\begin{array}{l}\text { Number of non-missing values in the range } \\
\text { (Q19a to 19f) }\end{array}$ & $(\mathrm{T} 2.7, \mathrm{~T} 2.8, \mathrm{~T} 2.9)$ \\
\hline & & & & Recode $2,8=0$ & $\begin{array}{l}\text { Calculation: NVALID( SC19Q01, SC19Q02, } \\
\text {..., SC19Q07) }\end{array}$ & \\
\hline \multirow[t]{2}{*}{ Q19INDEX } & $\begin{array}{l}\text { Composite index for Q19 (or index of } \\
\text { feedback from various stakeholders) }\end{array}$ & $\begin{array}{l}\text { Q19a to } \\
19 f\end{array}$ & numeric & Index of feedback & $\begin{array}{l}\text { This index is calculated by assigning a value } \\
\text { of } 1 \text { to all methods of support marked 'Yes' } \\
\text { and a value of } 0 \text { to all methods marked 'No } \\
\text { or 'Don't know'. M/R, N/ADM and Mis are } \\
\text { coded as «Missing» }\end{array}$ & T2.7,T2.8,T2.9 \\
\hline & & & & Recode $3=2,2=1,1=0$ & Calculation: $\Sigma($ SC19Q01 to SC19Q07) & \\
\hline \multirow[t]{2}{*}{ Q30VAL1 } & Number of valid values in Question 30 & $\begin{array}{l}\text { Q30a to } \\
30 f\end{array}$ & numeric & $\begin{array}{l}\text { Number of valid values in } \\
\text { the range }\end{array}$ & $\begin{array}{l}\text { Number of non-missing values in the range } \\
\text { (Q30a, .., 30f) }\end{array}$ & (T2.6) \\
\hline & & & & Recode $3=2,2=1,1=0$ & $\begin{array}{l}\text { Calculation: NVALID( SC30Q01, SC30Q02, } \\
\text {..., SC30Q06) }\end{array}$ & \\
\hline Q30IND1 & $\begin{array}{l}\text { Composite index for Q30 (or index } \\
\text { of school-related career counselling } \\
\text { methods) }\end{array}$ & $\begin{array}{l}\text { Q30a to } \\
30 f\end{array}$ & numeric & $\begin{array}{l}\text { Index of internal career } \\
\text { counselling methods }\end{array}$ & $\begin{array}{l}\text { This index is calculated by assigning a value } \\
\text { of } 1 \text { to all methods of support marked 'Yes' } \\
\text { and a value of } 0 \text { to all methods marked 'No } \\
\text { or ' Don't know'. M/R, N/ADM and Mis are } \\
\text { coded as «Missing» }\end{array}$ & T2.6 \\
\hline
\end{tabular}




\begin{tabular}{|c|c|c|c|c|c|c|}
\hline $\begin{array}{l}\text { Variable short } \\
\text { name }\end{array}$ & Variable name & Source & Value & Label & Description / notes & Table reference \\
\hline \multirow[t]{2}{*}{ Q30VAL2 } & Number of valid values in Question 30 & $\begin{array}{l}\text { Q30g to } \\
30 j\end{array}$ & numeric & $\begin{array}{l}\text { Number of valid values in } \\
\text { the range }\end{array}$ & $\begin{array}{l}\text { Number of non-missing values in the range } \\
\text { (Q30g to } 30 \mathrm{j} \text { ) }\end{array}$ & $(\mathrm{T} 2.6)$ \\
\hline & & & & Recode $3=2,2=1,1=0$ & $\begin{array}{l}\text { Calculation: NVALID( SC30Q07, ..., } \\
\text { SC30Q10) }\end{array}$ & \\
\hline Q30IND2 & $\begin{array}{l}\text { Composite index for Q30 (or index of } \\
\text { career counselling methods involving } \\
\text { external contacts) }\end{array}$ & $\begin{array}{l}\text { Q30g to } \\
30 \mathrm{j}\end{array}$ & numeric & $\begin{array}{l}\text { Index of external career } \\
\text { counselling methods }\end{array}$ & $\begin{array}{l}\text { This index is calculated by assigning a value } \\
\text { of } 1 \text { to all methods of support marked 'Yes' } \\
\text { and a value of } 0 \text { to all methods marked 'No } \\
\text { or 'Don't know'. M/R, N/ADM and Mis are } \\
\text { coded as «Missing» }\end{array}$ & T2.6 \\
\hline
\end{tabular}

\begin{tabular}{|c|c|c|c|c|c|c|}
\hline \multicolumn{7}{|c|}{ ICT-related variables } \\
\hline PCSTDRAT & & $\begin{array}{l}\text { Q21b, } \\
\text { SCH T }\end{array}$ & numeric & Computer/student ratio & Calculation: SC21Q02/SCH_T & T3.8 \\
\hline$\overline{\text { PCTCHRAT }}$ & $\begin{array}{l}\text { Ratio of computers for teachers' exclu- } \\
\text { sive use to number of teachers in the } \\
\text { school (full-time equivalents) }\end{array}$ & Q21d, & numeric & Computer/teacher ratio & Calculation: SC21Q04/TCHFTE & T3.8 \\
\hline RATPCWWW & $\begin{array}{l}\text { Ratio of computers connected to the } \\
\text { Internet }\end{array}$ & Q21a, 21f & numeric & $\begin{array}{l}\text { Ratio of Internet connected } \\
\text { computers }\end{array}$ & Calculation: SC21Q06/ SC21Q01 & T3.9 \\
\hline RATPCLAN & $\begin{array}{l}\text { Ratio of computers connected to the } \\
\text { Intranet }\end{array}$ & Q21a, 21g & numeric & $\begin{array}{l}\text { Ratio of Intranet connected } \\
\text { computers }\end{array}$ & Calculation: SC21Q07/ SC21Q01 & T3.9 \\
\hline \multirow[t]{8}{*}{ TCHUSEPC } & $\begin{array}{l}\text { Percentage of teachers using computers } \\
\text { in teaching }\end{array}$ & Q23a & & $\begin{array}{l}\text { Percentage of teachers using } \\
\text { computers at least once a month }\end{array}$ & $\begin{array}{l}\text { This variable should be used to report } \\
\text { distributions }\end{array}$ & T3.13 \\
\hline & & & 1 & $0 \%$ & $\mathrm{SC} 23 \mathrm{Q} 01=0$ & \\
\hline & & & 2 & $1-19 \%$ & $\mathrm{SC} 23 \mathrm{Q} 01=1$ to 19 & \\
\hline & & & 3 & $20-39 \%$ & $\mathrm{SC} 23 \mathrm{Q} 01=20$ to 39 & \\
\hline & & & 4 & $40-59 \%$ & $\mathrm{SC} 23 \mathrm{Q} 01=40$ to 59 & \\
\hline & & & 5 & $60-79 \%$ & $\mathrm{SC} 23 \mathrm{Q} 01=60$ to 79 & \\
\hline & & & 6 & $80-100 \%$ & $\mathrm{SC} 23 \mathrm{Q} 01=80$ to 100 & \\
\hline & & & & & SC23Q01 $=$ N $/$ ADM is coded as 'Missing' & \\
\hline \multirow[t]{8}{*}{ TCHUSEWW } & $\begin{array}{l}\text { Percentage of teachers using WWW } \\
\text { in teaching }\end{array}$ & Q23b & & $\begin{array}{l}\text { Percentage of teachers using } \\
\text { Internet at least once a month }\end{array}$ & $\begin{array}{l}\text { This variable should be used for reporting } \\
\text { distributions }\end{array}$ & T3.13 \\
\hline & & & 1 & $0 \%$ & SC23Q02 = 0 & \\
\hline & & & 2 & $1-19 \%$ & $\mathrm{SC} 23 \mathrm{Q} 02=1$ to 19 & \\
\hline & & & 3 & $20-39 \%$ & $\mathrm{SC} 23 \mathrm{Q} 02=20$ to 39 & \\
\hline & & & 4 & $40-59 \%$ & $\mathrm{SC} 23 \mathrm{Q} 02=40$ to 59 & \\
\hline & & & 5 & $60-79 \%$ & $\mathrm{SC} 23 \mathrm{Q} 02=60$ to 79 & \\
\hline & & & 6 & $80-100 \%$ & $\mathrm{SC} 23 \mathrm{Q} 02=80$ to 100 & \\
\hline & & & & & $\mathrm{SC} 23 \mathrm{Q} 02=\mathrm{N} / \mathrm{ADM}$ is coded as 'Missing' & \\
\hline \multirow[t]{8}{*}{ TCHUSEML } & $\begin{array}{l}\text { Percentage of teachers using e-mail in } \\
\text { teaching }\end{array}$ & Q23c & & $\begin{array}{l}\text { Percentage of teachers using } \\
\text { e-mail at least once a month }\end{array}$ & $\begin{array}{l}\text { This variable should be used for reporting } \\
\text { distributions }\end{array}$ & T3.13 \\
\hline & & & 1 & $0 \%$ & SC23Q03 = 0 & \\
\hline & & & 2 & $1-19 \%$ & $\mathrm{SC} 23 \mathrm{Q} 03=1$ to 19 & \\
\hline & & & 3 & $20-39 \%$ & $\mathrm{SC} 23 \mathrm{Q} 03=20$ to 39 & \\
\hline & & & 4 & $40-59 \%$ & $\mathrm{SC} 23 \mathrm{Q} 03=40$ to 59 & \\
\hline & & & 5 & $60-79 \%$ & $\mathrm{SC} 23 \mathrm{Q} 03=60$ to 79 & \\
\hline & & & 6 & $80-100 \%$ & $\mathrm{SC} 23 \mathrm{Q} 03=80$ to 100 & \\
\hline & & & & & SC23Q03 = N $/$ ADM is coded as 'Missing' & \\
\hline \multirow[t]{2}{*}{ Q24VALID } & Number of valid values in Question 24 & $\begin{array}{l}\text { Q24a to } \\
24 \mathrm{e}\end{array}$ & numeric & $\begin{array}{l}\text { Number of valid values in } \\
\text { Q24a to } 24 \mathrm{e}\end{array}$ & Number of non-missing values in this range & (T3.14b) \\
\hline & & & & Recode $2,8=0$ & $\begin{array}{l}\text { Calculation: NVALID( SC24Q01, SC24Q02, } \\
\text {..., SC24Q08) }\end{array}$ & \\
\hline \multirow[t]{2}{*}{ Q24INDEX } & $\begin{array}{l}\text { Index of variety of computer related } \\
\text { activities }\end{array}$ & Q24 & numeric & $\begin{array}{l}\text { Index of variety of computer } \\
\text { related activities }\end{array}$ & $\begin{array}{l}\text { This index is calculated by assigning a value of } \\
1 \text { to all activities marked 'Yes' and a value of } 0 \\
\text { to all methods marked 'No' or N/ADM }\end{array}$ & T3.14b \\
\hline & & & & Recode $2,3,8=0$ & Calculation: $\sum$ (SC24Q01 to SC24Q08) & \\
\hline \multirow[t]{2}{*}{ Q25VALID } & Number of valid values in Question 25 & $\begin{array}{l}\text { Q25a to } \\
25 \mathrm{f}\end{array}$ & numeric & $\begin{array}{l}\text { Number of valid values in } \\
\text { Q25a to } 25 \mathrm{f}\end{array}$ & Number of non-missing values in this range & (T3.15b) \\
\hline & & & & Recode $2,8=0$ & $\begin{array}{l}\text { Calculation: NVALID( SC25Q01, SC25Q02, } \\
\text {..., SC25Q06) }\end{array}$ & \\
\hline \multirow[t]{2}{*}{ Q25INDEX } & Index of variety of computer uses & $\begin{array}{l}\text { Q25a to } \\
25 f\end{array}$ & & $\begin{array}{l}\text { Index of variety of } \\
\text { computer uses }\end{array}$ & $\begin{array}{l}\text { This index is calculated by assigning a score of } \\
2 \text { to all uses marked 'A lot' and a score of } 1 \\
\text { to all methods marked 'A little' and a score } \\
\text { of } 0 \text { marked 'Not at all' or N/ADM }\end{array}$ & T3.15b \\
\hline & & & & Recode $2,8=0$ & Calculation: $\sum$ (SC25Q01 to SC25Q06) & \\
\hline \multirow[t]{2}{*}{ Q26VALED } & Number of valid values in Question 26 & $\begin{array}{l}\text { Q26a to } \\
26 \mathrm{e}\end{array}$ & numeric & $\begin{array}{l}\text { Number of valid values in } \\
\text { Q26a to 26e }\end{array}$ & Number of non-missing values in this range & \\
\hline & & & & Recode $2,8=0$ & $\begin{array}{l}\text { Calculation: NVALID( SC26Q02, .., } \\
\text { SC26Q22) }\end{array}$ & \\
\hline
\end{tabular}




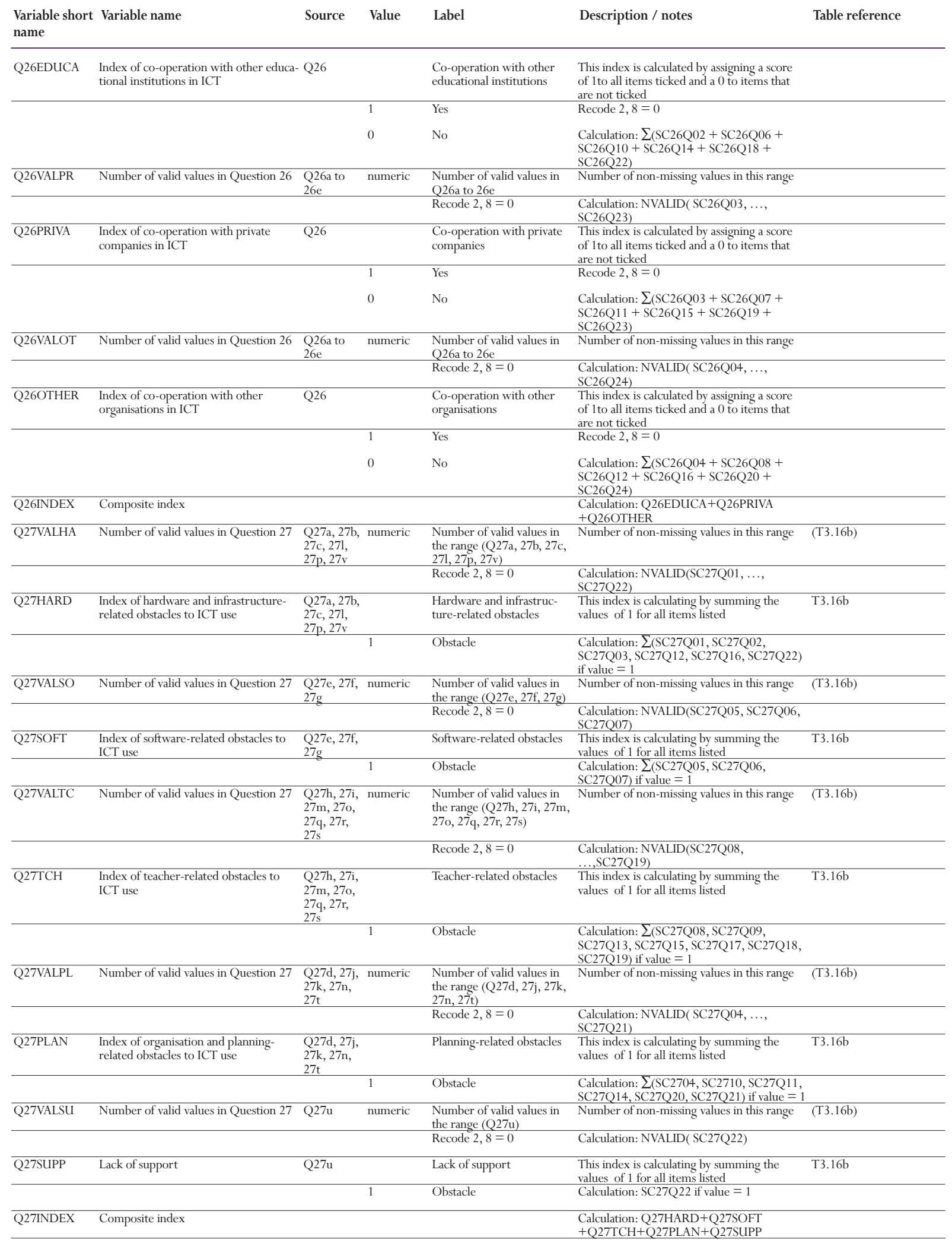


Annex

5

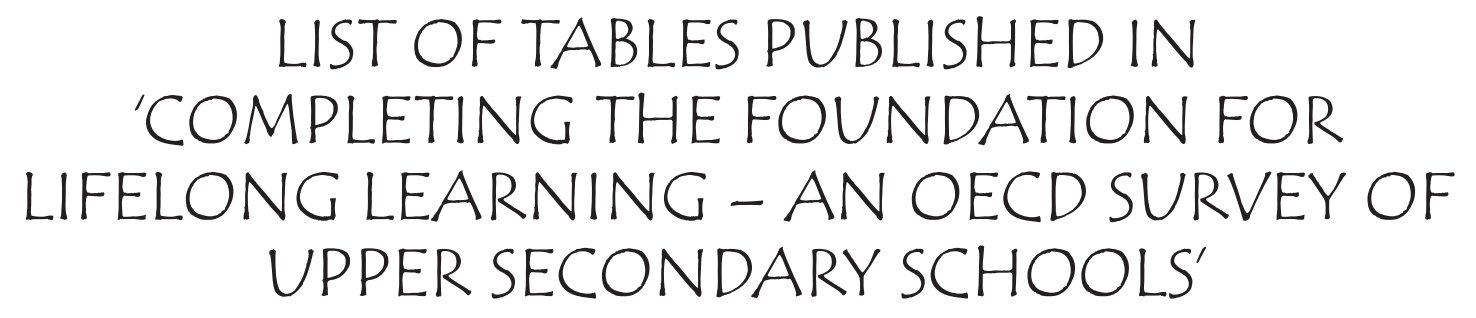


The list of tables used in the the following report 'Completing the Foundation for Lifelong Learning - An OECD Survey of Upper Secondary Schools' is detailed in the following pages. For each table its shows the links with the ISUSS Questionnaire, the variables used, the type of the 'indicator' shown in the table and the corresponding number of the figure and its type.

\section{Chapter 1: Introduction}

\begin{tabular}{|c|c|c|c|c|c|c|}
\hline $\begin{array}{l}\text { Table } \\
\text { code }\end{array}$ & Title and description & $\begin{array}{l}\text { Ques- } \\
\text { tion }\end{array}$ & Variables used & $\begin{array}{l}\text { Indicator } \\
\text { type }\end{array}$ & $\begin{array}{l}\text { Figure } \\
\text { code }\end{array}$ & Figure type \\
\hline T1.1a & $\begin{array}{l}\text { The demographic and educational context of upper secondary education } \\
\text { Percentage of the population in education, ratio of upper secondary graduates to total } \\
\text { population at typical age of graduation and percentage of the population that has attained } \\
\text { at least upper secondary education, by age group }\end{array}$ & & & Percentages & & \\
\hline
\end{tabular}

\section{Chapter 2: Managing upper secondary education as a stage of student transition}

\begin{tabular}{|c|c|c|c|c|c|c|}
\hline $\begin{array}{l}\text { Table } \\
\text { code }\end{array}$ & Title and description & $\begin{array}{l}\text { Ques- } \\
\text { tion }\end{array}$ & Variables used & $\begin{array}{l}\text { Indicator } \\
\text { type }\end{array}$ & $\begin{array}{l}\text { Figure } \\
\text { code }\end{array}$ & Figure type \\
\hline $\mathrm{T} 2.1 \mathrm{a}$ & $\begin{array}{l}\text { Admission and placement policies in upper secondary education as } \\
\text { reported by school principals (2001) } \\
\text { Percentage of upper secondary students attending schools where the principal reported } \\
\text { that various factors are always, sometimes or never considered when students are } \\
\text { admitted or placed in upper secondary programmes in the school }\end{array}$ & Q16 & $\begin{array}{l}\text { SC16Q01 to } \\
\text { SC16Q07 trans- } \\
\text { formed into 'ordinal' } \\
\text { variables }\end{array}$ & Percentages & F2.1 & Multiple chart bar \\
\hline $\mathrm{T} 2.1 \mathrm{~b}$ & $\begin{array}{l}\text { Indices of admission and placement policies related to students' perform- } \\
\text { ance (2001) } \\
\text { Country means and standard deviations on the international standard index and index } \\
\text { values at different percentiles of the upper secondary student population }\end{array}$ & Q16 & $\begin{array}{l}\text { Q16ACHIE, } \\
\text { Q16LOYAL }\end{array}$ & Index & $\begin{array}{l}-\mathrm{F} 2.2 \\
-\mathrm{F} 2.5\end{array}$ & $\begin{array}{l}\text { - Combination } \\
\text { bar chart with } \\
\text { percentiles } \\
\text { - Scatter diagram }\end{array}$ \\
\hline $\mathrm{T} 2.2 \mathrm{a}$ & $\begin{array}{l}\text { Frequency of using various criteria in grouping students in upper second- } \\
\text { ary schools as reported by school principals }(2001) \\
\text { Percentage of upper secondary students attending schools where the principal reported } \\
\text { that different grouping policies are always, sometimes or never used }\end{array}$ & Q17 & $\begin{array}{l}\text { SC17Q01 to } \\
\text { SC17Q07 } \\
\text { transformed into } \\
\text { 'ordinal' variables }\end{array}$ & Percentages & F2.3 & Multiple chart bar \\
\hline $\mathrm{T} 2.2 \mathrm{~b}$ & $\begin{array}{l}\text { Index of selective grouping policies within schools as reported by school } \\
\text { principals (2001) } \\
\text { Country means and standard deviations on the international standard index and index } \\
\text { values at different percentiles of the upper secondary student population }\end{array}$ & Q17 & Q17INDEX & Index & $\begin{array}{l}-\mathrm{F} 2.4 \\
-\mathrm{F} 2.5\end{array}$ & $\begin{array}{l}\text { - Combination } \\
\text { bar chart with } \\
\text { percentiles } \\
\text { - Scatter diagram }\end{array}$ \\
\hline $\mathrm{T} 2.4 \mathrm{a}$ & $\begin{array}{l}\text { Frequency of use of different career guidance and counselling methods in } \\
\text { upper secondary schools as reported by school principals (2001) } \\
\text { Percentage of upper secondary students attending schools where principals reported that } \\
\text { they always, sometimes of never use different career counselling methods }\end{array}$ & Q30 & $\begin{array}{l}\text { SC30Q01 to } \\
\text { SC30Q10 }\end{array}$ & Percentages & F2.8 & $\begin{array}{l}\text { Bar chart for each } \\
\text { career guidance and } \\
\text { counselling method }\end{array}$ \\
\hline$\overline{\mathrm{T} 2.4 \mathrm{~b}}$ & $\begin{array}{l}\text { Frequency of use of career guidance and counselling methods in different } \\
\text { programme types }(2001) \\
\text { Percentage of students attending different programme types for which principals } \\
\text { reported that the always, sometimes or never }\end{array}$ & Q30 & $\begin{array}{l}\text { SC30Q01 to } \\
\text { SC30Q10 }\end{array}$ & Percentages & & \\
\hline$\overline{\mathrm{T} 2.5}$ & $\begin{array}{l}\text { Indices of variety of career guidance and counselling methods in upper } \\
\text { secondary schools (2001) } \\
\text { Country means on the international standard indices and index values at different per- } \\
\text { centiles of the upper secondary student population }\end{array}$ & Q30 & $\begin{array}{l}\text { Q30IND1, } \\
\text { Q30IND2 }\end{array}$ & Index & F2.9 & $\begin{array}{l}\text { Combination bar } \\
\text { chart with } \\
\text { percentiles }\end{array}$ \\
\hline$\overline{\mathrm{T} 2.6}$ & $\begin{array}{l}\text { Percentage of upper secondary students who received individual career } \\
\text { guidance in the final year of their programme, by type of programme (2001) }\end{array}$ & Q31 & SC31Q01 & Percentages & F2.10 & $\begin{array}{l}\text { Combination chart: } \\
\text { bars and dots }\end{array}$ \\
\hline$\overline{\mathrm{T} 2.7}$ & $\begin{array}{l}\text { Feedback on school functioning as reported by school principals (2001) } \\
\text { Percentage of upper secondary students attending schools where the principal reported } \\
\text { that the school gets feedback from different groups of stakeholders }\end{array}$ & Q19 & $\begin{array}{l}\text { SC19Q01 to } \\
\text { QC19Q07 }\end{array}$ & Percentages & & \\
\hline$\overline{\mathrm{T} 2.8}$ & $\begin{array}{l}\text { Standardised frequencies of feedback from various groups of stakeholders } \\
\text { as reported by school principals }(2001) \\
\text { Country means and standard deviations of internationally comparable standardised } \\
\text { frequencies }\end{array}$ & Q19 & $\begin{array}{l}\text { SC19Q01 to } \\
\text { QC19Q07 }\end{array}$ & $\begin{array}{l}\text { Standardised } \\
\text { frequencies }\end{array}$ & F2.11 & $\begin{array}{l}\text { Radar chart by } \\
\text { country }\end{array}$ \\
\hline$\overline{\mathrm{T} 2.9}$ & $\begin{array}{l}\text { Index of variety of feedback from various stakeholders (2001) } \\
\text { Country means and standard deviations on the international standard index and index } \\
\text { values at different percentiles of the upper secondary student population }\end{array}$ & Q19 & Q19INDEX & Index & F2.12 & $\begin{array}{l}\text { Combination bar } \\
\text { chart with } \\
\text { percentiles }\end{array}$ \\
\hline
\end{tabular}




\section{Chapter 3: Quality and adaptability: inputs and processes that help schools meet changing demands}

\begin{tabular}{|c|c|c|c|c|c|c|}
\hline $\begin{array}{l}\text { Table } \\
\text { code }\end{array}$ & Description & $\begin{array}{l}\text { Ques- } \\
\text { tion }\end{array}$ & Variables used & $\begin{array}{l}\text { Indicator } \\
\text { type }\end{array}$ & $\begin{array}{l}\text { Figure } \\
\text { code }\end{array}$ & Figure type \\
\hline T3.1a & $\begin{array}{l}\text { Ratio of students to school staff (2001) } \\
\text { Ratios of students to teachers, to professional personnel and to total personnel (full-time } \\
\text { equivalents) }\end{array}$ & $\begin{array}{l}\text { Q5, } \\
\text { Q6 }\end{array}$ & $\begin{array}{l}\text { RSTDCH, RST- } \\
\text { PROF, RSTDPERS }\end{array}$ & Ratio & F3.1 & $\begin{array}{l}\text { Combination bar } \\
\text { chart with per- } \\
\text { centiles }\end{array}$ \\
\hline T3.1b & $\begin{array}{l}\text { Ratio of students to school staff by school size (2001) } \\
\text { Ratios of students to classroom teachers, to professional personnel and to total } \\
\text { personnel, by school size (full-time equivalents) }\end{array}$ & $\begin{array}{l}\text { Q5, } \\
\text { Q6 }\end{array}$ & $\begin{array}{l}\text { RSTDCH, RST- } \\
\text { PROF, RSTDPERS, } \\
\text { SCHSIZE2 }\end{array}$ & Ratio & & \\
\hline T3.1c & $\begin{array}{l}\text { Ratio of students to school staff by size of the community in which the } \\
\text { school is located ( } 2001) \\
\text { Ratios of students to classroom teachers, to professional personnel and to total personnel, } \\
\text { by size of the community in which the school is located (full-time equivalents) }\end{array}$ & $\begin{array}{l}\text { Q4, } \\
\text { Q5, } \\
\text { Q6 }\end{array}$ & $\begin{array}{l}\text { RSTDCH, RST- } \\
\text { PROF, RSTDPERS, } \\
\text { CITYSIZE }\end{array}$ & Ratio & & \\
\hline T3.1d & $\begin{array}{l}\text { Ratio of students to school staff in publicly and privately managed schools } \\
\text { (2001) } \\
\text { Ratios of students to classroom teachers, to professional personnel and to total } \\
\text { personnel, by type of provider (full-time equivalents) }\end{array}$ & $\begin{array}{l}\text { Q2, } \\
\text { Q5, } \\
\text { Q6 }\end{array}$ & $\begin{array}{l}\text { RSTDCH, RST- } \\
\text { PROF, RSTDPERS, } \\
\text { SC02Q01 trans- } \\
\text { formed into 'ordinal' } \\
\text { variable }\end{array}$ & Ratio & & \\
\hline $\mathrm{T} 3.2 \mathrm{~b}$ & $\begin{array}{l}\text { Distribution of school staff by personnel category and school size (2001) } \\
\text { Professional personnel, teachers and non-professional support personnel as a percentage } \\
\text { of total personnel, by school size (full-time equivalents) }\end{array}$ & $\begin{array}{l}\text { Q5, } \\
\text { Q6 }\end{array}$ & $\begin{array}{l}\text { STAPERFT, TCH- } \\
\text { PERFT, SUPPERFT, } \\
\text { SCHSIZE2 }\end{array}$ & Ratio & & \\
\hline $\mathrm{T} 3.2 \mathrm{c}$ & $\begin{array}{l}\text { Distribution of school staff by personnel category and the size of the } \\
\text { community in which the school is located (2001) } \\
\text { Professional personnel, teachers and other support personnel as a percentage of total } \\
\text { personnel, by size of the community in which the school is located (full-time equivalents) }\end{array}$ & $\begin{array}{l}\text { Q4, } \\
\text { Q6 }\end{array}$ & $\begin{array}{l}\text { STAPERFT, TCH- } \\
\text { PERFT, SUPPERFT, } \\
\text { CITYSIZE }\end{array}$ & Ratio & & \\
\hline$\overline{\mathrm{T}} 3.2 \mathrm{~d}$ & $\begin{array}{l}\text { Distribution of school staff by personnel by category in publicly and } \\
\text { privately managed schools (2001) } \\
\text { Professional personnel, teachers and other support personnel as a percentage of total } \\
\text { personnel in public and private schools (full-time equivalents) }\end{array}$ & $\begin{array}{l}\text { Q2, } \\
\text { Q3, } \\
\text { Q6 }\end{array}$ & $\begin{array}{l}\text { STAPERFT, TCH- } \\
\text { PERFT, SUPPERFT, } \\
\text { SC02Q01 } \\
\text { transformed into } \\
\text { 'ordinal' variable }\end{array}$ & Ratio & & \\
\hline T3.3 & $\begin{array}{l}\text { Percentage of temporary teachers, teachers who do not fully meet } \\
\text { qualification requirements (2001) } \\
\text { Percentage of full-time and part-time teachers who are temporaries or do not fully meet } \\
\text { qualification requirements, as reported by school principals }\end{array}$ & $\begin{array}{l}\text { Q2, } \\
\text { Q6, } \\
\text { Q7, } \\
\text { Q8 }\end{array}$ & $\begin{array}{l}\text { RTEMPFT, } \\
\text { RTEMPPT, } \\
\text { RNQUALFT, } \\
\text { RNQUALPT, } \\
\text { TCHPT, } \\
\text { SC08Q01 } \\
\text { transformed into } \\
\text { 'ordinal' variable }\end{array}$ & Percentages & F3.3 & Bar chart \\
\hline T3.4 & $\begin{array}{l}\text { Methods used to cover teacher vacancies (2001) } \\
\text { Percentage of upper secondary students attending schools with no teaching vacancies, } \\
\text { percentage of vacant posts to total number of full-time equivalent teachers, percentage } \\
\text { of upper secondary students attending schools which are responsible for hiring teachers } \\
\text { by type of institution, and use of various methods to respond to teacher vacancies, as } \\
\text { reported by school principals }\end{array}$ & $\begin{array}{l}\text { Q8, } \\
\text { Q9, } \\
\text { Q10 }\end{array}$ & $\begin{array}{l}\text { SC08Q02, } \\
\text { SC09Q01, RTCH- } \\
\text { VAC, SC10Q01 to } \\
\text { SC10Q05 }\end{array}$ & Percentages & $\begin{array}{l}\text { - F3.4 } \\
\text { - F3.5 }\end{array}$ & $\begin{array}{l}\text { - Double bar chart } \\
\text { - Multiple bar chart }\end{array}$ \\
\hline T3.5 & $\begin{array}{l}\text { Teacher absenteeism (2001) } \\
\text { Percentage of class periods cancelled or covered by another teacher in the second month } \\
\text { of the school year because of the absence of the assigned teacher }\end{array}$ & Q15 & $\begin{array}{l}\text { CLP_CANC, } \\
\text { CLP_COV }\end{array}$ & Percentages & F3.6 & Bar chart \\
\hline T3.6a & $\begin{array}{l}\text { Perceived difficulty of hiring teachers who fully meet qualification } \\
\text { requirements (2001) } \\
\text { Percentage of upper secondary students attending schools where the principal reported } \\
\text { that hiring teachers who fully meet qualification requirements is difficult, by study area }\end{array}$ & Q11 & $\begin{array}{l}\text { SC11Q01 to } \\
\text { SC11Q10 }\end{array}$ & Percentages & $\begin{array}{r}\mathrm{F} 3.7 \\
-\mathrm{F} 3.8\end{array}$ & $\begin{array}{l}\text { - Bar chart (country } \\
\text { mean) } \\
\text { - Density chart }\end{array}$ \\
\hline T3.6b & $\begin{array}{l}\text { Index of difficulty of hiring fully qualified upper secondary teachers across } \\
\text { countries by study area (2001) } \\
\text { Country means and standard deviations on the international standard index and index } \\
\text { values at different percentiles of the upper secondary student population }\end{array}$ & Q11 & Q11INDEX & Index & F3.9 & $\begin{array}{l}\text { Combination bar } \\
\text { chart with per- } \\
\text { centiles }\end{array}$ \\
\hline T3.7 & $\begin{array}{l}\text { Introduction of information and communication technology in schools } \\
\text { (2001) } \\
\text { Percentages of upper secondary students attending schools where standard computer } \\
\text { applications, Internet and e-mail were introduced between } 1980 \text { and } 2001 \text {, by year; } \\
\text { percentage of upper secondary students attending schools where these were 'not in use' } \\
\text { in } 2001\end{array}$ & Q22 & $\begin{array}{l}\text { SC22Q01 to } \\
\text { SC22Q03 }\end{array}$ & Percentages & F3.10 & $\begin{array}{l}\text { Line chart by } \\
\text { country }\end{array}$ \\
\hline
\end{tabular}


ANNEX 5

Chapter 3: Quality and adaptability: inputs and processes that help schools meet changing demands (continued)

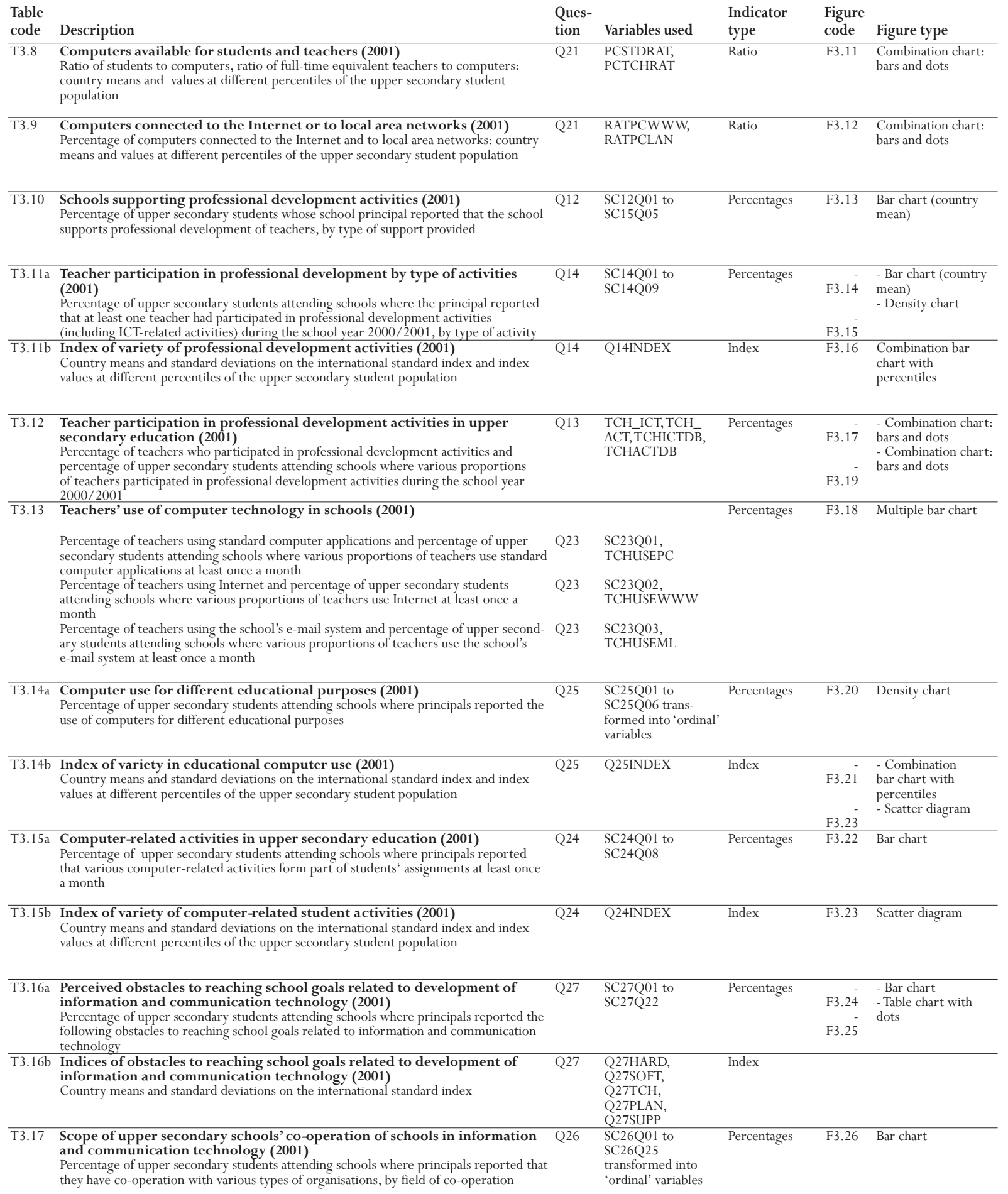


Chapter 4: Main findings, policy implications and some preliminairy benchmarks

\begin{tabular}{|c|c|c|c|c|c|c|}
\hline $\begin{array}{l}\text { Table } \\
\text { code }\end{array}$ & Title and description & $\begin{array}{l}\text { Ques- } \\
\text { tion }\end{array}$ & Variables used & $\begin{array}{l}\text { Indicator } \\
\text { type }\end{array}$ & $\begin{array}{l}\text { Figure } \\
\text { code }\end{array}$ & Figure type \\
\hline $\mathrm{T} 4.1 \mathrm{a}$ & $\begin{array}{l}\text { Eleven benchmark indicators of upper secondary school characteristics } \\
\text { Percentage of the population in education, ratio of upper secondary graduates to total } \\
\text { population at typical age of graduation and percentage of the population that has attained } \\
\text { at least upper secondary education, by age group }\end{array}$ & & & Country $n$ & & \\
\hline
\end{tabular}

T4.2 Indicators of upper secondary education and PISA results

Scores

\section{Annex 2: Background information on the education systems that provided data for this report}

\begin{tabular}{|c|c|c|c|c|c|c|}
\hline $\begin{array}{l}\text { Table } \\
\text { code }\end{array}$ & Description & $\begin{array}{l}\text { Ques- } \\
\text { tion }\end{array}$ & Variables used & $\begin{array}{l}\text { Indicator } \\
\text { type }\end{array}$ & $\begin{array}{l}\text { Figure } \\
\text { code }\end{array}$ & Figure type \\
\hline$\overline{\mathrm{A} 2.1}$ & List of upper secondary programmes included in the ISUSS study & - & & & & \\
\hline$\overline{\mathrm{A} 2.2}$ & $\begin{array}{l}\text { Mainstream upper secondary programmes and enrolments of upper } \\
\text { secondary students in different programmes (2001) } \\
\text { Grade at entry level, length of programme and percentage of students in upper } \\
\text { secondary education, by type of programme }\end{array}$ & $\begin{array}{l}\text { Q1, } \\
\text { Q5 }\end{array}$ & $\begin{array}{l}\text { SC01Q01 to } \\
\text { SC01Q12; } \\
\text { SC05Q01 to } \\
\text { SC05Q18 } \\
\text { Programmes: 3AG, } \\
\text { 3AP/V, 3B/CG, } \\
\text { 3B/CP/V }\end{array}$ & Percentages & & \\
\hline$\overline{\mathrm{A} 2.3}$ & $\begin{array}{l}\text { Programme levels provided in the schools of upper secondary students } \\
(2001) \\
\text { Percentage of upper secondary students in schools, by level of education available at the } \\
\text { school }\end{array}$ & Q1 & PROVLEVL & Percentages & & \\
\hline$\overline{\mathrm{A} 2.4}$ & $\begin{array}{l}\text { Upper secondary providers by combination of programme types offered } \\
(2001) \\
\text { Percentage of upper secondary students enrolled in schools offering various programme } \\
\text { combinations }\end{array}$ & $\begin{array}{l}\text { Q1, } \\
\text { Q5 }\end{array}$ & $\begin{array}{l}\text { Part 1:PROVSMLT; } \\
\text { Part 2: SC05Q01 to } \\
\text { SC05Q18; PROVG; } \\
\text { weighted by WGHT } \\
\text { because of country's } \\
\text { calculations for } \\
\text { enrolments by } \\
\text { programme } \\
\text { combination offered }\end{array}$ & Percentages & & \\
\hline$\overline{\mathrm{A} 2.5}$ & $\begin{array}{l}\text { Enrolments in upper secondary education by type of provider and size of } \\
\text { the school site }(2001) \\
\text { Percentage of upper secondary students in publicly and privately managed institutions, } \\
\text { average school size and percentage of students in upper secondary education, by size of } \\
\text { school site }\end{array}$ & $\begin{array}{l}\text { Q2, } \\
\text { Q3, } \\
\text { Q5 }\end{array}$ & $\begin{array}{l}\text { Part 1: PROVLEVL, } \\
\text { FP_GVT, FP_STU, } \\
\text { FP_BEN, FP_OTH; } \\
\text { Part 2: SCH_T, } \\
\text { SCHSIZE }\end{array}$ & Percentages & & \\
\hline
\end{tabular}


Annex

6

GLOSSARY 
Academic (pre-) vocational programmes: refer to programmes with a destination to higher education and a pre-vocational or vocational content orientation. See Annex A2.

Academic general programmes: refer to upper secondary programmes with a destination to higher education and a general content orientation. See Annex A2.

Academic programmes: refer to upper secondary programmes leading to higher education either with a general or with a (pre-)vocational content orientation (ISCED 3A programmes).

Career guidance: refers to services intended to assist individuals, of any age and at any point throughout their lives, to make educational, training and occupational choices and to manage their careers. It includes a wide range of activities. For example activities within schools to help students clarify career goals and understand the world of work; personal or group-based assistance with decisions about initial courses of study, courses of vocational training, further education and training, initial job choice, job change, or work force re-entry; computer-based or on-line services to provide information about jobs and careers or to help individuals make career choices; and services to produce and disseminate information about jobs, courses of study and vocational training. It includes services provided to those who have not yet entered the labour force, services to job seekers, and services to those who are employed.

Class period: the length of time each lesson runs for on a normal day. Some classes may run for 'double periods' or even more, but the class period refers to the basic unit of time used to break up the teaching day.

Comprehensive academic providers: refer to providers offering programmes which can lead to higher education, including both general and (pre-)vocational programmes. See Table A2.4 in Annex 2, in the report 'Completing the Foundation for Lifelong Learning - An OECD Survey of Upper Secondary Schools'.

Computers: in this study they are defined as computers capable of supporting other multimedia equipment such as a CD-ROM or a soundcard and which are used for educational purposes in the school. Computers used only for recreation purposes are excluded.

Educational purpose: computer use for educational purpose includes any activity related to the functioning of the school including teaching and learning, the use of computers in school management, educational planning and evaluation.

Formal feedback: refers to written reports which are addressed to school principals or to the manager of an unit within the school but not to individual teachers.

Full-time equivalent: the calculation of the number of teachers as full-time equivalent (FTE) attempts to estimate the total amount of available teacher working time in the unit of a full-time teacher's statutory teaching (working) hours. In this study, a part-time teacher was calculated as 0.5 full-time teacher to calculate full-time equivalents.

Full-time teacher: a teacher employed for at least 90 per cent of the normal or statutory number of hours of work for a full-time teacher over a complete school year is classified as a full-time teacher. 
Fully qualified teacher: refers to teachers who have fulfilled all the training requirements for teaching a certain subject at the upper secondary level according to the qualification requirements of the country and further meets all other administrative requirements to fill a permanent post in the school.

General programmes: refer to programmes that are not designed explicitly to prepare participants for a specific class of occupations or trades or for entry into further vocational or technical education programmes. Less than 25 per cent of the programme content is classified as vocational or technical.

General providers: refer to providers offering only general programmes. See Table A2.4 in Annex 2 in the report 'Completing the Foundation for Lifelong Learning - An OECD Survey of Upper Secondary Schools'.

Head counts: refer to the method of calculation indicating how the number of individuals is counted. See also full-time equivalents.

Information and communication technology (ICT): represents the set of activities and technologies that fall into the union of information technology referring to the electronic display, processing and storage of information and communication technology.

International Standard Classification of Education (ISCED): the International Standard Classification of Education (ISCED-97) is used to define education programmes by level, destination and content. For details on ISCED 1997 and how it is implemented see Classifying Educational Programmes: Manual For ISCED97 Implementation in OECD Countries (Paris, 1999).

Internet: refers to an electronic communications network that connects computer networks and organisational computer facilities around the world.

Intranet: refers to a local area network of compters linked by cable, which can communicate directly with other devices in the network. See also local area network.

Local area network ( $L A N)$ : refers to a network of personal computers in a small area (as an office) that are linked by cable, can communicate directly with other devices in the network and can share resources. See also Intranet.

Management personnel (non teaching): professional personnel who is responsible for school management/administration. It includes principals, assistant principals and other management staff with similar responsibilities. It does not include receptionists, secretaries, clerks and other staff who support the administrative activities of the school. Management personnel with part-time teaching duties should be pro-rated (i.e., classified in the category where he/she spends the large part of the statutory working time).

Metropolitan area: a large city with over more than 1000000 inhabitants with the surrounding settlements well integrated in the urban (public) transportation system.

Non-academic (pre-)vocational programmes: refer to ISCED 3B and 3C programmes with a prevocational or vocational content orientation. See Annex 2.

Non-academic general programmes: refers to ISCED 3B and 3C programmes with a general content orientation. See Annex A2. 
Other comprehensive providers: refer to providers offering programmes with different destinations and different content orientation. See Annex 2 in the report 'Completing the Foundation for Lifelong Learning - An OECD Survey of Upper Secondary Schools'.

Other support personnel: according to the UOE definition this category includes all personnel who supports the administration and management of the school and the personnel who support the maintenance and operation of schools, the transportation of student, school security and food services operations. Included are receptionists, secretaries, typists, bookkeepers, clerks, masons, carpenters, electricians, locksmiths, maintenance repairers, painters, paperhangers, plasterers, plumbers, vehicle mechanics, bus drivers, construction workers, gardeners, groundskeepers, cooks, custodians, security guards, etc. See also support personnel.

Part-time teacher: a teacher employed for less than 90 per cent of the normal or statutory number of hours of work for a full-time teacher over a complete school year is classified as a part-time teacher.

Pre-vocational programmes: refer to programmes with at least 25 per cent of vocational content, which are designed to introduce participants to the world of work and to prepare them for entry into further vocational or technical programmes. Successful completion of such programmes does not lead to a labourmarket relevant vocational or technical qualification.

(Pre-)vocational providers: refer to providers offering prevocational and/or vocational programmes but no general programmes. See Annex 2 in the report 'Completing the Foundation for Lifelong Learning - An OECD Survey of Upper Secondary Schools'.

Privately managed institution: an institution is classified as privately managed if it is controlled and managed by a non-governmental organisation (i.e., a Church, Trade Union or business enterprise), or if its Governing Board consists mostly of members not selected by a public agency.

Professional development: any activity which develops an individual's skills, knowledge, expertise and other characteristics as a teacher. These include personal study and reflection, collaborative development of new approaches, as well as formal courses.

Professional personnel: includes school management personnel, teachers and professional support personnel. See aslo school management personnel, teacher and professional support personnel.

Professional support personnel: includes, for example, guidance counsellors, librarians, psychologists, nurses, social workers, speech therapists

Programme: is a set of (related) subjects or modules put together with known combination and sequencing rules, generally lasting for more than one year of study (some examples should be provided with regard to the country in question). In the ISUSS study, it refers to the programmes listed in the ISCED implementation for a given country. 
Publicly managed institution: an institution is classified as publicly managed if it is controlled and managed directly by a public education authority or agency or; is controlled and managed either by a government agency directly or by a governing body (Council, Committee, etc.), most of whose members are appointed by a public authority or elected by public franchise.

School: in this publication it refers to "school site" i.e., the education unit where service is provided. In the majority of cases school and school site is the same. However, in some countries a school can be a larger administrative entity comprising several school sites, each of which has a teaching staff allocated to that particular school site.

School management personnel: includes the principal and deputy principals. See also professional personnel.

School site: see also school.

Support personnel: includes teacher aids and other support personnel. See also teacher aid and other support personnel.

Teacher aid: refers to non-professional personnel who provide instruction or support teachers in providing instruction.

Teacher: refers to classroom teachers directly involved in instructional practice. See also professional personnel.

Temporary teacher: refers to a teacher who has no tenure, or a a person employed for a fixed term not longer than one school year.

Upper secondary education (ISCED 3): corresponds to the final stage of secondary education in most OECD countries. The entrance age to this level is typically 15 or 16 years. There are substantial differences in the typical duration of ISCED 3 programmes both across and between countries, typically ranging from two to five years of schooling. ISCED 3 programmes may directly give access to tertiary type A programmes (3A programmes), or to tertiary type B programmes (3B programmes), or to other ISCED 3 programmes or the labour market (3C programmes). See also International Standard Classification of Education (ISCED).

Vocational programmes: prepare participants for direct entry, without further training, into specific occupations. Successful completion of such programmes leads to a labour-market relevant vocational qualification.

World Wide Web $(\boldsymbol{W} \boldsymbol{W} \boldsymbol{W})$ : the World Wide Web is a part of the Internet designed to allow easier navigation of the network through the use of graphical user interfaces and hypertext links between different addresses. 
OECD PUBLICATIONS, 2, rue André-Pascal, 75775 PARIS CEDEX 16 PRINTED IN FRANCE

(96 2004021 P) ISBN 92-64-10572-7 - No. 533312004 